\title{
Handling Qualities of a Blended Wing Body Aircraft
}

by

Timothy Shaw Peterson

A thesis submitted in conformity with the requirements for the degree of Master of Applied Science

Institute for Aerospace Studies

University of Toronto

Copyright (c) 2011 by Timothy Shaw Peterson 


\author{
Abstract \\ Handling Qualities of a Blended Wing Body Aircraft \\ Timothy Shaw Peterson \\ Master of Applied Science \\ Institute for Aerospace Studies \\ University of Toronto \\ 2011
}

The blended wing body (BWB) is a tailless aircraft with the potential to use $27 \%$ less fuel than a conventional aircraft with the same passenger capacity and range. The primary purpose of the current study was to determine the handling qualities of the BWB, using piloted-handling trials in a moving-base simulator. The secondary purpose was to determine the effect of simulator motion on handling-quality ratings. De Castro conducted piloted-handling trials in a fixed-base simulator. De Castro's tasks and flight model were modified in the current study. In the current study, three subjects rated the handling qualities as Level 1 or 2, depending on the task. Simulator motion did not have a significant effect on the results. 


\section{Acknowledgements}

I would like to thank Professor Peter Grant for welcoming me into the Vehicle Simulation Group and sharing his knowledge. Professor Grant gave me a choice of several interesting thesis topics; I appreciate being able to pick the one I found most exciting. I would also like to thank Bruce Haycock, Stacey Liu, and Amir Naseri for their help with setting up the piloted-handling trials and their expertise in flight simulation. To the pilots who volunteered for the handling trials - I thank you for participating. This research was made far more meaningful because of your contribution.

I am grateful to my wife, Vanessa, for encouraging me to undertake the challenge of graduate studies and supporting me throughout. I would like to thank my parents for sparking my interest in aerospace and for showing me the importance of lifelong learning. 


\section{Contents}

\begin{tabular}{lll}
\hline 1 & Introduction & 1
\end{tabular}

1.1 Background $\ldots \ldots \ldots \ldots$. . . . . . . . . . . . . . . . . 1

1.2 Literature Review . . . . . . . . . . . . . . . . . . . . . . . . . 1

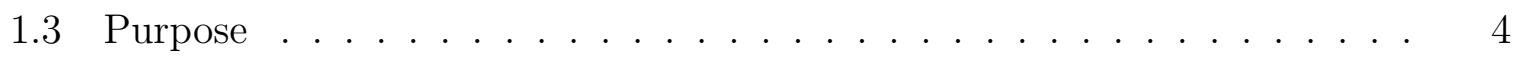

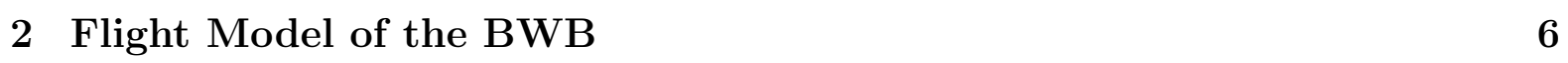

2.1 Equations of Motion . . . . . . . . . . . . . . . . . . . . 6

2.2 Aerodynamic Model $\ldots \ldots$. . . . . . . . . . . . . . . . . . . . . . . . . . . 8

2.2 .1 Ground Effect . . . . . . . . . . . . . . . . . . . . . . . . . 10

2.3 Ground Model . . . . . . . . . . . . . . . . . . . . . . . . . . . . . . . . . 12

2.3 .1 Landing Gear Struts . . . . . . . . . . . . . . . . . . . . . 12

2.3 .2 Tires . . . . . . . . . . . . . . . . . . . . . . 14

2.4 Engine Model . . . . . . . . . . . . . . . . . . . . . . . . . . . . . 15

2.5 Wind and Turbulence Model . . . . . . . . . . . . . . . . . . . . . . . . . 17

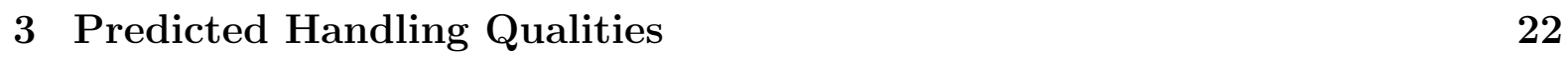

3.1 Inceptor Dynamics . . . . . . . . . . . . . . . . . . . . 22

3.2 Longitudinal Flight Control System . . . . . . . . . . . . . . . . . . . . . 24

3.3 Longitudinal Handling Qualities . . . . . . . . . . . . . . . . . . . . . . . 26

3.3.1 Bandwidth/Phase Delay . . . . . . . . . . . . . . . . . 27

3.3 .2 Dropback Criterion . . . . . . . . . . . . . . . . . . 29

3.4 Lateral Flight Control System . . . . . . . . . . . . . . . . . . . . . . . . 31

3.5 Lateral Handling Qualities . . . . . . . . . . . . . . . . . . . . . . . . . . 32

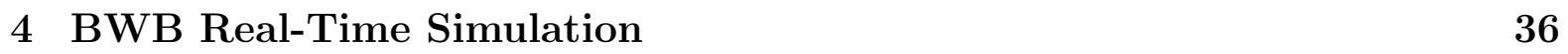

$4.1 \quad$ Flight Research Simulator . . . . . . . . . . . . . . . . . . . 36 
4.2 Motion Drive Algorithm $\ldots \ldots \ldots$

4.2 .1 Description $\ldots \ldots \ldots \ldots \ldots$

4.2 .2 Frequency Response $\ldots \ldots \ldots$. . . . . . . . . . . 40

4.2 .3 Tuning the Parameters for Each Task . . . . . . . . . . . . . . . 41

4.2 .4 Simulator Motion Fidelity . . . . . . . . . . . . . . . 43

4.2 .5 Reduced Motion . . . . . . . . . . . . . . . . . . . 43

\begin{tabular}{|lll}
5 & Pilot Handling Quality Experiments & 49
\end{tabular}

$5.1 \quad$ Experimental Setup . . . . . . . . . . . . . . . . . . . . . . . . . . . . . . . 49

5.2 Experimental Results . . . . . . . . . . . . . . . . . . . . . . . . 51

5.2 .1 Handling-Quality Ratings $\ldots \ldots \ldots \ldots \ldots$

5.2 .2 Analysis of Variance $\ldots \ldots \ldots \ldots \ldots$

5.2 .3 Subjects' Comments . . . . . . . . . . . . . . . . 59

5.3 Discussion of Results . . . . . . . . . . . . . . . . . . . . . . . . . 61

5.3 .1 Comparison with Previous Handling Trials . . . . . . . . . . . 61

5.3 .2 Comparison with Predicted Handling Qualities. . . . . . . . . . 63

5.3 .3 Effect of Simulator Motion . . . . . . . . . . . . . . . . . . . 64

5.3 .4 Limitations . . . . . . . . . . . . . . . . . . . . . . . 64

6 Conclusion and Recommendations 66

\begin{tabular}{ll}
\hline References & 68
\end{tabular}

\begin{tabular}{lll}
\hline Appendix A Stability Derivatives and Data & 72
\end{tabular}

\begin{tabular}{|ll}
\hline Appendix B Pilot Briefing & 74
\end{tabular} 


\section{List of Tables}

1.1 Mean Cooper Harper ratings of de Castro's trials . . . . . . . . . . . . . 3

2.1 Coefficients in ground effect equations . . . . . . . . . . . . . . . . . . . 12

2.2 Nonlinear spring force and damping coefficients . . . . . . . . . . . . . 14

2.3 Tire parameters . . . . . . . . . . . . . . . . . . . . . . 15

$2.4 \quad$ Engine position relative to $\mathrm{CG}$, body axes, $\mathrm{m}$. . . . . . . . . . . . . 17

3.1 Spring force and damping of the model column. . . . . . . . . . . . . . . 23

3.2 Spring force and damping of the model wheel . . . . . . . . . . . . . . . 24

$3.3 \quad$ Spring force and damping of the model rudder pedals . . . . . . . . . . . 24

3.4 Linearized dynamic characteristics of the simulated BWB inceptors . . . 24

3.5 Pitch-rate-command FCS gains and dynamic parameters . . . . . . . . . 26

3.6 Summary of BWB response to step pitch-rate command . . . . . . . . . 30

3.7 Lateral FCS gains and dynamic parameters . . . . . . . . . . . . . . . 32

3.8 Differences in Dutch roll mode characteristics . . . . . . . . . . . . . . . 35

$4.1 \quad$ Single degree of freedom motion envelope of the FRS . . . . . . . . . . 36

4.2 Inceptor range of motion and gain . . . . . . . . . . . . . . . . . . . 38

4.3 Description of the tasks . . . . . . . . . . . . . . . . . . . . . . . . 42

4.4 Initial and modified MDA parameters . . . . . . . . . . . . . . . . . . 42

5.1 Subjects used in the handling trials . . . . . . . . . . . . . . . 50

5.2 Cooper Harper ratings for subtasks . . . . . . . . . . . . . . . . . . . 52

5.3 Mean Cooper Harper ratings . . . . . . . . . . . . . . . . . . . . . 54

5.4 Run order of the tasks and motion condition ( $\mathrm{f}=$ full, $\mathrm{r}=$ ruse $)$. . . . . . . 54

5.5 Performance level for subtasks ( $1=$ desired, $2=$ adequate, $3=$ inadequate) . 55

5.6 Mean ratings and variance of subjects . . . . . . . . . . . . . . . . 57 
A.1 Longitudinal nondimensional derivatives . . . . . . . . . . . . . . . 72

A.2 Lift, and pitching moment coefficients with $\alpha=0 \ldots \ldots \ldots 72$

A.3 Lateral nondimensional derivatives . . . . . . . . . . . . . . 72

A.4 Longitudinal nondimensional control derivatives . . . . . . . . . . . . . 73

A.5 Lateral nondimensional control derivatives . . . . . . . . . . . . . . . 73

A.6 Drag parameters . . . . . . . . . . . . . . . . . . . . . . . . . . . . . . 73

A.7 Mass and other data . . . . . . . . . . . . . . . . . . . . . 73

A.8 $\quad$ Pilot's eye position relative to CG . . . . . . . . . . . . . . . . . . . 73 


\section{List of Figures}

2.1 Control-surface numbering of de Castro . . . . . . . . . . . . . . . . . . . 9

2.2 Ground effect on trimmed flight in landing configuration . . . . . . . . 13

$2.3 \quad$ Maximum sea-level thrust of one engine with $T_{\text {air }}=15^{\circ} \mathrm{C} \ldots \ldots$

2.4 Elementary flow field $\ldots \ldots \ldots \ldots$

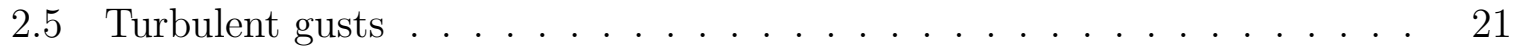

3.1 Pitch-rate-command-attitude-hold FCS from de Castro . . . . . . . . . . 25

3.2 Bandwidth $/$ phase-delay criterion evaluated at $180 \mathrm{kts} \ldots \ldots \ldots . . \ldots 28$

3.3 Bode plot of PRCAH FCS pitch-attitude response to pitch-rate input . . 28

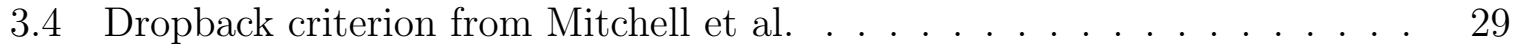

3.5 Pitch-rate and attitude response to a step pitch-rate input . . . . . . . 30

3.6 De Castro's lateral FCS $\ldots \ldots \ldots$

3.7 Bode plots of the simulated BWB wheel and BWB actuator . . . . . . 34

4.1 Out-the-window scene for approach tasks . . . . . . . . . . . . . . . 37

4.2 Screen shots of EFIS displays $\ldots \ldots \ldots$

4.3 UTIAS Flight Research Simulator . . . . . . . . . . . . . . . . . . 38

4.4 Classical-linear-washout motion-drive algorithm . . . . . . . . . . . 40

4.5 Expected simulator motion fidelity . . . . . . . . . . . . . . . . . 44

4.6 Frequency response of the exact gust transfer function and a first-order approximation . . . . . . . . . . . . . . . . . 46

4.7 Time history of the specific force $f_{z}$, altitude $679 \mathrm{~m}, \mathrm{~V}=92.6 \mathrm{~m} / \mathrm{s} \ldots 47$

4.8 Time history of the specific force $f_{z}$, altitude $1524 \mathrm{~m}, \mathrm{~V}=129 \mathrm{~m} / \mathrm{s} \ldots 48$

5.1 Cooper Harper ratings of tasks with full motion and ruse motion . . . . . 53

5.2 Subtask performance and $\mathrm{HQ}$ rating $\ldots \ldots \ldots \ldots . \ldots 56$

5.3 Mean ratings and standard deviation of subtasks . . . . . . . . . . 58 


\section{Nomenclature}

$\alpha$

$\alpha_{c}$

$\Delta \alpha$

$\Delta \delta_{e}$

$\Delta \theta$

$\Delta \theta_{\text {peak }}$

$\delta_{a}, \delta_{e}, \delta_{r}$

$\delta_{c}, \delta_{w}, \delta_{p}$

$\Delta C_{D}$

$\Delta C_{L}$

$\Delta C_{m}$

$\Delta V$

$\delta_{b f}=0$

$\delta_{L G}$

$\dot{\theta}_{\text {lim }}$

$\epsilon$
Angle of attack, rad

Corrected angle of attack, rad

Change in angle of attack from reference condition, rad

Change in deflection of control surfaces allocated to pitch control from reference condition, rad

Change in pitch attitude from reference condition, rad

Pitch-attitude overshoot, rad

Deflection of control surfaces allocated to roll, pitch, and yaw axes, $\mathrm{rad}$

Control column, wheel, and rudder pedal deflections, deg

Change in coefficient of drag due to ground effect

Change in coefficient of lift due to ground effect

Change in coefficient of pitching moment due to ground effect

Change in aircraft speed from reference condition, $\mathrm{m} / \mathrm{s}$

Belly flap deflection, rad

Landing-gear-extension state

Rate limit of tilt-coordination of $x$ specific force, body axes, deg/s

Landing gear strut compression, $\mathrm{m}$ 


\begin{tabular}{|c|c|}
\hline$\epsilon_{\max }$ & Landing gear strut stroke, $\mathrm{m}$ \\
\hline$\hat{h}$ & Nondimensional height above ground \\
\hline$\hat{p}, \hat{q}$, and $\hat{r}$ & Nondimensional roll, pitch, and yaw rates \\
\hline$\lambda$ & Longitudinal tire slip \\
\hline$\left(L_{u_{g}}\right)_{a s y m},\left(L_{w_{g}}\right)_{a s y m}$ & $\begin{array}{l}\text { Length scales of asymmetric turbulent gusts along } x \text { and } z \text {, body } \\
\text { axes, } \mathrm{m}\end{array}$ \\
\hline$\omega_{B}$ & Angular velocity in body axes, $\mathrm{rad} / \mathrm{s}$ \\
\hline $\mathbf{f}_{B}$ & $\begin{array}{l}\text { The sum of the external forces acting on the BWB, in body axes, } \\
\mathrm{N}\end{array}$ \\
\hline $\mathbf{G}_{B}$ & Sum of all external moments acting on the BWB, N.m \\
\hline $\mathbf{h}_{B}$ & Angular momentum of the BWB in body axes, $\mathrm{kg} \cdot \mathrm{m}^{2} / \mathrm{s}$ \\
\hline $\mathbf{I}_{B}$ & Inertia matrix, $\mathrm{kg} \cdot \mathrm{m}^{2}$ \\
\hline$\overline{\mathbf{y}}(s)$ & State vector in Laplace domain \\
\hline $\mathbf{a}$ & Inertial acceleration, $\mathrm{m} / \mathrm{s}^{2}$ \\
\hline $\mathbf{A}(s)$ & $\begin{array}{l}\text { Laplace-transformed system matrix of longitudinal force and mo- } \\
\text { ment coefficients }\end{array}$ \\
\hline f & Specific force, $\mathrm{m} / \mathrm{s}^{2}$ \\
\hline $\mathrm{g}$ & Acceleration due to gravity, $\mathrm{m} / \mathrm{s}^{2}$ \\
\hline $\mathbf{L}_{B S}$ & Transformation matrix from the stability axes to body axes \\
\hline $\mathbf{V}_{B}^{E}$ & Translational velocity in body axes, relative to Earth, m/s \\
\hline$\mu$ & Nondimensional mass coefficient \\
\hline$\nu$ & Ground roughness constant \\
\hline$\Omega$ & Spatial frequency of turbulence, $\mathrm{rad} / \mathrm{m}$ \\
\hline & Break frequency of low-pass filter in engine model, rad/s \\
\hline
\end{tabular}




\begin{tabular}{|c|c|}
\hline$\omega_{d}$ & Dutch roll mode natural frequency, rad/s \\
\hline$\omega_{t}$ & Circular frequency of turbulence, $\mathrm{rad} / \mathrm{s}$ \\
\hline$\omega_{180}$ & $\begin{array}{l}\text { Frequency of the pitch-attitude-frequency-response stability bound- } \\
\text { ary, rad/s }\end{array}$ \\
\hline$\omega_{a c}$ & Natural frequency of control-surface actuator, $\mathrm{rad} / \mathrm{s}$ \\
\hline$\omega_{B W}$ & Pitch-attitude bandwidth, rad/s \\
\hline$\omega_{H P_{i}}$ & $\begin{array}{l}\text { Natural frequencies of high-pass filters on angular velocity } i \text {, body } \\
\text { axes, rad/s }\end{array}$ \\
\hline$\omega_{H P_{j}}$ & $\begin{array}{l}\text { Natural frequencies of high-pass filters on specific force } j \text {, inertial } \\
\text { frame, } \mathrm{rad} / \mathrm{s}\end{array}$ \\
\hline$\omega_{L P_{i}}$ & $\begin{array}{l}\text { Natural frequency of low-pass filter on specific force } i \text {, body axes, } \\
\mathrm{rad} / \mathrm{s}\end{array}$ \\
\hline$\overline{\Delta n}$ & Change in normal load factor from reference condition \\
\hline $\bar{c}$ & Mean aerodynamic chord, m \\
\hline $\bar{i}$ & Laplace transform of aircraft motion state or control state $i$ \\
\hline $\bar{q}$ & Dynamic pressure, $\mathrm{Pa}$ \\
\hline$\overline{u_{g}}, \overline{w_{g}}$ & $\begin{array}{l}\text { Laplace transforms of the nondimensional turbulence gust compo- } \\
\text { nents along the aircraft's } x \text { and } z \text { body axes }\end{array}$ \\
\hline $\bar{U}_{10}$ & Mean wind speed at a height of $10 \mathrm{~m}$ above ground, $\mathrm{m} / \mathrm{s}$ \\
\hline$\Phi_{u_{g} u_{g}}, \Phi_{w_{g} w_{g}}$ & Dryden spectra of turbulent gusts $u_{g}$ and $w_{g}$ \\
\hline$\Phi_{2 \omega_{180}}$ & $\begin{array}{l}\text { Phase at twice the pitch-attitude-frequency-response stability bound- } \\
\text { ary, deg }\end{array}$ \\
\hline$\Phi_{\tau}$ & $\begin{array}{l}\text { Linear approximation to the phase of the pitch frequency response, } \\
\text { deg }\end{array}$ \\
\hline$\sigma_{u_{g}}, \sigma_{v_{g}}, \sigma_{w_{g}}$ & Intensity of turbulent gusts along $x, y$, and $z$, body axes, $\mathrm{m}^{2} / \mathrm{s}^{2}$ \\
\hline
\end{tabular}




\begin{tabular}{|c|c|}
\hline$\tau_{p}$ & $\begin{array}{l}\text { Linear approximation to phase delay of the pitch frequency re- } \\
\text { sponse, } \mathrm{s}\end{array}$ \\
\hline$\zeta_{d}$ & Dutch roll mode damping ratio \\
\hline$\zeta_{z}$ & Damping ratio of high-pass filters on $z$ specific force, inertial frame \\
\hline$b$ & Wingspan, m \\
\hline$b_{c}, b_{w}, b_{p}$ & $\begin{array}{l}\text { Model control column, wheel, and rudder pedal damping coeffi- } \\
\text { cients, } \mathrm{lb} / \mathrm{deg} / \mathrm{s}\end{array}$ \\
\hline$C_{D}$ & Coefficient of drag, wind frame \\
\hline$C_{L}$ & Coefficient of lift, wind frame \\
\hline$C_{l}, C_{m}, C_{n}$ & Coefficients of rolling, pitching, and yawing moments, body frame \\
\hline$C_{T}$ & Coefficient of thrust \\
\hline$C_{x}, C_{y}, C_{z}$ & Coefficients of forces along $x, y$, and $z$, body axes \\
\hline$C_{D_{0}}$ & Coefficient of drag at zero lift \\
\hline$C_{D_{\delta L G}}$ & Coefficient of drag due to landing gear \\
\hline$C_{i_{j_{k}}}$ & $2^{n d}$ partial derivative of coefficient of force or moment $i, \frac{\partial^{2} C_{i}}{\partial j \partial k}$ \\
\hline$C_{i_{j}}$ & Derivative of coefficient of force or moment $i$ with respect to $j, \frac{\mathrm{d} C_{i}}{\mathrm{~d} j}$ \\
\hline$C_{L_{0}}$ & Coefficient of lift at zero angle of attack \\
\hline$C_{W_{e}}$ & Coefficient of weight at equilibrium or reference speed \\
\hline$d_{r}$ & Commanded rudder deflection, deg \\
\hline$F_{c}, F_{w}, F_{p}$ & Control column, wheel, and rudder pedal forces, lb \\
\hline$F_{E}$ & The earth-fixed reference frame \\
\hline$f_{a a}^{i}$ & $i$ component of specific force in aircraft-fixed reference frame \\
\hline$F_{s_{c}}, F_{s_{w}}, F_{s_{p}}$ & Model control column, wheel, and rudder pedal spring forces, lb \\
\hline
\end{tabular}




\begin{tabular}{|c|c|}
\hline$f_{s s}^{i}$ & $i$ component of specific force in simulator-fixed reference frame \\
\hline$h$ & Height above ground, $\mathrm{m}$ \\
\hline$H P_{p}, H P_{q}, H P_{r}$ & $\begin{array}{l}\text { Transfer functions of high-pass filters on angular velocity about } x, \\
y \text {, and } z \text { body axes }\end{array}$ \\
\hline$H P_{x}, H P_{y}, H P_{z}$ & $\begin{array}{l}\text { Transfer functions of high-pass filters on } x, y \text {, and } z \text { specific forces, } \\
\text { inertial frame }\end{array}$ \\
\hline$I_{\hat{u}_{g}}, I_{\alpha_{g}}$ & $\begin{array}{l}\text { One-dimensional spectral density function of yawing and rolling } \\
\text { gusts }\end{array}$ \\
\hline K & Lateral FCS gain on rudder pedal deflection \\
\hline$K_{1}$ & Landing gear strut nonlinear spring force, $\mathrm{N}$ \\
\hline$k_{1}$ & First coefficient of drag equation \\
\hline$K_{2}$ & Landing gear strut non-linear damping, $\mathrm{N} / \mathrm{m}^{2} / \mathrm{s}^{2}$ \\
\hline$k_{2}$ & Second coefficient of drag equation \\
\hline$K_{3}$ & Landing gear strut linear damping, $\mathrm{N} / \mathrm{m} / \mathrm{s}$ \\
\hline$K_{i}$ & Pitch rate feedback integral gain \\
\hline$k_{i}$ & Gain on the $i$ component of specific force, body axes \\
\hline$K_{m}$ & Commanded pitch rate feedforward gain \\
\hline$k_{n}$ & Static margin \\
\hline$K_{p}$ & Pitch rate feedback gain \\
\hline$K_{r}$ & Yaw rate feedback gain \\
\hline$K_{\alpha}$ & Angle of attack feedback gain \\
\hline$K_{\beta}$ & Sideslip angle feedback gain \\
\hline$K_{A R I}$ & Aileron to rudder interconnect gain \\
\hline$K_{e_{f}}$ & Front landing gear strut spring endpoint stiffness, $\mathrm{N} / \mathrm{m}$ \\
\hline
\end{tabular}




\begin{tabular}{|c|c|}
\hline$K_{e_{m}}$ & Main landing gear strut spring endpoint stiffness, $\mathrm{N} / \mathrm{m}$ \\
\hline$k_{n_{d}}$ & Static margin of the BWB in de Castros' study \\
\hline$k_{n_{s}}$ & Static margin of the BWB in Staelens' study \\
\hline$K_{n w}$ & Speed-dependent scaling factor of transfer function $L P_{n w}$ \\
\hline$L_{u_{g}}, L_{v_{g}}, L_{w_{g}}$ & $\begin{array}{l}\text { Length scales of symmetric turbulent gusts along } x, y \text {, and } z \text {, body } \\
\text { axes, } \mathrm{m}\end{array}$ \\
\hline$L P_{x}, L P_{y}$ & $\begin{array}{l}\text { Transfer functions of low-pass filters on } x \text { and } y \text { specific forces, } \\
\text { body axes }\end{array}$ \\
\hline$L P_{n w}$ & $\begin{array}{l}\text { Transfer function of low-order normal-load-factor response to a } \\
\text { turbulent gust } w_{g}\end{array}$ \\
\hline$M_{c}, M_{w}, M_{p}$ & Model control column, wheel, and rudder pedal inertia, $\mathrm{lb} / \mathrm{deg} / \mathrm{s}^{2}$ \\
\hline$n$ & Load factor \\
\hline$p_{g}, r_{g}$ & Rotational components of turbulent gust, $\mathrm{rad} / \mathrm{s}$ \\
\hline$q_{\text {peak }}$ & Peak pitch rate, $\mathrm{rad} / \mathrm{s}$ \\
\hline$q_{s s}$ & Steady-state pitch rate, $\mathrm{rad} / \mathrm{s}$ \\
\hline$S$ & Trapezoidal wing area, $\mathrm{m}^{2}$ \\
\hline$u_{g}, v_{g}, w_{g}$ & Translational components of turbulent gust, $\mathrm{m} / \mathrm{s}$ \\
\hline$V$ & Aircraft speed, $\mathrm{m} / \mathrm{s}$ \\
\hline$V_{e}$ & Aircraft speed at a reference condition, $\mathrm{m} / \mathrm{s}$ \\
\hline$V_{R}$ & Takeoff rotation speed, kts \\
\hline CG & Centre of gravity \\
\hline EFIS & Electronic Flight Instrument System \\
\hline EPR & Engine pressure ratio \\
\hline FCS & Flight control system \\
\hline
\end{tabular}




$\begin{array}{ll}\text { HQR } & \text { Handling-quality rating } \\ \mathrm{L}, \mathrm{M}, \mathrm{N} & \text { Moments about } x, y \text {, and } z \text {, body axes, } \mathrm{N} \cdot \mathrm{m} \\ \mathrm{m} & \text { Mass of the BWB, } \mathrm{kg} \\ \text { MTOW } & \text { Maximum takeoff weight, } \mathrm{kg} \\ \mathrm{N}_{1} & \text { Engine compressor first stage speed, percent } \\ \mathrm{PF}(\mathrm{s}) & \text { Commanded pitch rate prefilter in the Laplace domain } \\ \mathrm{PRCAH} & \text { Pitch rate command attitude hold } \\ \mathrm{R} & \text { Turbulence patchiness parameter } \\ \mathrm{S} & \text { Laplace variable } \\ \text { TOGW } & \text { Takeoff gross weight, } \mathrm{kg} \\ \mathrm{X}, \mathrm{Y}, \mathrm{Z} & \text { Forces along } x, y, \text { and } z \text {, body axes, } \mathrm{N}\end{array}$




\section{Chapter 1}

\section{Introduction}

\section{$1.1 \quad$ Background}

The blended wing body (BWB) is an innovative aircraft design with the potential for greatly-improved aerodynamic efficiency over traditional tube-with-wings transport aircraft. Liebeck et al. reported on a preliminary feasibility study by NASA and Boeing on an 800 passenger, $7000 \mathrm{nmi}$ range aircraft [1]. They found that the amount of fuel used by a BWB is expected to be $27 \%$ less than for a conventional configuration. The BWB in that study had a takeoff gross weight (TOGW) of $823000 \mathrm{lb}(373000 \mathrm{~kg}$ ) and a wingspan of $280 \mathrm{ft}(85 \mathrm{~m})$. The NASA/Boeing study and research by EADS and several universities have created interest in the use of a BWB in a transport role [2]. Research conducted to date has examined the basic aerodynamic properties and the stability and control of this design, and has identified the need for stability augmentation to compensate for the statically-unstable airframe. In addition, scale models have been built and tested extensively in a wind tunnel and in flight [3] [4]. However, little is known about the handling qualities of this aircraft with a pilot-in-the-control loop.

\subsection{Literature Review}

Handling qualities are defined by Cooper and Harper [5] as "those qualities or characteristics of an aircraft that govern the ease and precision with which a pilot is able to perform the tasks required in support of an aircraft role". Cooper and Harper developed a ten-point scale that is used to rate handling qualities. After performing some flight task, the pilot assigns a numerical Cooper Harper rating to the task based on the char- 
acteristics of the aircraft and the demands on the pilot. Handling qualities are affected by the cockpit interface, the aircraft environment, and pilot stress [5]. The military handbook MIL-HDBK-1797 [6] uses the term "flying qualities" somewhat interchangeably with "handling qualities". In the current study, only the term "handling qualities" is used.

In 2000, Cameron and Princen wrote about piloted-handling trials of a BWB commercial airplane that were conducted in the NASA Langley Visual Motion Simulator [7]. However, the results of these tests are not widely available.

De Castro [8] conducted piloted-handling trials at Cranfield University in 2003 to assess the handling qualities of a BWB. The trials are the most extensive and publiclyavailable research on the handling qualities of the BWB. The BWB in those trials had a maximum takeoff weight (MTOW) of $371280 \mathrm{~kg}$ and a wingspan of $80 \mathrm{~m}$. The aerodynamic data that were used are only valid at low speeds, and assume linear aerodynamics. De Castro developed several flight controllers; the controllers that were used in the Cranfield handling trials are also used in the current study: a pitch-rate-command longitudinal controller, and a lateral controller (called FCS1). The results of de Castro's handling trials are shown in Table 1.1. Four subjects, all of whom were test pilots, flew six or seven tasks. The first two subjects were asked to rate seven complete tasks. De Castro then broke each task into several subtasks. The second two subjects only completed six tasks; Task 4, the crosswind approach and landing, was deleted during the course of de Castro's study. Table 1.1 shows the mean ratings of the second two subjects and all four subjects. Task 4 is not shown because it was only completed by the first two subjects. The mean ratings of the second two subjects are used in the following discussion, because the subjects in the current study rated the subtasks, and not the complete tasks.

Task 1 has the lowest mean Cooper Harper rating (3.17), while Task 7 has the highest mean rating (5.00). Task 7 might have been rated poorly due to poor control sensitivity or low Dutch roll damping. The ratings of Tasks 1, 2, and 5 may have been affected by changes made to the engine model to reduce the engines' pitching and yawing moments. De Castro intentionally made the engines' pitching moment zero, so that the aircraft could rotate during takeoff at an airspeed of $180 \mathrm{kts}$. Similarly, the engines' yawing moment was made to be $1 / 3.5$ what it would actually be in the aircraft. This was done because of limited rudder control power.

De Castro's handling trials [8] were conducted in a fixed-based simulator, without motion cues. Therefore, the subjects would have relied primarily on visual cues. Showal- 
Table 1.1: Mean Cooper Harper ratings of de Castro's trials [8]

\begin{tabular}{llll}
\hline & Description & $\begin{array}{l}\text { Subjects } \\
3 \& 4\end{array}$ & $\begin{array}{l}\text { Subjects } \\
1-4\end{array}$ \\
\hline Task 1 & Normal takeoff & 3.17 & 3.50 \\
Task 2 & Engine failure during takeoff & 3.75 & 4.33 \\
Task 3 & Normal approach and landing & 4.00 & 3.75 \\
Task 5 & Engine failure during & & \\
$\quad$ approach and landing & 4.00 & 3.75 \\
Task 6 & Approach and landing with & & \\
& longitudinal offset correction & 4.00 & 3.50 \\
Task 7 & $\begin{array}{l}\text { Approach and landing } \\
\text { with lateral offset correction }\end{array}$ & 5.00 & 4.75 \\
\hline
\end{tabular}

ter and Parris [9] conducted experiments into the effect of simulator-base motion (and other variables) on the performance of pilots flying three tasks in a simulated KC-135 large-transport aircraft. The experiments used the Flight Simulator for Advanced Aircraft, which can move $40 \mathrm{ft}$ laterally. However, the simulator motion was restricted to be similar to the motion obtainable with a synergistic six-degree-of-motion motion base. Showalter and Parris found that performance on the tasks improved with simulator motion. Performance is related to handling-quality ratings (HQRs) by the performance criteria that are specified for handling-trial tasks. The lack of motion cues in de Castro's study may have increased the time it took the subjects to respond to a disturbance to the aircraft, possibly affecting the HQRs.

Grantham [10] compared handling-quality ratings obtained in an in-flight simulator to those obtained in a ground-based simulator, the Langley Visual/Motion Simulator. The aircraft that was modeled was a jet-transport airplane, with 31 configurations of longitudinal flight control systems. For those configurations that had a pitch-rate command response, the Cooper Harper ratings of the landing-flare task were generally lower in the in-flight simulator than they were in the ground-based simulator; handling-quality ratings obtained in a ground-based simulator tended to be conservative. The majority (81\%) of the 31 configurations had ground-based ratings that were within \pm 1 Cooper Harper ratings of the corresponding in-flight ratings. Grantham also found that performance tended to be worse in the ground-based simulator than in the in-flight simulator. 
Sink rates at touchdown tended to be approximately $3.5 \mathrm{ft} / \mathrm{s}$ greater in the ground-based simulator. While that study supports using ground-based simulation to obtain HQRs of an aircraft, it does not provide guidelines for the motion requirements of the ground-based simulator.

Soparkar and Reid [11] used a model of a generic jet trainer to determine the effect of simulator motion on HQRs. They found that pilots preferred simulator motion with low washout levels to the no-motion case. The task was lateral tracking under gust upsets applied to the roll axis. Schroeder [12] studied the requirements for simulator motion to achieve good simulation fidelity. First, his literature review revealed that simulator motion is unnecessary in tasks in which the pilot creates his or her own motion, such as in a tracking task in a disturbance-free environment. Second, he conducted extensive tests in a simulator with a large displacement capability. Helicopter tasks were simulated with one-to-one motion of the simulator. Schroeder analyzed pilot performance as the tasks were repeated with varying amounts of motion. Third, based on that analysis, and consolidating data from many earlier studies, Schroeder defined boundaries of simulator motion fidelity. The boundaries that separate low, medium, and high motion fidelity are functions of the motion amplitude ratio and phase distortion from the highpass washout filters at $1 \mathrm{rad} / \mathrm{s}$. Schroeder developed these fidelity boundaries specifically for helicopters. Compared to pilots of fixed-wing aircraft, helicopter pilots tend to use external cues to a greater extent in order to stabilize the pilot-helicopter system. Acknowledging this increased dependence on external cues by helicopter pilots, in 1994 the US Federal Aviation Administration (FAA) made helicopter-simulator motion requirements more stringent than fixed-wing-aircraft-simulator motion requirements. It is possible that Schroeder's motion-fidelity requirements for helicopters are therefore more demanding than what is necessary for fixed-wing aircraft. Nonetheless, the motion fidelity criteria developed by Schroeder can still be applied to fixed-wing aircraft, as was done by Reid and Nahon [13].

\subsection{Purpose}

The primary purpose of the current research is to determine the handling qualities of a BWB aircraft, using piloted-handling trials in a moving-base simulator. The secondary purpose is to determine the effect that simulator motion has on the HQRs. The current research builds upon previously-conducted research that used a fixed-base simulator. The 
BWB modeled in the current research is a "hybrid" BWB, because parts of the model are drawn from various data sources. The aerodynamic model, ground-force model, engine model, and wind and turbulence model have all been modified from de Castro's model and are described in Chapter 2. Chapter 3 describes de Castro's flight control system [8], which was the system implemented in the current research with some modifications to the gains. Chapter 3 also examines the effect of inceptor dynamics on HQRs, and predicts the HQRs using established standards. De Castro's study did not describe the inceptor dynamics, nor their effect on handling qualities. Clearly, the inceptor dynamics and control sensitivity will have an effect on HQRs. While handling qualities can be predicted analytically, piloted-handling trials by test pilots provide the ultimate measure of an aircraft's handling qualities. The first half of Chapter 4 describes the simulator facility used in the current research. The second half of Chapter 4 finds the expected fidelity of the simulator motion. Chapter 4 contains new developments compared to previous studies, because it describes the particular simulator used in the current study. Chapter 5 of the current study describes the experimental setup used in the piloted-handling trials, and presents the results. The results of the current research are then compared to the results of previous handling trials and to the predicted handling qualities of Chapter 3 . 


\section{Chapter 2}

\section{Flight Model of the BWB}

The real-time simulation model of the BWB was developed in MATLAB Simulink and compiled into a real-time executable using OPAL-RT's RT-LAB. The model was based on an existing Boeing 747 Simulink model, which was modified to have the aerodynamic properties of the BWB. The 747 model was also changed to have a landing gear appropriate for the BWB. The BWB has different ground effect than the 747 , so this too was changed. Another element in the flight model was the atmospheric turbulence, the amount of which was deliberately set. Turbulence was used to add realism to the simulation, and to increase the pilot's workload.

The Simulink model of the BWB was compiled using RT-Lab. The compiled code was run on one processor of the real-time host computer, a Harris iHawk 848 running RedHawk Linux. The equations of motion were solved at $180 \mathrm{~Hz}$.

\subsection{Equations of Motion}

The rigid-body equations of motion that are implemented in the flight model are taken from Etkin [14]. Euler's equations of motion are rearranged to solve for the derivatives of translational and angular velocity. The derivatives are then integrated. The translational velocity $\mathbf{V}_{B}^{E}$ is the velocity relative to an earth-fixed frame expressed in a body axis. The earth-fixed frame, $F_{E}$, is taken to be an inertial frame. Rotation and curvature of the earth are neglected. The translational equation of motion is taken as,

$$
\mathbf{f}_{B}=m\left(\dot{\mathbf{V}}_{B}^{E}+\tilde{\omega}_{B} \mathbf{V}_{B}^{E}\right)
$$


where $\mathbf{f}_{B}$ is the sum of the external forces, $m$ is the aircraft mass, and $\tilde{\omega}_{B}$ is the skewsymmetric matrix of angular velocity expressed in body axes. The previous equation is rearranged to solve for $\dot{\mathbf{V}}_{B}^{E}$ :

$$
\dot{\mathbf{V}}_{B}^{E}=\frac{1}{m} \mathbf{f}_{B}-\tilde{\omega}_{B} \mathbf{V}_{B}^{E}
$$

The rotational equation of motion is also expressed in the body frame as,

$$
\mathbf{G}_{B}=\dot{\mathbf{h}}_{B}+\tilde{\omega}_{B} \mathbf{h}_{B}
$$

where $\mathbf{G}$ is the sum of all moments on the BWB. The angular momentum is given as

$$
\mathbf{h}_{B}=\mathbf{I}_{B} \omega_{B}
$$

and therefore the derivative of the angular momentum relative to the body frame, expressed in the body frame, is

$$
\dot{\mathbf{h}}_{B}=\dot{\mathbf{I}}_{B} \omega_{B}+\mathbf{I}_{B} \dot{\omega}_{B}
$$

where $\mathbf{I}_{B}$ is the inertia matrix. The BWB is treated as a rigid body, so

$$
\dot{\mathbf{I}}_{B}=0
$$

and therefore

$$
\dot{\mathbf{h}}_{B}=\mathbf{I}_{B} \dot{\omega}_{B}
$$

Rearranging Equation 2.2 to solve for $\dot{\omega}_{B}$ gives

$$
\dot{\omega}_{B}=\mathbf{I}_{B}^{-1}\left(\mathbf{G}_{B}-\tilde{\omega}_{B} \mathbf{I}_{B} \omega_{B}\right)
$$

The principal axes of the BWB are assumed to be coincident with the body axes, so

$$
\mathbf{I}_{B}=\left[\begin{array}{ccc}
I_{x} & 0 & 0 \\
0 & I_{y} & 0 \\
0 & 0 & I_{z}
\end{array}\right]
$$




\subsection{Aerodynamic Model}

The aerodynamic forces and moments are calculated in stability axes. The stability axes are chosen so that the $x$-axis is aligned with $\mathbf{V}$ in a reference condition of steady, symmetric flight [14]. The forces and moments are then transformed to the body axes and summed with other forces and moments, such as those from the engine and ground contact.

The non-dimensional force and moment coefficients are first calculated and are then multiplied by the dynamic pressure and a reference area or volume to get the actual forces and moments. The following equations, from de Castro [8], give the force and moment coefficients, in the absence of ground effect:

$$
\begin{aligned}
C_{D}= & C_{D_{0}}+C_{L} k_{1}+C_{L}^{2} k_{2}+C_{D_{\delta L G}} \delta_{L G} \\
C_{y}= & \left(C_{y_{\beta_{\alpha}}} \alpha+C_{y_{\beta_{0}}}\right) \beta+\left(C_{y_{p_{\alpha}}} \alpha+C_{y_{p_{0}}}\right) \hat{p}+\left(C_{y_{r_{\alpha}}} \alpha+C_{y_{r_{0}}}\right) \hat{r} \\
& +\left(C_{y_{\delta a_{\alpha}}} \alpha+C_{y_{\delta a_{0}}}\right) \delta_{a}+\left(C_{y_{\delta r_{\alpha}}} \alpha+C_{y_{\delta r_{0}}}\right) \delta_{r} \\
C_{L}= & C_{L_{0}}+C_{L_{\alpha}} \alpha-C_{z_{q}} \hat{q} \cos (\alpha)+C_{L_{\delta_{e}}} \delta_{e} \\
C_{l}= & \left(C_{l_{\beta_{\alpha}}} \alpha+C_{l_{\beta_{0}}}\right) \beta+\left(C_{l_{p_{\alpha}}} \alpha+C_{l_{p_{0}}}\right) \hat{p}+\left(C_{l_{r_{\alpha}}} \alpha+C_{l_{r_{0}}}\right) \hat{r} \\
& +\left(C_{l_{\delta a_{\alpha}}} \alpha+C_{l_{\delta a_{0}}}\right) \delta_{a}+\left(C_{l_{\delta r_{\alpha}}} \alpha+C_{l_{\delta r_{0}}}\right) \delta_{r} \\
C_{m}= & C_{m_{0}}+C_{m_{\alpha}} \alpha+C_{m_{q}} \hat{q}+C_{m_{\delta_{e}}} \delta_{e} \\
C_{n}= & \left(C_{n_{\beta_{\alpha}}} \alpha+C_{n_{\beta_{0}}}\right) \beta+\left(C_{n_{p_{\alpha}}} \alpha+C_{n_{p_{0}}}\right) \hat{p}+\left(C_{n_{r_{\alpha}}} \alpha+C_{n_{r_{0}}}\right) \hat{r} \\
& +\left(C_{n_{\delta a_{\alpha}}} \alpha+C_{n_{\delta a_{0}}}\right) \delta_{a}+\left(C_{n_{\delta r_{\alpha}}} \alpha+C_{n_{\delta r_{0}}}\right) \delta_{r}
\end{aligned}
$$

where $\hat{p}, \hat{q}$, and $\hat{r}$ are nondimensional angular rates (roll, pitch, and yaw rate, respectively) expressed in stability axes. The stability derivatives are listed in Appendix A.

The controls surfaces are the elevons and winglet rudders, which are grouped together to act like the elevator, ailerons, and rudder on a conventional aircraft. The aerodynamic control deflections are $\delta_{e}, \delta_{a}$, and $\delta_{r}$. Figure 2.1 shows the control surface numbering, when the aircraft is viewed from above (the engines are not shown). The control surfaces that are allocated to control motion about each axis are described in Chapter 3 . The landing-gear-extension state, $\delta_{L G}$, is 0 when the landing gear is retracted and 1 when the landing gear is extended. The coefficients above are dimensionalized and transformed 


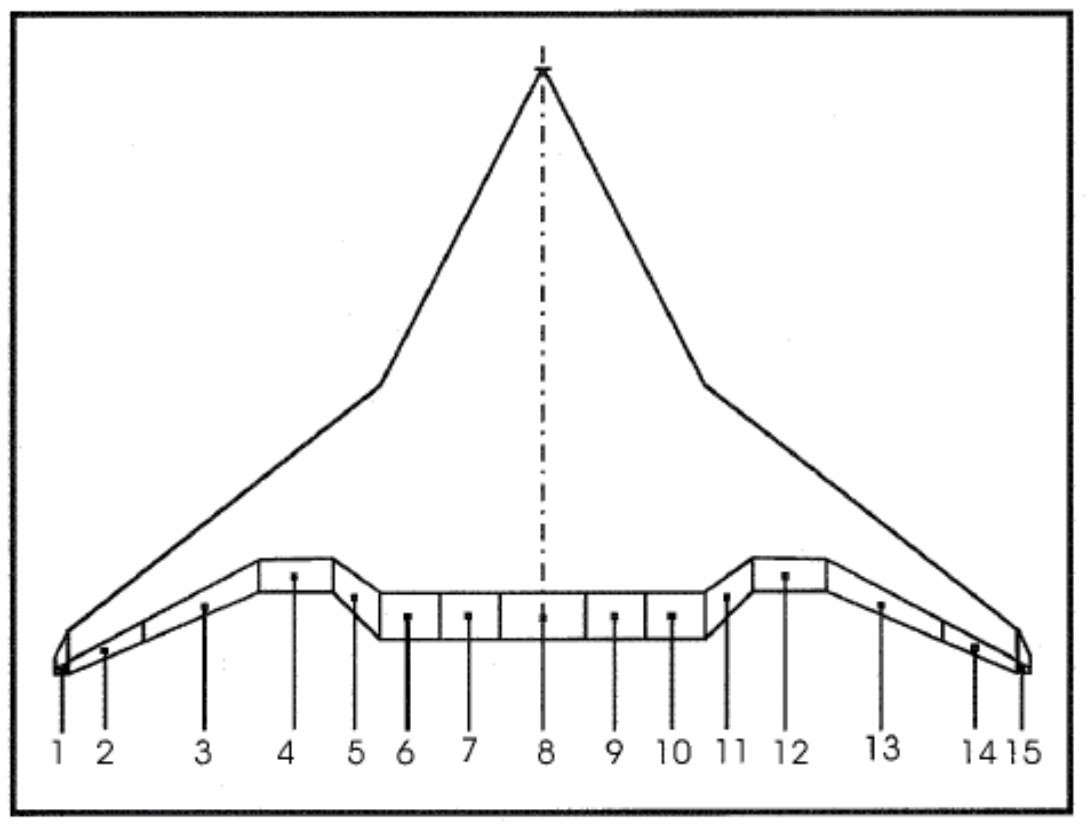

Figure 2.1: Control-surface numbering of de Castro 8. Reprinted with permission.

into body axes as follows,

$$
\begin{gathered}
{\left[\begin{array}{c}
X \\
Y \\
Z
\end{array}\right]=\bar{q} S \mathbf{L}_{B S}\left[\begin{array}{c}
-C_{D} \\
C_{y} \\
-C_{L}
\end{array}\right]} \\
{\left[\begin{array}{c}
L \\
M \\
N
\end{array}\right]=\bar{q} S \mathbf{L}_{B S}\left[\begin{array}{c}
C_{l} b \\
C_{m} \bar{c} \\
C_{n} b
\end{array}\right]} \\
\mathbf{L}_{B S}=\left[\begin{array}{ccc}
\cos (\alpha) & 0 & -\sin (\alpha) \\
0 & 1 & 0 \\
\sin (\alpha) & 0 & \cos (\alpha)
\end{array}\right] \\
\bar{q}=\frac{1}{2} \rho V^{2}
\end{gathered}
$$

where $b$ is the wingspan, $\bar{c}$ is the mean aerodynamic chord, $S$ is the trapezoidal wing area, $\bar{q}$ is the dynamic pressure, and $\mathbf{L}_{B S}$ is the transformation matrix from the stability axes to body axes. 


\subsubsection{Ground Effect}

The airflow around an aircraft is altered as the aircraft approaches the ground. Since the tasks of the piloted-handling trials in the current study include landings and takeoffs, ground effect is expected to occur. Etkin [15] states that, for conventional aircraft, significant changes in trim and stability take place due to ground effect. In ground effect the downwash at the tail of a conventional aircraft is reduced, the wing-body lift-curve slope is increased, and the tail lift-curve slope is increased. Clearly, tail downwash and tail lift are not applicable to the BWB, but the change in wing-body lift-curve slope may be significant.

During the piloted-handling trials, de Castro 8$]$ found that the aircraft could not be rotated during takeoff at $180 \mathrm{kts}(92.6 \mathrm{~m} / \mathrm{s})$. As a solution, the engine height was lowered to be coincident with the CG. Rotation at $180 \mathrm{kts}$ might have been possible if ground effect increased the lift slope significantly or gave a positive pitching moment. The ground effect model that was used by de Castro only changed the lift slope, $C_{z_{\alpha}}$, and did not change the pitching moment. For small angles of attack, $C_{z_{\alpha}} \approx-C_{L_{\alpha}}$. The change in $C_{z_{\alpha}}$ with proximity to the ground from de Castro is given as,

$$
C_{z_{\alpha}}(h)=\left\{\begin{aligned}
-7.495 & \text { if } h=0 \\
0.1454 h-7.495 & \text { if } 0<h \leq 5 m \\
0.0397 h-6.4388 & \text { if } 5 m<h<15 m \\
0.00375 h-5.8993 & \text { if } 15 m \leq h \leq 110 m \\
-5.4868 & \text { if } h>110 m
\end{aligned}\right.
$$

Subsequent to the work of de Castro $[8]$ an improved longitudinal ground-effect model was developed by Staelens [16]. Staelens tested a $1 / 67^{\text {th }}$ scale model of a BWB in a wind tunnel to find the changes to the longitudinal aerodynamic coefficients due to ground effect. The full-size BWB had a hypothetical wingspan of $239 \mathrm{ft}(73 \mathrm{~m})$ and a TOGW of $500000 \mathrm{lb}(226800 \mathrm{~kg})$. Staelens also investigated the use of a belly flap to generate a greater nose-up pitching moment during takeoff and to reduce flight path "sag" during a go-around on approach. Staelens gives the lift, drag, and pitching moment as three polynomial functions of angle of attack, height above ground $h$, elevon deflection, and belly-flap deflection. The height above ground is nondimensionalized by dividing by the wingspan, $b$,

$$
\hat{h}=\frac{h}{b}
$$


The zero-lift line of Staelens' model was 2.1 (0.037 rad) greater (a positive rotation about the $y$-axis) than the zero-lift line of de Castro's model. To account for the difference in zero-lift lines, a corrected angle of attack $\alpha_{c}$ is used in the ground-effect equations,

$$
\alpha_{c}=\alpha+0.037
$$

Staelens' results were used in the current research, with the belly flap retracted $\left(\delta_{b f}=0\right)$. Ground effect was forced to be zero at a nondimensional height $\hat{h} \geq 1$. In ground effect, the total drag and lift are found by adding to Equations 2.9 and 2.11 the following increments,

$$
\begin{aligned}
& \Delta C_{D}=\left\{\begin{aligned}
0 & \text { if } \hat{h}>1 \\
C_{D}\left(\alpha_{c}, \hat{h}, \delta_{e}\right)-C_{D}\left(\alpha_{c}, 1, \delta_{e}\right) & \text { if } 0.115<\hat{h} \leq 1 \\
C_{D}\left(\alpha_{c}, 0.115, \delta_{e}\right)-C_{D}\left(\alpha_{c}, 1, \delta_{e}\right) & \text { if } \hat{h} \leq 0.115 \\
0 & \text { if } \hat{h}>1
\end{aligned}\right. \\
& \Delta C_{L}=\left\{\begin{aligned}
C_{L}\left(\alpha_{c}, \hat{h}, \delta_{e}\right)-C_{L}\left(\alpha_{c}, 1, \delta_{e}\right) & \text { if } 0.115<\hat{h} \leq 1 \\
C_{L}\left(\alpha_{c}, 0.115, \delta_{e}\right)-C_{L}\left(\alpha_{c}, 1, \delta_{e}\right) & \text { if } \hat{h} \leq 0.115
\end{aligned}\right.
\end{aligned}
$$

Staelens [16] found the ground effect for nondimensionalized heights from 1 down to 0.057. However, Staelens only compared the polynomial functions for lift, drag, and pitching moment to the wind-tunnel measurements down to a nondimensional height of 0.115. This was the lower limit used in the current study. Ground effect is greater in Staelens' model than in de Castro's model [8]; at a nondimensional height of 0.115, the change in lift slope of the former is $0.96 \mathrm{rad}^{-1}$ while that of the latter is $0.59 \mathrm{rad}^{-1}$.

The total pitching moment in ground effect is found by adding to Equation 2.13 the following increment,

$$
\Delta C_{m}=\left\{\begin{aligned}
0 & \text { if } \hat{h}>1 \\
C_{m}\left(\alpha_{c}, \hat{h}, \delta_{e}\right)-C_{m}\left(\alpha_{c}, 1, \delta_{e}\right) & \\
+\Delta C_{L}\left(k_{n_{s}}-k_{n_{d}}\right) & \text { if } 0.115<\hat{h} \leq 1 \\
C_{m}\left(\alpha_{c}, 0.115, \delta_{e}\right)-C_{m}\left(\alpha_{c}, 1, \delta_{e}\right) & \\
+\Delta C_{L}\left(k_{n_{s}}-k_{n_{d}}\right) & \text { if } \hat{h} \leq 0.115
\end{aligned}\right.
$$

The ground effect on pitching moment includes the difference in static margins between the configurations of Staelens and de Castro. In the former, the static margin $k_{n_{s}}=0.105$ while in the latter, $k_{n_{d}}=-0.13$. 
Modifying Staelens' 16 equations for drag, lift, and pitching moment in ground effect gives the following equations:

$$
\begin{aligned}
& C_{D}\left(\alpha_{c}, \hat{h}, \delta_{e}\right)=a_{2} \hat{h}+a_{5} \frac{\alpha_{c}}{\hat{h}}+a_{9} \frac{\delta_{e}}{\hat{h}}+a_{10} \frac{\alpha_{c}}{\hat{h}^{2}}+a_{15} \frac{\delta_{e}}{\hat{h}^{2}} \\
& C_{L}\left(\alpha_{c}, \hat{h}, \delta_{e}\right)=a_{2} \hat{h}+a_{5} \frac{\alpha_{c}}{\hat{h}}+a_{9} \frac{\delta_{e}}{\hat{h}}+a_{10} \frac{\alpha_{c}}{\hat{h}^{2}}+a_{15} \frac{\delta_{e}}{\hat{h}^{2}} \\
& C_{m}\left(\alpha_{c}, \hat{h}, \delta_{e}\right)=a_{2} \hat{h}+a_{5} \frac{\alpha_{c}}{\hat{h}}+a_{8} \frac{\alpha_{c}}{\hat{h}^{3}}+a_{9} \frac{\delta_{e}}{\hat{h}}+a_{10} \frac{\alpha_{c}}{\hat{h}^{2}}+a_{15} \frac{\delta_{e}}{\hat{h}^{2}}
\end{aligned}
$$

\begin{tabular}{|c|c|c|c|}
\hline & $C_{L}$ & $C_{D}$ & $C_{m}$ \\
\hline$a_{2}$ & 0.010852 & 0.021121 & -0.040100 \\
\hline$a_{5}$ & -0.020298 & 0.055524 & 0.093076 \\
\hline$a_{8}$ & - & - & 0.003156 \\
\hline$a_{9}$ & -0.001112 & -0.000502 & 0.031372 \\
\hline$a_{10}$ & 0.014992 & -0.005446 & -0.034477 \\
\hline$a_{15}$ & 0.001061 & 0.000149 & -0.006184 \\
\hline
\end{tabular}

The coefficients $a_{i}$ are given in Table 2.1.

In the current study, the inclusion of $\Delta C_{m}$ due to ground effect was sufficient to allow rotation at $180 \mathrm{kts}$, with the engines $2.8 \mathrm{~m}$ above the $\mathrm{CG}$. While adding the pitching moment and lift increment due to ground effect helps achieve rotation, it changes the trimmed condition on the approach to landing. At an approach speed of $180 \mathrm{kts}$, ground effect lowers the trimmed angle of attack by $3.2^{\circ}$ and increases the elevon to trim by $4^{\circ}$ over the free-air case. Figure 2.2 shows the changes to trimmed angle of attack due to ground effect. The graphs are for the approach-to-landing configuration; the landing gear is extended and the aircraft is descending on the glideslope at $3^{\circ}$. The impact of ground effect on longitudinal handling qualities is discussed in Chapter 3.

\subsection{Ground Model}

\subsubsection{Landing Gear Struts}

The ground model consists of a tricycle landing gear. The front bogey has 2 tires, while the left and right body bogeys have 10 tires each. The parameters of the suspension and 

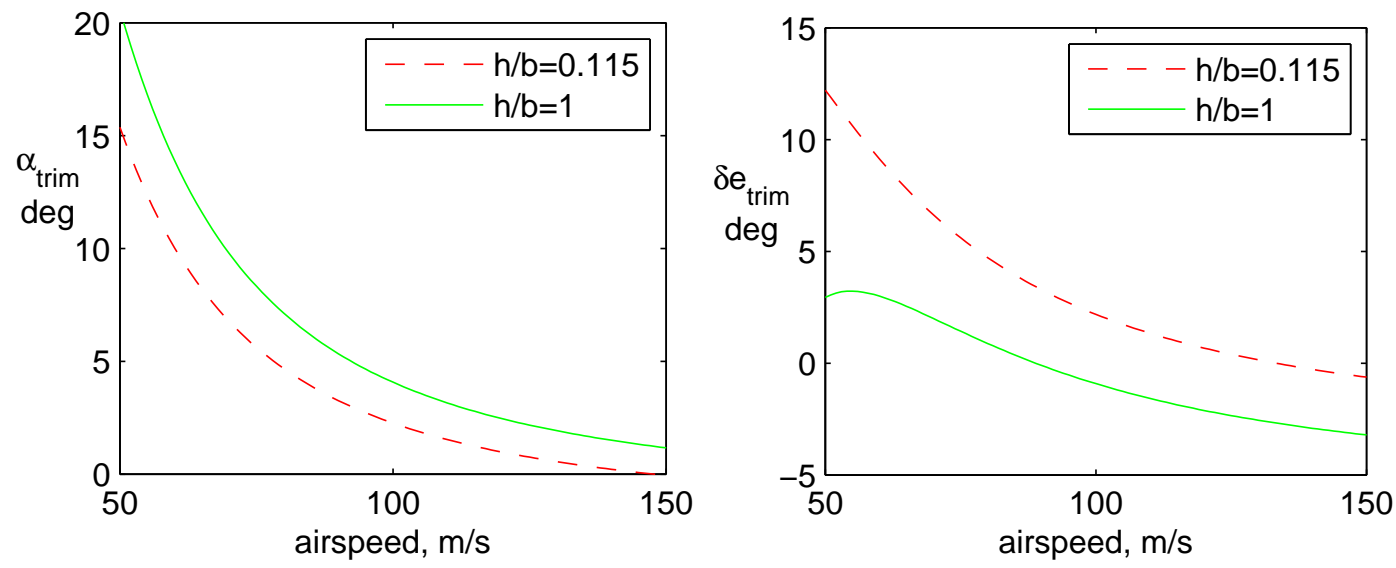

Figure 2.2: Ground effect on trimmed flight in landing configuration

tire models were selected to suit the BWB, and used the parameters for a Boeing 747 as a starting point [17]. The front bogey was located $25.4 \mathrm{~m}$ in front of the centre of gravity (CG). The body bogeys were located $2.82 \mathrm{~m}$ behind the $\mathrm{CG}$, and $5.5 \mathrm{~m}$ laterally from the CG. The distance from the CG to the ground was $4 \mathrm{~m}$, when the landing gear struts are fully extended. The landing gear struts were modeled with non-linear springs and oleo-pneumatic dampers. The strut force for a single bogey is given by:

$$
\begin{aligned}
F_{\text {strut }} & =F_{\text {spring }}+F_{\text {damp }} \\
& =K_{1}(\epsilon)+K_{2}(\epsilon) \dot{\epsilon}|\dot{\epsilon}|+K_{3} \dot{\epsilon}
\end{aligned}
$$

where $K_{1}$ is the nonlinear spring force, and $K_{2}$ and $K_{3}$ are the non-linear and linear damping coefficients, respectively and $\epsilon$ is the strut compression.

The spring forces and non-linear damping coefficients are given in Table 2.2. The spring force and non-linear damping coefficients are interpolated between the given values of $\epsilon$. The linear damping coefficients $K_{3}$ are $311486 \mathrm{~N} / \mathrm{m} / \mathrm{s}$ and $800964 \mathrm{~N} / \mathrm{m} / \mathrm{s}$ for the front and main bogeys, respectively. The main landing gear spring stiffness was determined assuming a strut stroke $\epsilon_{\max }=0.673 \mathrm{~m}$ and a load factor $n=2.485$ [18. The shape of the spring force-deflection curve was kept the same as the Boeing 747. However, the spring stiffness was increased to achieve the desired spring endpoint stiffness for the given load factor and strut stroke. The endpoint stiffness is given by the following 
equation, assuming equal loading of both main landing gear struts:

$$
\begin{aligned}
K_{e_{m}} & =\frac{1}{2} \frac{m \cdot g \cdot n}{\epsilon_{\max }} \\
& =\frac{371280 \mathrm{~kg} \cdot 9.81 \mathrm{~m} / \mathrm{s}^{2} \cdot 2.485}{2 \cdot 0.673 \mathrm{~m}} \\
& =6.72 e 6 \mathrm{~N} / \mathrm{m}
\end{aligned}
$$

The endpoint spring stiffness used in the flight model was slightly higher than this, 6.97e6 $\mathrm{N} / \mathrm{m}$. The front (or "nose") landing gear strut is designed to carry $40 \%$ of the force of one of the main landing gear struts. The required front landing gear strut endpoint stiffness is given as,

$$
\begin{aligned}
K_{e_{f}} & =0.4 \frac{1}{2} \frac{m \cdot g \cdot n}{\epsilon_{\max }} \\
& =2.79 e 6 \mathrm{~N} / \mathrm{m}
\end{aligned}
$$

The endpoint spring stiffness of the front strut used in the flight model was $4.04 \mathrm{e} 6 \mathrm{~N} / \mathrm{m}$, considerably larger than what is recommended by Chester's [18] method.

Table 2.2: Nonlinear spring force and damping coefficients

\begin{tabular}{lcccc}
\hline \multicolumn{3}{c}{ Front } & \multicolumn{2}{c}{ Main } \\
$\mathrm{SC}, \mathrm{m}$ & $K_{1}(\epsilon), 10^{6} \mathrm{~N}$ & $K_{2}(\epsilon), 10^{5} \mathrm{~N} / \mathrm{m}^{2} / \mathrm{s}^{2}$ & $K_{1}(\epsilon), 10^{6} \mathrm{~N}$ & $K_{2}(\epsilon), 10^{5} \mathrm{~N} / \mathrm{m}^{2} / \mathrm{s}^{2}$ \\
\hline 0.000 & 0 & 0.338 & 0 & 0.689 \\
0.127 & 0.133 & 0.338 & 0.203 & 0.689 \\
0.254 & 0.266 & 0.482 & 0.439 & 1.034 \\
0.381 & 0.444 & 0.772 & 0.845 & 2.068 \\
0.508 & 1.112 & 1.576 & 1.690 & 3.240 \\
0.635 & 2.224 & 3.282 & 3.803 & 5.102 \\
0.762 & 3.870 & 4.826 & 6.761 & 8.273 \\
\hline
\end{tabular}

\subsubsection{Tires}

The ground model calculates the forces acting on the landing gear tires. The tire model calculates the wheel's angular velocity, longitudinal and lateral slip, and normal deflection. The 2 front bogey tires and 10 main bogey tires are each treated as one "homogenous" or equivalent tire. The normal load on the equivalent tire is the strut normal 
load divided by the number of tires. The total force acting on that strut is found by multiplying the forces on the equivalent tire by the number of tires. The tire parameters are given in Table 2.3 .

Table 2.3: Tire parameters

\begin{tabular}{lcc}
\hline & Front & Main \\
\hline Pressure, Pa & $1.24 \mathrm{e} 6$ & $1.24 \mathrm{e} 6$ \\
Rated pressure, Pa & $1.45 \mathrm{e} 6$ & $1.45 \mathrm{e} 6$ \\
Diameter, m & 1.16 & 1.16 \\
Width, m & 0.41 & 0.41 \\
Tire type & VII & VII \\
Maximum un-yawed braking & & \\
friction coefficient & 0.7 & 0.7 \\
Steer angle, deg & \pm 70 & 0 \\
Brake torque limit, Nm & 0 & 41000 \\
\hline
\end{tabular}

During offline (non-real-time) testing of the flight model, some instabilities of the ground model were discovered. When the aircraft came to a stop, it would often begin to accelerate backwards. The linearized equation for the longitudinal tire force is given as,

$$
F_{x}=\frac{\partial F_{x}}{\partial \lambda} \lambda+F_{x_{0}}
$$

where $\lambda$ is the longitudinal tire slip. Clover [19] describes a basic algorithm for implementing the wheel slip and wheel spin equations. The algorithm includes a step that multiplies $\partial F_{x} / \partial \lambda$ and $F_{x_{0}}$ by the sign of the wheel longitudinal velocity, $u$. When this step was added to the algorithm of Cheung [17], the instability whereby the aircraft accelerated backwards no longer occurred. One other change was made to the tire model. When the tire is not in contact with the ground, the angular velocity of the wheel is set to 0 .

\subsection{Engine Model}

The engines in the BWB flight model are the same as the engines in an existing Boeing 747 flight model, which was based on work by Reid and Nahon [20]. The engine model 
calculates thrust as a function of air temperature, Mach number, altitude, and powerlever angle. Reid and Nahon model the lag of the engine response with a lag filter, which is given as,

$$
\mathrm{EPR}_{2}=\frac{\omega_{b}}{s+\omega_{b}} \mathrm{EPR}_{1}
$$

where $\mathrm{EPR}_{1}$ is the commanded engine pressure ratio and $\mathrm{EPR}_{2}$ is the actual $\mathrm{EPR}$. The break frequency of the filter is a function of the compressor first-stage speed $\left(\mathrm{N}_{1}\right)$, and is given as,

$$
\omega_{b}=0.35\left(0.03056 \mathrm{~N}_{1}-0.5556\right)
$$

At $\mathrm{N}_{1}=50 \%$, the filter time constant is $2.9 \mathrm{~s}$. The Boeing 747 model has four JT9D-3 engines, while the BWB flight model has three. In the current study, the thrust of each JT9D-3 engine was multiplied by 2.2. The engines in the current study, being larger than the Boeing 747's JT9D-3 engines, would probably have a greater lag than the JT9D-3 engine. However, the break frequency of the low-pass filter was not changed in the current study.

De Castro [8] gives an engine static thrust at sea level of $418.4 \mathrm{kN}$. The static thrust at sea level of the engines in the current study is $460 \mathrm{kN}$. At sea level, the thrust-to-weight ratio is 0.38 . Figure 2.3 shows the maximum thrust per engine as a function of airspeed. The thrust decreases by less than $1 \%$ at an altitude of $5000 \mathrm{ft}$, the maximum altitude used in the current piloted-handling trials.

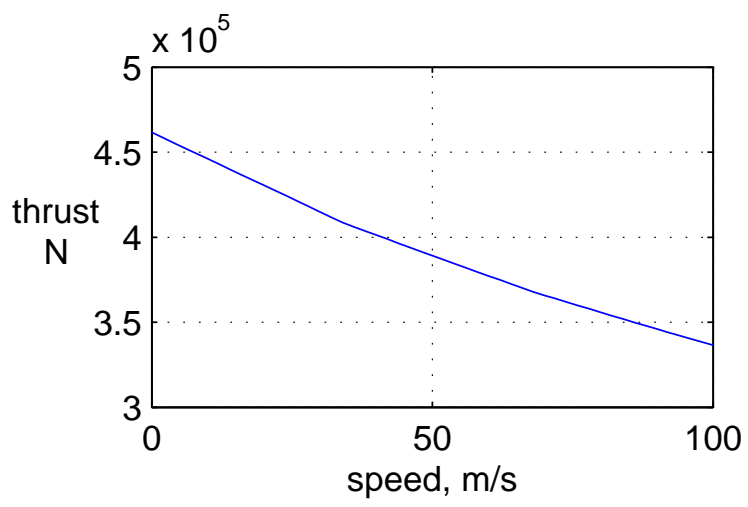

Figure 2.3: Maximum sea-level thrust of one engine with $T_{\text {air }}=15^{\circ} \mathrm{C}$

The engines' positions relative to the center of gravity are given in Table 2.4. The distance along the $y$ body axis from the CG was given in Appendix D of de Castro's 
study, whereas the distance along the $z$ body axis was measured from a diagram in that study.

Table 2.4: Engine position relative to $\mathrm{CG}$, body axes, $\mathrm{m}$

\begin{tabular}{lc}
\hline & {$\left[\begin{array}{lll}x & y & z\end{array}\right]$} \\
\hline Engine 1 & {$\left[\begin{array}{lll}0 & -7.5 & -2.8\end{array}\right]$} \\
Engine 2 & {$\left[\begin{array}{lll}0 & 0 & -2.8\end{array}\right]$} \\
Engine 3 & {$\left[\begin{array}{lll}0 & 7.5 & -2.8\end{array}\right]$} \\
\hline
\end{tabular}

To allow the aircraft to rotate at $180 \mathrm{kts}$, de Castro set the pitching moment of the engines to zero. Due to the limited control power of the winglet rudders, de Castro set the yawing moment of the engines to $1 / 3.5$ what it would be in the aircraft. Neither of these modifications were made in the current study.

\subsection{Wind and Turbulence Model}

The flight model included a wind and turbulence model. The turbulence model came from an existing Boeing 747 flight model, and was based on work by Reid and Nahon [20] and Robinson [21]. The wind and turbulence model in the current study consisted of a constant-direction mean wind that increased with height above ground, and patchy turbulent gusts. The turbulent gusts had 5 components, aligned with the body axes of the aircraft: $u_{g}, v_{g}, w_{g}, p_{g}$, and $r_{g}$. Wind and turbulence were included in the pilotedhandling trials for two reasons: to increase the pilot's workload and to provide "ruse" motion for the reduced-simulator-motion condition. The mean wind at any height above ground level was a function of the mean wind at a height of $10 \mathrm{~m}$ above the ground $\bar{U}_{10}$ and a ground roughness constant, $\nu$, and was given as,

$$
\overline{U_{h}}=\bar{U}_{10}\left(\frac{h}{10}\right)^{\nu}
$$

A ground roughness constant of 0.19 was used, which is suitable for flat grasslands. The mean wind speed at $10 \mathrm{~m}$ above ground was set to $2 \mathrm{~m} / \mathrm{s}$. The turbulence intensity in the flight model would probably be classified as light turbulence or light chop. Selection of $\bar{U}_{10}$ was constrained by the heave capability of the simulator. During the early stages of model development, a mean wind speed $\bar{U}_{10}$ of $5 \mathrm{~m} / \mathrm{s}$ was used. However, it was found that this speed was too high, such that the simulator actuator length was reaching 
the limits. For this reason the mean wind speed $\bar{U}_{10}$ was reduced to $2 \mathrm{~m} / \mathrm{s}$. The wind direction varied between tasks, and is given in Section 5.1.

The five turbulent gusts $\left(u_{g}, v_{g}, w_{g}, p_{g}\right.$, and $\left.r_{g}\right)$ are obtained by filtering white noise [20]. The spectral properties of the turbulence are described by the Dryden spectra, which are given as,

$$
\begin{aligned}
\Phi_{u_{g} u_{g}}(\omega) & =\frac{2}{\pi} \sigma_{u_{g}}^{2} \frac{L_{u_{g}}}{V} \frac{1}{1+\omega^{2}\left(\frac{L_{u_{g}}}{V}\right)^{2}} \\
\Phi_{w_{g} w_{g}}(\omega) & =\frac{1}{\pi} \sigma_{w_{g}}^{2} \frac{L_{w_{g}}}{V} \frac{1+3 \omega^{2}\left(\frac{L_{w_{g}}}{V}\right)^{2}}{\left(1+\omega^{2}\left[\frac{L_{w_{g}}}{V}\right]^{2}\right)^{2}}
\end{aligned}
$$

The same equation is used for $v_{g}$ and $w_{g}$. Non-Gaussian characteristics are obtained by modifying the kurtosis of the probability density function. The kurtosis of a Gaussian distribution is 3 . Using a higher kurtosis increases the probability of low and high gusts while decreasing the probability of mid-range gusts. Reid and Nahon 20] experimented with several values of kurtosis and found that a value of 8.4 produced turbulence that was acceptable. This was the value of kurtosis used in the current study. The patchiness of the turbulence can be adjusted with a patchiness parameter $\mathrm{R}$, which can range from 0 to 1 . The length of a patch of turbulence increases as $\mathrm{R}$ decreases. Reid and Nahon used test flights of a 747 in the UTIAS flight-research simulator (FRS) and found that $R=0.1$ gave realistic-feeling turbulence. The same value of $\mathrm{R}$ was used in the current study.

The lengthscales and intensities of $u_{g}, v_{g}$, and $w_{g}$ are functions of the height above ground. Different lengthscales and intensities below the gradient height of $661 \mathrm{~m}$ are used to model anisotropy in the atmospheric boundary layer. Below the gradient height $(h<661 \mathrm{~m})$, the intensities are given as,

$$
\begin{aligned}
\sigma_{u_{g}} & =\left(0.867+0.556 \log _{10} h-0.246\left(\log _{10} h\right)^{2}\right) \frac{0.76}{z_{o}^{0.07}} \frac{\bar{U}_{h}}{\ln \left(h / z_{o}\right)} \\
\sigma_{v_{g}} & =\left(0.655+0.201 \log _{10} h-0.095\left(\log _{10} h\right)^{2}\right) \frac{0.76}{z_{o}^{0.07}} \frac{\bar{U}_{h}}{\ln \left(h / z_{o}\right)} \\
\sigma_{w_{g}} & =\left(0.381+0.172 \log _{10} h-0.062\left(\log _{10} h\right)^{2}\right) \frac{0.76}{z_{o}^{0.07}} \frac{\bar{U}_{h}}{\ln \left(h / z_{o}\right)}
\end{aligned}
$$


and the lengthscales are given as,

$$
\begin{aligned}
& L_{u_{g}}=25 \frac{h^{0.35}}{z_{o}^{0.063}} \\
& L_{v_{g}}=10.2 \frac{h^{0.48}}{z_{o}^{0.086}} \\
& L_{w_{g}}=\left\{\begin{aligned}
0.7 h & \text { if } h<400 \\
280 & \text { if } h \geq 400
\end{aligned}\right.
\end{aligned}
$$

while the lengthscales for the rotational, or asymmetric, gusts are given by,

$$
\begin{aligned}
& \left(L_{u_{g}}\right)_{a s y m}=\max \left(b, L_{u_{g}}\right) \\
& \left(L_{w_{g}}\right)_{\text {asym }}=\max \left(b, L_{w_{g}}\right)
\end{aligned}
$$

where $z_{o}$ is a surface roughness parameter, 0.1 for open grassland.

Above the gradient height $(h \geq 661 \mathrm{~m})$, the intensities are given by,

$$
\begin{aligned}
\sigma_{u_{g}} & =0.4 \frac{\bar{U}_{h}}{\ln \left(h / z_{o}\right)} \\
\sigma_{v_{g}} & =\sigma_{u_{g}} \\
\sigma_{w_{g}} & =\sigma_{u_{g}}
\end{aligned}
$$

and the lengthscales above the gradient height are given by,

$$
\begin{aligned}
L_{u_{g}} & =280 \\
L_{v_{g}} & =L_{u_{g}} \\
L_{w_{g}} & =L_{u_{g}} \\
\left(L_{u_{g}}\right)_{\text {asym }} & =L_{u_{g}} \\
\left(L_{w_{g}}\right)_{\text {asym }} & =L_{u_{g}}
\end{aligned}
$$

The rolling and yawing gusts, $p_{g}$ and $r_{g}$ are found by an "equivalent one-dimensional power spectrum". The equivalent function integrates the asymmetric contribution from the variation of the $u$ or $w$ gust along the y axis. Gerlach and Baarspul [22] describe how to calculate the rolling and yawing gusts, assuming an elementary, two-dimensional flow field as depicted in Figure 2.4. The reference frame $\mathrm{O}_{e} \mathrm{X}_{e} \mathrm{Y}_{e} \mathrm{Z}_{e}$ is earth-fixed.

Gerlach and Baarspul [22] give the equivalent one-dimensional spectral density function for the yawing gust $r_{g}$ due to variations in $u_{g}$ along the $y_{e}$ axis. An approximate 


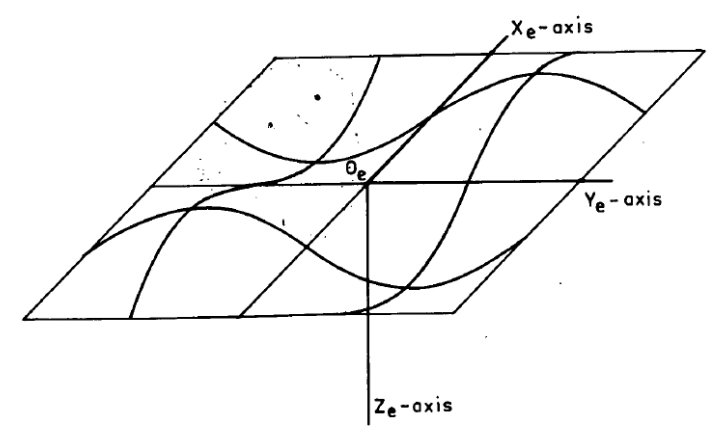

Figure 2.4: Elementary flow field 22

expression is also given, and it is this approximation that was implemented in the flight model. The approximation to $I_{\hat{u}_{g}}$ is given as,

$$
I_{\hat{u}_{g}}\left(\Omega_{x}\left(L_{u_{g}}\right)_{\text {asym }}, B\right)=I_{\hat{u}_{g}}(0, B) \frac{1+\tau_{3}^{2} \Omega_{x}^{2}\left(L_{u_{g}}\right)_{\text {asym }}^{2}}{\left(1+\tau_{1}^{2} \Omega_{x}^{2}\left(L_{u_{g}}\right)_{a s y m}^{2}\right)\left(1+\tau_{2}^{2} \Omega_{x}^{2}\left(L_{u_{g}}\right)_{\text {asym }}^{2}\right)}
$$

where $B=b / 2\left(L_{u_{g}}\right)_{\text {asym }}$. Equation 2.53 uses graphs for $I_{\hat{u}_{g}}(0, B), \tau_{1}, \tau_{2}$, and $\tau_{3}$, which are functions of $B[22$. The implementation of Equation 2.53 in the current research uses the asymmetric lengthscales $\left(L_{u_{g}}\right)_{\text {asym }}$ and $\left(L_{w_{g}}\right)_{\text {asym }}$. The circular frequency of the turbulence $\omega_{t}$ is related to the aircraft velocity $V$ and turbulence spatial frequency $\Omega$ by:

$$
\omega_{t}=\Omega V
$$

Similar to the yawing gust, the rolling gust $p_{g}$ due to variations in $w_{g}$ along the $y_{e}$ axis is described by the following spectral equation:

$$
I_{\alpha_{g}}\left(\Omega_{x}\left(L_{w_{g}}\right)_{\text {asym }}, B\right)=I_{\alpha_{g}}(0, B) \frac{1+\tau_{6}^{2} \Omega_{x}^{2}\left(L_{w_{g}}\right)_{\text {asym }}^{2}}{\left(1+\tau_{4}^{2} \Omega_{x}^{2}\left(L_{w_{g}}\right)_{\text {asym }}^{2}\right)\left(1+\tau_{5}^{2} \Omega_{x}^{2}\left(L_{w_{g}}\right)_{\text {asym }}^{2}\right)}
$$

where $B=b / 2\left(L_{w_{g}}\right)_{\text {asym }}$. Similar to Equation 2.53, $I_{\alpha_{g}}(0, B), \tau_{4}, \tau_{5}$, and $\tau_{6}$ are functions of $B$ and are given as graphs by Gerlach and Baarspul [22]. Figure 2.5 shows a time history of the turbulent gusts at an airspeed $V=92.6 \mathrm{~m} / \mathrm{s}$, an altitude $h=679 \mathrm{~m}$, and $\bar{U}_{10}=2 \mathrm{~m} / \mathrm{s}$ (the initial condition for the approach tasks). 

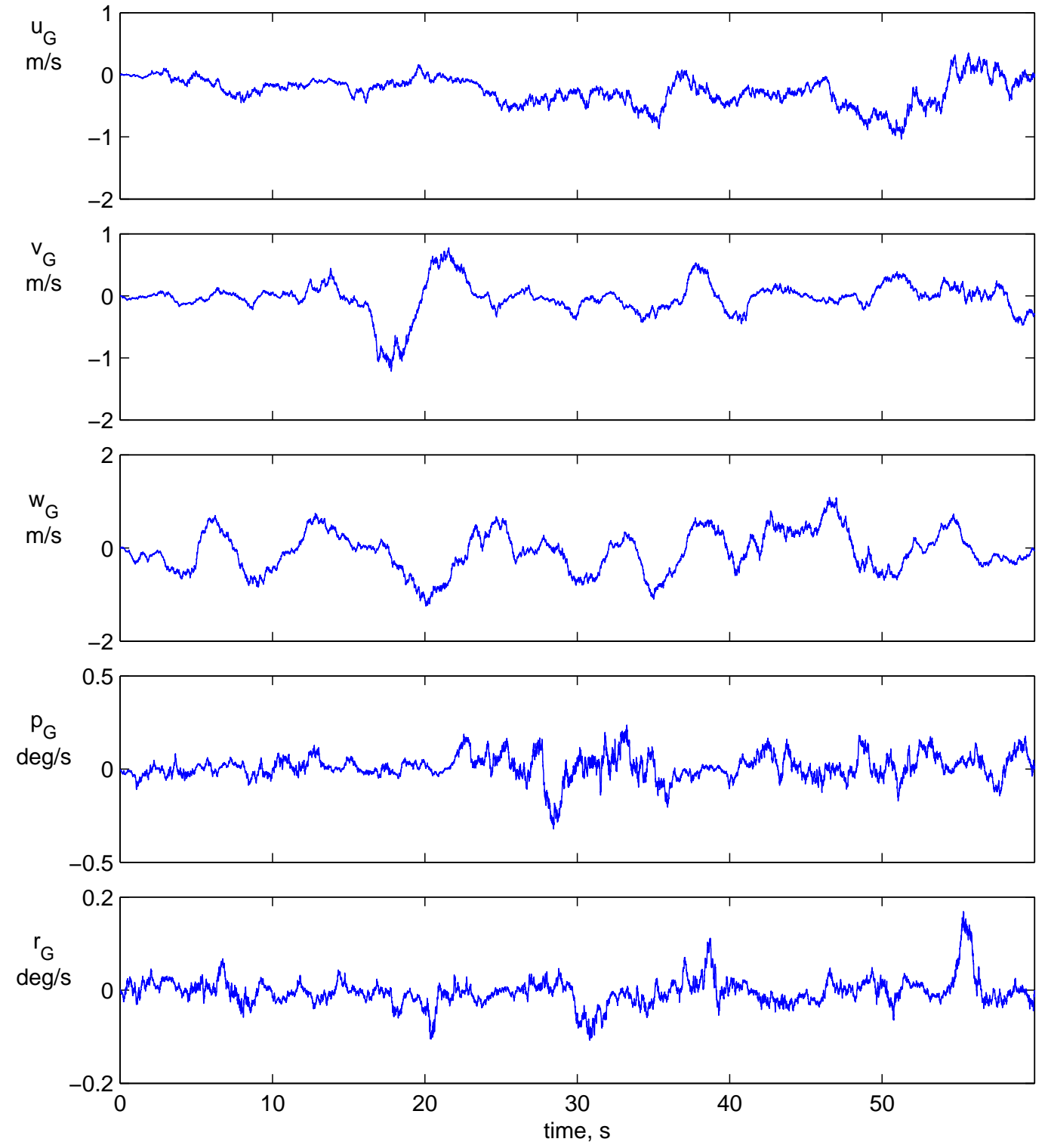

Figure 2.5: Turbulent gusts 


\section{Chapter 3}

\section{Predicted Handling Qualities}

Bailey and Knotts 23] conducted in-flight experiments to determine the effect of the feel system on the lateral handling qualities of a fighter aircraft. They found that the feel system has an effect on handling qualities, distinct from the effect that the aircraft dynamics have on handling qualities. Part of the reason for the unique effect of the feel system is that the pilot senses both the force and displacement of an inceptor; Bailey and Knotts found that the feel system has an effect on handling qualities whether it is a force-sensing type or a displacement-sensing type. Mitchell et al. 24 recommended that changes be made to MIL-STD-1797A, to replace handling-qualities criteria based on flight phases with criteria based on mission-task-elements. They also recommended that the dynamics of the feel system be taken into account in handling-qualities analyses, because control force, not position, is the important reference for handling qualities. However, their recommendations were not implemented in the handbook MIL-HDBK1797A [6]. The handbook considers the feel-system dynamics for force-sensing inceptors, and excludes the feel-system dynamics for position-sensing inceptors. In the current study the inceptor dynamics are described and their effect on handling qualities is considered.

\subsection{Inceptor Dynamics}

The dynamic characteristics of the simulated BWB controls are described in this section. The inceptor dynamics are then used to determine the expected handling qualities. Aside from control sensitivity (static gain), the dynamic characteristics of the controls used in de Castro's handling trials 8$]$ were not given.

An Opinicus control loader provides the forces on the FRS controls. The control 
loader is a model-following system. Force transducers on the controls measure the net force acting on each control. The measured force is corrected for the gravitational force on the control, which depends on the control position. This corrected force is used as an approximation to the force exerted on the control by the pilot. By using a model-following system, the inertia and any viscous damping of the actual control in the FRS are almost canceled out. Instead of feeling the inertia of the actual control, the pilot feels the inertia, spring force, and damping force of the model control. Although force transducers are used by the control loader for the purposes of model-following, the inceptors are used as position-sensing controls (not force-sensing controls). The output of the controls to the rest of the flight model is control position.

A broad range of inceptor characteristics can be modeled. Though it was not done in the current study, the control forces can be made to vary with dynamic pressure $\bar{q}$. In the current study, the controls were modeled as second-order, spring-mass-damper systems. The differential equations governing the motion of the controls are given as,

$$
\begin{aligned}
F_{c}\left(\delta_{c}\right) & =M_{c} \ddot{\delta}_{c}+b_{c}\left(\delta_{c}\right) \dot{\delta}_{c}+F_{s_{c}}\left(\delta_{c}\right) \\
F_{w}\left(\delta_{w}\right) & =M_{w} \ddot{\delta}_{w}+b_{w}\left(\delta_{w}\right) \dot{\delta}_{w}+F_{s_{w}}\left(\delta_{w}\right) \\
F_{p}\left(\delta_{p}\right) & =M_{p} \ddot{\delta}_{p}+b_{p}\left(\delta_{p}\right) \dot{\delta}_{p}+F_{s_{p}}\left(\delta_{p}\right)
\end{aligned}
$$

where $M_{c}$ is the rotational inertia of the model column, $1 / 50 \mathrm{lb} / \mathrm{deg} / \mathrm{s}^{2}, M_{w}$ is the rotational inertia of the model wheel, $1 / 130 \mathrm{lb} / \mathrm{deg} / \mathrm{s}^{2}$, and $M_{p}$ is the rotational inertia of the model rudder pedals, $1 / 20 \mathrm{lb} / \mathrm{deg} / \mathrm{s}^{2}$. The spring constant of the simulated BWB controls varies with control deflection. The spring constant is the largest when the control is centered to simulate the breakout friction that typically occurs on the controls of a heavy-transport aircraft. The spring forces $F_{s}$ and damping $b$ are interpolated between values of control deflection $\delta$. Tables 3.1, 3.2, and 3.3 give the model spring force and damping as functions of displacement of the column, wheel, and rudder pedals, respectively. The column radius (measured to where the pilot holds the column) is $0.661 \mathrm{~m}$. The wheel radius is $0.165 \mathrm{~m}$.

Table 3.1: Spring force and damping of the model column

\begin{tabular}{lccccccc}
\hline$\delta_{c}, \mathrm{deg}$ & -12.2 & -3 & -0.5 & 0 & 0.5 & 3 & 12.2 \\
\hline$k_{c}, \mathrm{lb}$ & -42.1 & -16 & -6.3 & 0 & 6.3 & 16 & 42.1 \\
$b_{c}, \mathrm{lb} / \mathrm{deg} / \mathrm{s}$ & 0.2 & 0.2 & 0.6 & 0.6 & 0.6 & 0.2 & 0.2 \\
\hline
\end{tabular}


Table 3.2: Spring force and damping of the model wheel

\begin{tabular}{lccccccccc}
\hline$\delta_{w}, \mathrm{deg}$ & -105 & -80 & -40 & -2.4 & 0 & 2.4 & 40 & 80 & 105 \\
\hline$k_{w}, \mathrm{lb}$ & -12.6 & -12.6 & -8 & -2 & 0 & 2 & 8 & 12.6 & 12.6 \\
$b_{w}, \mathrm{lb} / \mathrm{deg} / \mathrm{s}$ & 0.02 & 0.02 & 0.02 & 0.04 & 0.04 & 0.04 & 0.02 & 0.02 & 0.02 \\
\hline
\end{tabular}

Table 3.3: Spring force and damping of the model rudder pedals

\begin{tabular}{lccccccc}
\hline$\delta_{p}, \mathrm{deg}$ & -3.4 & -1.5 & -0.5 & 0 & 0.5 & 1.5 & 3.4 \\
\hline$k_{p}, \mathrm{lb}$ & -60 & -40 & -20 & 0 & 20 & 40 & 60 \\
$b_{p}, \mathrm{lb} / \mathrm{deg} / \mathrm{s}$ & 1 & 1 & 2 & 2 & 2 & 1 & 1 \\
\hline
\end{tabular}

The inceptor forces are linearized for the handling-quality analysis in the following sections. The changes in spring constant and damping around the centered-control position is ignored. For the column, the linearized spring constant is found using the change in spring force between $3^{\circ}$ and $12.2^{\circ}$. The linearized spring constant of the wheel is found using the change in spring force between $2.4^{\circ}$ and $80^{\circ}$. The linearized spring constant of the rudder pedals is found using the change in spring force between $-3.5^{\circ}$ and $0^{\circ}$. Table 3.4 gives the linearized spring force, natural frequency, and damping ratio of the simulated BWB inceptors.

Table 3.4: Linearized dynamic characteristics of the simulated BWB inceptors

\begin{tabular}{cccc}
\hline & Column & Wheel & Pedals \\
\hline Spring constant, lb/deg & 2.84 & 0.14 & 17.65 \\
Natural frequency, rad/s & 11.9 & 4.22 & 18.79 \\
Damping ratio & 0.42 & 0.31 & 0.53 \\
\hline
\end{tabular}

\subsection{Longitudinal Flight Control System}

The flight control system used in the Cranfield University piloted-handling trials [8] was a "Pitch-Rate-Command-Attitude-Hold" (PRCAH) controller. An input from the pilot, through the control column, produces a certain pitch rate. This is in contrast to a conventional response type, which typically produces a time-varying pitch rate for a certain column input 24]. A PRCAH FCS was used by de Castro to reduce the 
pilot's workload on approach to landing. During approach to landing, pitch angle is a good indicator of glide path angle. A PRCAH FCS would enable the pilot to select a pitch angle and have the FCS maintain it, without the pilot having to apply continuous control inputs. The PRCAH feedback structure is shown in Figure 3.1. All trailing-edge control surfaces (called "elevons") were used for longitudinal control. The deflection of the trailing-edge surfaces was limited to $\pm 30^{\circ}$.

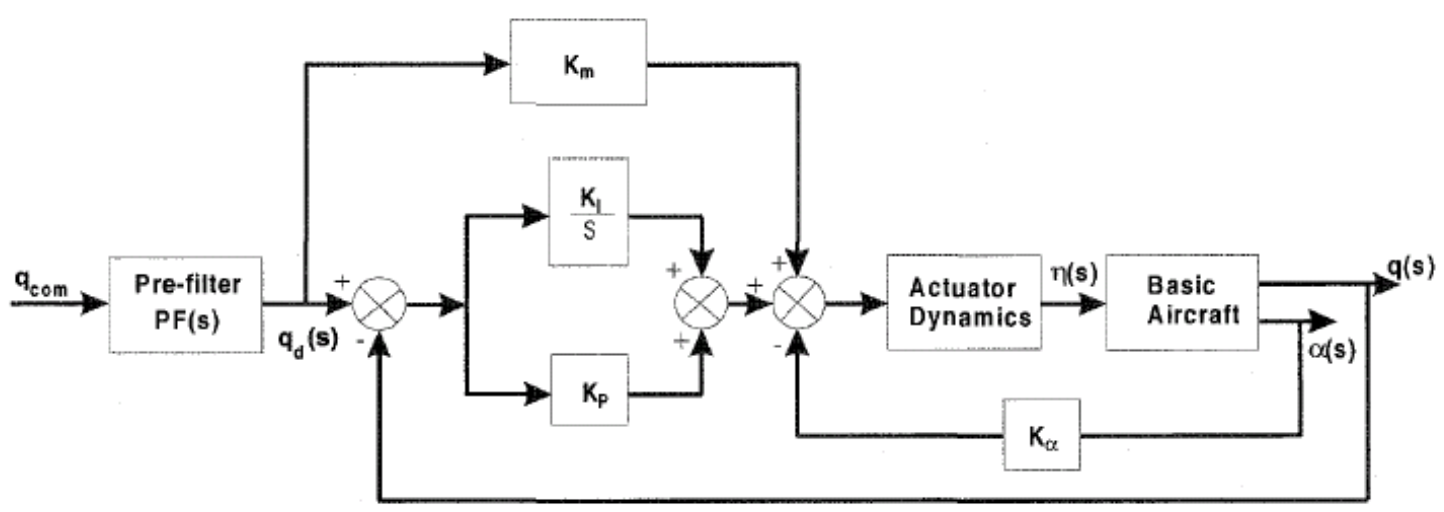

Figure 3.1: Pitch-rate-command-attitude-hold FCS from de Castro [8]. Reprinted with permission.

The BWB model used in the Cranfield piloted-handling trials had a negative static margin of $-13 \%$ of the mean aerodynamic chord. To overcome this instability, angleof-attack feedback was used for stability augmentation. Pitch-rate feedback increased the short-period-mode damping. In order to maintain a constant pitch attitude with no control input (by eliminating the steady-state pitch-rate error), an integrator was used. A disadvantage of the pitch-rate-command-attitude-hold response is that the pitch angle is held constant, even if airspeed decreases and angle of attack approaches the stall angle. Therefore, some type of speed protection is desirable. While de Castro's FCS did not include a speed controller, Rahman 25 developed a speed controller for the BWB. A speed controller was not implemented in the current study.

De Castro developed the PRCAH FCS to meet four goals. The first goal was a shortperiod-mode damping ratio of 0.7. The second goal was a Generic Control Anticipation Parameter [26] of $0.6 \mathrm{rad} \cdot \mathrm{s}^{2} \cdot \mathrm{g}$. The third goal was to satisfy the Gibson dropback criterion [27], and the fourth goal was a phugoid damping ratio of greater than 0.1. De Castro found two sets of PRCAH FCS gains, one for a speed of $100 \mathrm{~m} / \mathrm{s}$ and the other for a speed of $180 \mathrm{~m} / \mathrm{s}$. The gains that de Castro used in the piloted-handling trials were 
approximately equal to the gains obtained by interpolating the two sets of gains at 150 $\mathrm{m} / \mathrm{s}$. In the current study, however, the set of gains for a speed of $100 \mathrm{~m} / \mathrm{s}$ were used, because the speeds specified for all the approach tasks $(92.6 \mathrm{~m} / \mathrm{s})$ and most of the takeoff task is close to $100 \mathrm{~m} / \mathrm{s}$. The gains, pre-filter, and actuator dynamics that were used in the current study are given in Table 3.5 .

Table 3.5: Pitch-rate-command FCS gains and dynamic parameters

\begin{tabular}{cc}
\hline$K_{\alpha}$ & 0.9 \\
$K_{p}$ & -2.7 \\
$K_{i}$ & -5.92 \\
$K_{m}$ & 1.97 \\
& $\frac{0.78 s+1}{0.87 s+1}$ \\
$\mathrm{PF}(\mathrm{s})$ & $30^{2}$ \\
\hline Actuator Dynamics & $s^{2}+2 \cdot 0.7 \cdot 30 \cdot s+30^{2}$ \\
\hline
\end{tabular}

\subsection{Longitudinal Handling Qualities}

De Castro 8 predicted the longitudinal handling qualities using the bandwidth/phasedelay criterion, dropback criterion, and the Generic Control Anticipation Parameter (GCAP) criterion. These criteria use the pitch-attitude-to-stick-displacement transfer function of the aircraft-plus-controller system. Mitchell et al. 24 recommend using the first two criteria, together, for predicting the handling qualities of an aircraft with a pitch-rate-command-attitude-hold flight control system. The third criterion, GCAP, is suitable for use as a design tool only.

The handling qualities will now be predicted using the first two criteria, including the dynamics of the simulated BWB column. The handling qualities are evaluated at a low speed and MTOW only. These are the conditions under which de Castro's pilotedhandling trials were conducted, and are also the conditions used in the current study. De Castro's trials used takeoff and landing tasks, with a maximum specified speed during climbout of $250 \mathrm{kts}(129 \mathrm{~m} / \mathrm{s})$. The landing approach speed was $180 \mathrm{kts}(92.6 \mathrm{~m} / \mathrm{s})$. This is considerably greater than the approach speed of $150 \mathrm{kts}$ specified by Liebeck [1]; the difference in approach speed may be due to the absence of clamshell-type drag rudders 
in de Castro's model.

\subsubsection{Bandwidth/Phase Delay}

One measure of an aircraft's handling qualities is its stability margin when operated in a closed, pilot-in-the-loop compensatory pitch attitude tracking task [8]. The input is the commanded pitch rate, and the output is the pitch attitude, $\theta$. The pitch-attitude error is presented to the pilot on some display. The pilot then applies an input to the control column to minimize the pitch-attitude error. If the pilot gain can take any value, then the boundary between stable and unstable control is defined as that frequency at which the open-loop-transfer-function phase crosses $-180^{\circ}$. The pilot plus aircraft would be unstable if the pilot gain is such that the total open-loop gain is $0 \mathrm{~dB}$ or larger at this frequency. The pitch-attitude bandwidth $\omega_{B W}$ is defined as the lower of the gain and phase bandwidth. The gain bandwidth is the frequency at which the gain is $6 \mathrm{~dB}$ greater than the gain at the stability boundary, while the phase bandwidth is the frequency at which the phase is $-135^{\circ}$.

At frequencies above the stability boundary it is assumed that the phase can be represented as a linear function,

$$
\Phi_{\tau}=-\tau_{p} \omega
$$

Then the phase delay $\tau_{p}$ is approximately:

$$
\tau_{p}=-\frac{\Phi_{2 \omega_{180}}}{57.3 \cdot 2 \omega_{180}}
$$

where $\omega_{180}$ is the frequency at the stability boundary, and $\Phi_{2 \omega_{180}}$ is the phase at $2 \cdot \omega_{180}$.

The handling qualities can be related to the pitch-attitude bandwidth and the phase delay, as shown in Figure 3.2. The bandwidth/phase-delay criterion was applied to trimmed, level flight at $90 \mathrm{~m} / \mathrm{s}$. The column dynamics (Table 3.4) are included in the following analysis. As discussed in Chapter 2, ground effect may have an effect on handling qualities. Two cases are considered: flight out of ground effect (nondimensional height $\hat{h} \geq 1$ ), and flight with maximum ground effect (nondimensional height $\hat{h}=0.115$ ). The bandwidth in the first case was limited by the phase margin to $2.1 \mathrm{rad} / \mathrm{s}$, as shown in Figure 3.3a. In the second case, the bandwidth is also limited by the phase margin, 


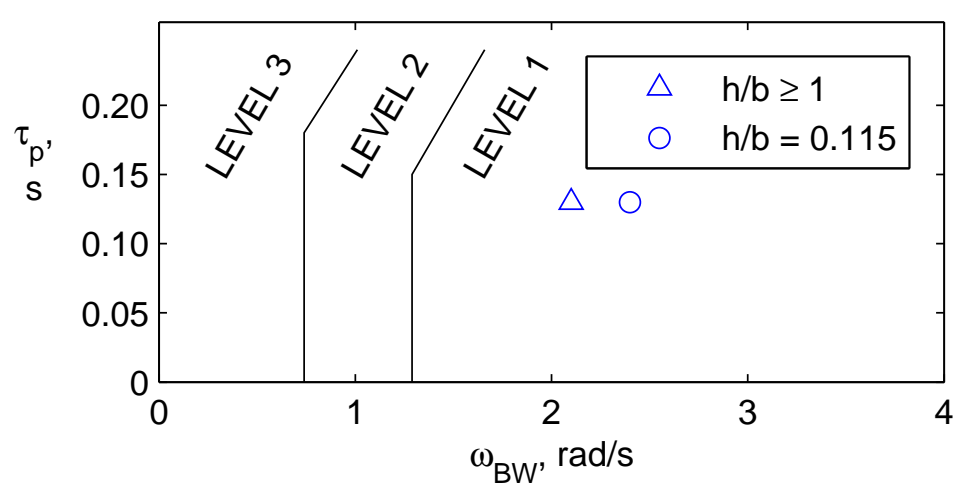

Figure 3.2: Bandwidth/phase-delay criterion evaluated at $180 \mathrm{kts}$ [24]

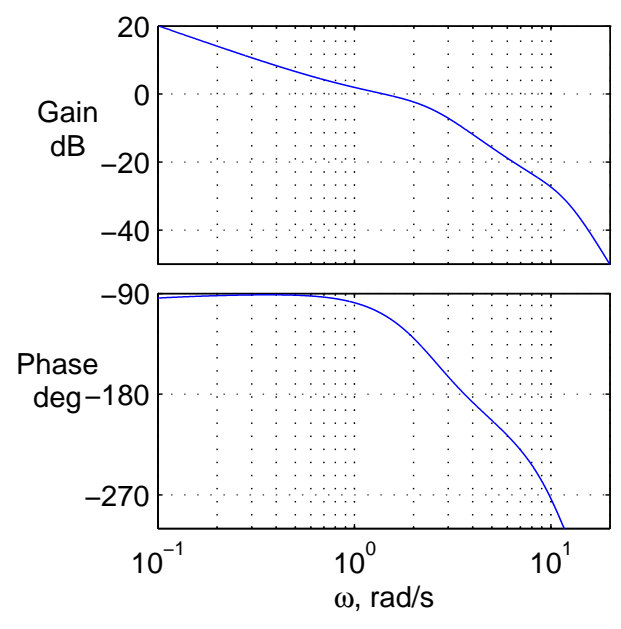

(a) $\hat{h}=1$

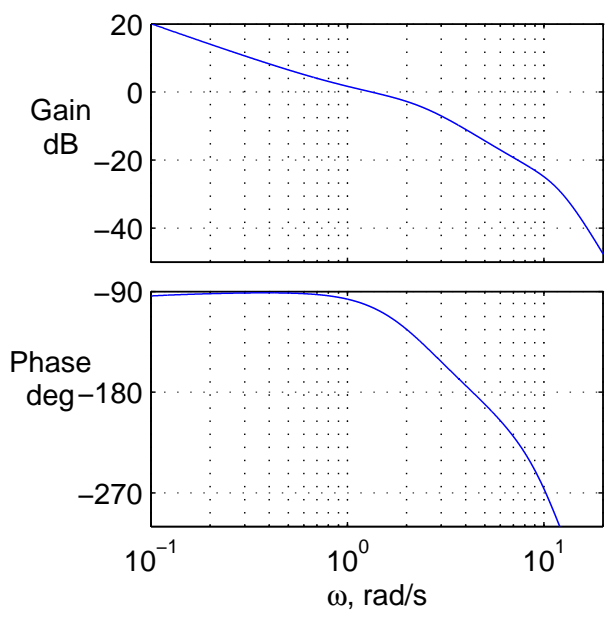

(b) $\hat{h}=0.115$

Figure 3.3: Bode plot of PRCAH FCS pitch-attitude response to pitch-rate input 
to $2.4 \mathrm{rad} / \mathrm{s}$. The phase delay for the first case is given by,

$$
\begin{aligned}
\tau_{p} & =-\frac{-53^{\circ}}{57.3 \frac{\circ}{\mathrm{rad}} \cdot 7.28 \frac{\mathrm{rad}}{\mathrm{s}}} \\
& =0.13 \mathrm{~s}
\end{aligned}
$$

A phase delay of $0.13 \mathrm{~s}$ with a pitch-attitude bandwidth of $2.1 \mathrm{rad} / \mathrm{s}$ should give Level 1 handling qualities. The phase delay for the second case is also $0.13 \mathrm{~s}$. The second case is also expected to give Level 1 handling qualities. Ground effect does not change the longitudinal handling qualities significantly, based on the bandwidth/phase-delay criterion.

\subsubsection{Dropback Criterion}

The dropback criterion for longitudinal handling qualities is based on the relationship between pitch-rate and pitch-attitude overshoot following a step control-column input. The peak pitch rate $q_{\text {peak }}$ is plotted relative to the amount of pitch-attitude overshoot $\Delta \theta_{\text {peak }}$. Both are normalized with respect to the steady state pitch rate $q_{s s}$.
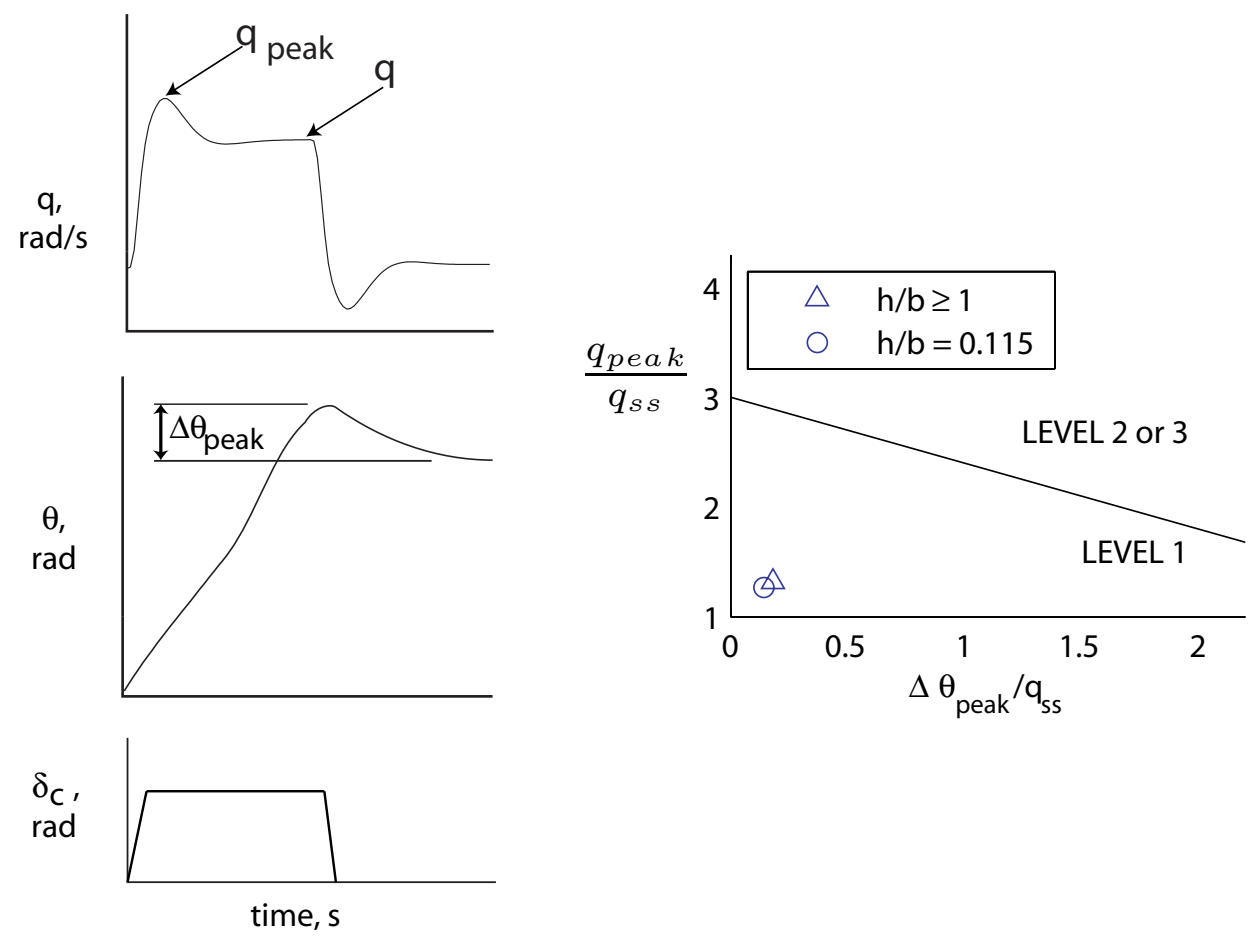

Figure 3.4: Dropback criterion from Mitchell et al. 24.

The handling qualities were evaluated using the dropback criterion at an airspeed of $90 \mathrm{~m} / \mathrm{s}$. Two cases are considered: flight out of ground effect $(\hat{h} \geq 1)$, and flight with 
maximum ground effect $(\hat{h}=0.115)$. Figure 3.5 shows a linearized simulation of the pitch-rate and attitude response to a step pitch-rate command. The input is set to zero halfway through the simulation. Although the pitch attitude is large in the simulation, in real-time handling trials the maximum pitch-rate input would be much less than $1 \mathrm{rad} / \mathrm{s}$. Since a linear model was used, the equations of motion do not include any sine or cosine terms, and any nonlinearities due to flow separation are not included. The values of the
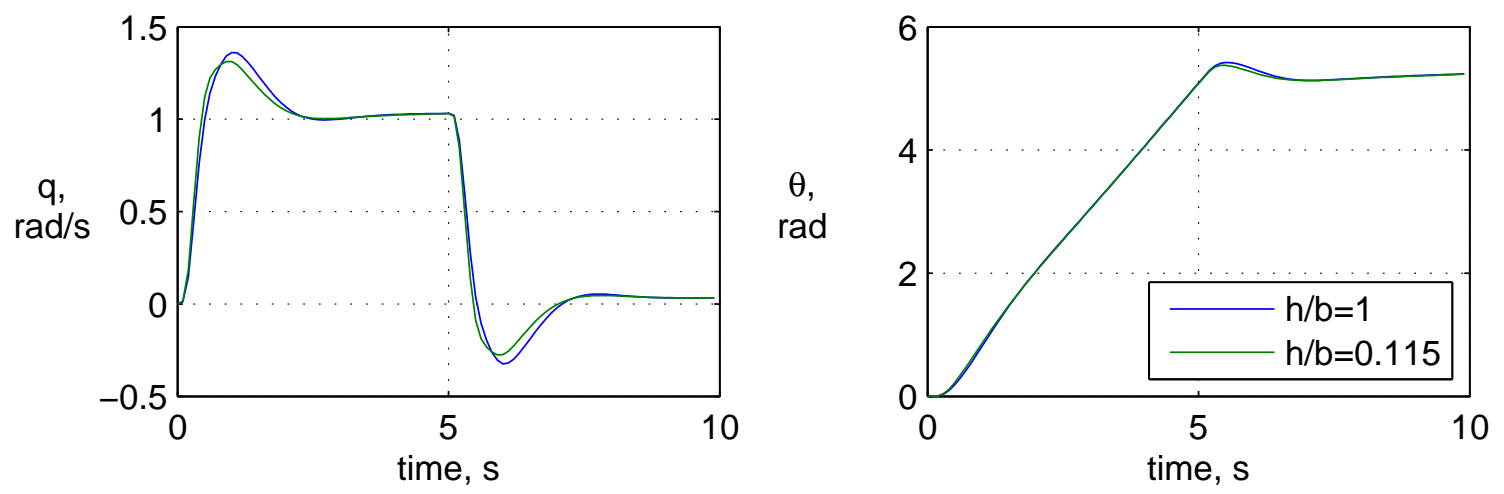

Figure 3.5: Pitch-rate and attitude response to a step pitch-rate input

augmented-BWB response that were used to apply the dropback criterion are shown in Table 3.6. Comparing these values to Figure 3.4 shows that Level 1 handling qualities are expected at $90 \mathrm{~m} / \mathrm{s}$, for both ground-effect cases. As discussed in the previous subsection, the column is not expected to affect longitudinal handling qualities because the column has a sufficiently-high natural frequency.

Table 3.6: Summary of BWB response to step pitch-rate command

\begin{tabular}{rcc}
\hline & $\hat{h} \geq 1$ & $\hat{h}=0.115$ \\
\hline Peak pitch rate, $q_{\text {peak }}, \mathrm{rad} / \mathrm{s}$ & 1.36 & 1.31 \\
Steady state, $q_{s s}, \mathrm{rad} / \mathrm{s}$ & 1.03 & 1.03 \\
$\Delta \theta_{p k}, \mathrm{rad}$ & 0.18 & 0.14 \\
$\frac{q_{\text {peak }}}{q_{s s}}$ & 1.32 & 1.27 \\
$\frac{\Delta \theta_{\text {peak }}}{q_{s s}}$ & 0.18 & 0.14 \\
\hline
\end{tabular}




\subsection{Lateral Flight Control System}

The lateral flight control system developed by de Castro [8] is shown in Figure 3.6. Control surfaces 3 and 13 (Figure 2.1) are used for roll control, and 1 and 15 (the

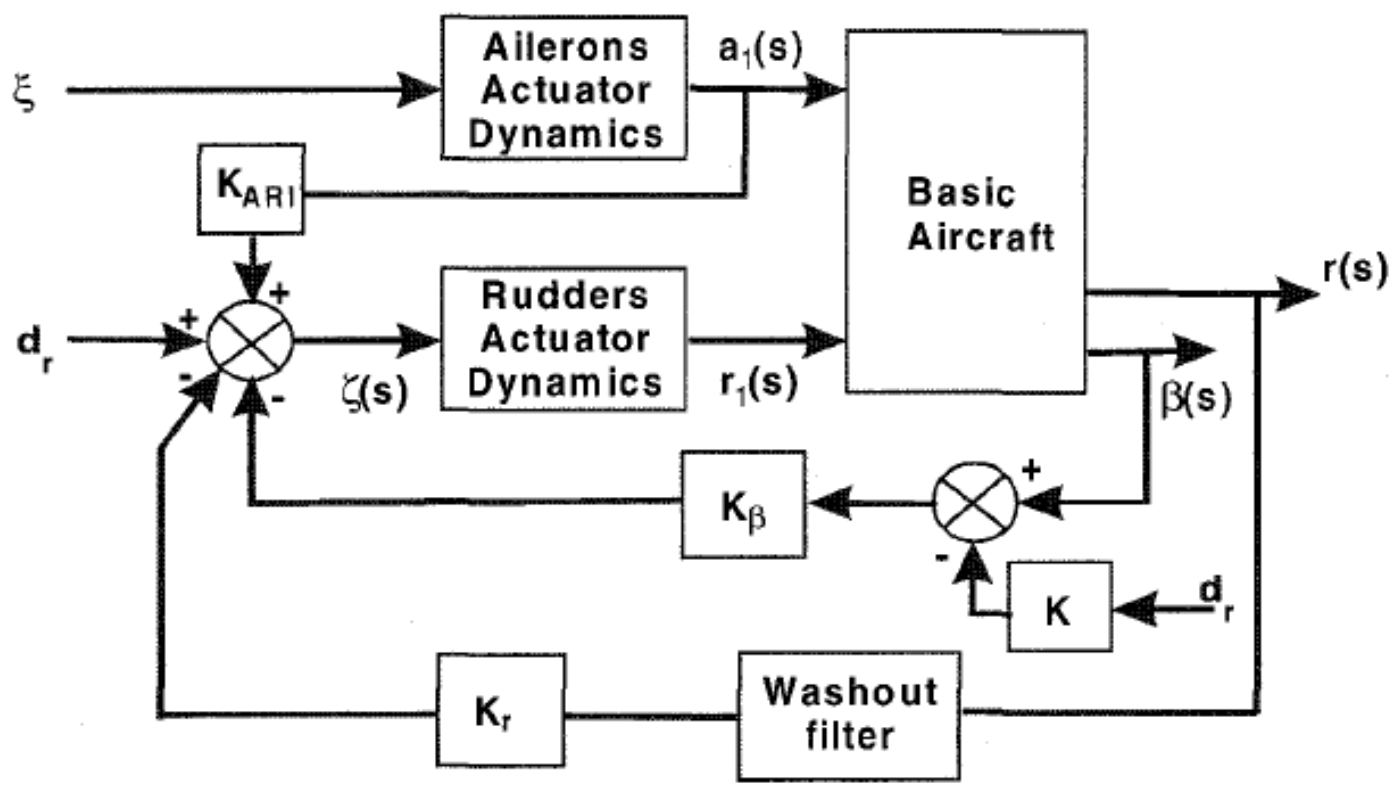

Figure 3.6: De Castro's lateral FCS [8]. Reproduced with permission.

winglet rudders) are used together for directional control. The first feedback loop uses the sideslip angle. The un-augmented BWB does not have weathercock stability; in fact, it is statically unstable at angles of attack below $5^{\circ}$. If disturbed from symmetric flight, the un-augmented BWB will diverge. The second feedback loop uses the yaw rate, $\mathrm{r}$. The washout filter is a high-pass filter, and it acts as a yaw damper. It also allows the aircraft to perform a normal turn, in which the steady-state yaw rate is non-zero. There is an interconnection between the aileron and rudder channels, which reduces the amount of aerodynamic cross-coupling. The controller gains that were used are given in Table 3.7. Different gains were used in the current study relative to de Castro's as the gains used in de Castro's handling trials yielded a Dutch roll damping of 0.045, for level flight at $90 \mathrm{~m} / \mathrm{s}$, which was considered too light. The modified gains shown in Table 3.7 yield a Dutch roll damping of 0.14 .

De Castro includes a sideslip-reference input to the lateral FCS. In effect, the gain $K$ multiplies the commanded rudder deflection $d_{r}$ (the input to the four-way summation block) by $\left(1+K_{\beta} K\right)$. The gain $K$, which was used by de Castro to allow a larger sideslip 
Table 3.7: Lateral FCS gains and dynamic parameters

\begin{tabular}{rcc}
\hline & Current study & De Castro $|8|$ \\
\hline$K_{\beta}$ & 3.6 & 3.0 \\
$K_{r}$ & -7 & -5 \\
$K_{A R I}$ & $0.6+7.162 \alpha$ & $1.6+7 \alpha$ \\
$K$ & 0 & 0.5 \\
Washout filter & $\mathrm{s}$ & $\mathrm{s}$ \\
\cline { 2 - 3 } Actuator dynamics & \multicolumn{2}{c}{$30^{2}$} \\
\hline
\end{tabular}

in response to a given rudder-pedal deflection, was set to zero in the current study. The commanded rudder deflection $d_{r}$ (Figure 3.6) is a function of the gain on the simulator's rudder pedals (converting a linear displacement of the pedal to a commanded angular displacement of the rudder). Because the maximum-commandable rudder deflection in the current study was much larger than that in de Castro's study, using $K=0$ was not expected to have much effect on directional control. The maximum-commandable rudder deflection in the current study was $68^{\circ}$, while in de Castro's study it is $25^{\circ}$. With $K_{\beta}=3$ and $K=0.5$, the effective maximum-commandable rudder deflection in de Castro's study is $62.5^{\circ}$. In both studies all control surfaces, including the rudder, were limited to $\pm 30^{\circ}$ of deflection. In effect, in both de Castro's study and the current study, the rudder would reach saturation when a pilot displaced the rudder pedals less than half of their available travel.

\subsection{Lateral Handling Qualities}

De Castro [8] applied several criteria to determine the lateral handling qualities of the BWB. Most of the criteria were from the military specification MIL-F-8785C [28]. In the current study, reference is made to the military handbook MIL-HDBK-1797 [6], which is based on the material of MIL-F-8785C. De Castro assessed the roll-axis control power by finding the time taken to roll the aircraft $30^{\circ}$. De Castro predicted Level 1 handling qualities for airspeeds of $120 \mathrm{~m} / \mathrm{s}$ and higher, and worse than Level 1 handling qualities for speeds of $80 \mathrm{~m} / \mathrm{s}$. Mitchell et al. 24] state that time-to-roll is a suitable criterion for 
predicting handling qualities of large-angle maneuvers. Since the tasks used in de Castro's handling trials and the current study do not require aggressive, large-angle maneuvers, the time-to-roll analysis was considered irrelevant.

The roll-oscillations analysis of de Castro is also not relevant when the lateral FCS gains of the current study are used (Table 3.7). The handbook MIL-HDBK-1797 states that the roll oscillation criterion is applicable to aircraft with two properties: a medium to high ratio $|\phi / \beta|_{d}$, which is the ratio of the magnitudes of the roll-to-sideslip response of the Dutch roll mode, and marginally low Dutch roll damping. The ratio $|\phi / \beta|_{d}$ is considered low if it is less than 1.5. The minimum Dutch roll damping for Level 1 handling qualities is 0.08 . For trimmed, level flight at $90 \mathrm{~m} / \mathrm{s}$, the augmented BWB has a ratio $|\phi / \beta|_{d}$ of 1.9 , and Dutch roll damping of 0.14 . The ratio $|\phi / \beta|_{d}$ is not much larger than 1.5 and the Dutch roll damping is not especially low.

Mitchell et al. 24 make a distinction between criteria that are applicable to smallangle maneuvers and criteria that are applicable to large-angle maneuvers. Mitchell et al. also define four categories of mission-task-elements, based on the level of precision (precise or non-precise) and aggressiveness (aggressive and non-aggressive). The handling trials of the current study have two types of tasks: takeoffs and approaches, including landing. Mitchell et al. categorize these as non-aggressive mission-task-elements. As such, smallangle criteria are suitable to predict the handling qualities. The takeoff and landing are non-precise, while the approach is a precise mission-task-element.

Mitchell et al. state that the roll-mode time constant is one criterion that is suitable for small-angle maneuvers. MIL-HDBK-1797 specifies a maximum roll-mode time constant of $1.4 \mathrm{~s}$ for Level 1 handling qualities of a heavy-transport aircraft. The augmented BWB has a roll-mode time constant of $0.64 \mathrm{~s}$, for level flight at $90 \mathrm{~m} / \mathrm{s}$.

The roll time delay is another criterion that is suitable to apply to the tasks of the piloted-handling trials. Mitchell et al. state that the feel system must be considered when predicting handling qualities. Mitchell et al. give the allowable delay for heavy-transport aircraft as $0.20 \mathrm{~s}, 0.24 \mathrm{~s}$, and $0.33 \mathrm{~s}$ for Level 1, 2, and 3 handling qualities, respectively. The wheel of the simulated BWB has a fairly low natural frequency, and this may cause considerable phase error. As a first-order approximation, the wheel of the simulated BWB can be modeled as a pure time delay of $0.14 \mathrm{~s}$. This approximation is valid at low frequencies only, below $2 \mathrm{rad} / \mathrm{s}$. Since the tasks of the piloted-handling trials generally require low-bandwidth control, it is possible to predict the lateral handling qualities using the roll time delay criterion. 
Figure 3.7a shows the frequency response of the simulated BWB wheel, and Figure $3.7 \mathrm{~b}$ shows the frequency response of the BWB control-surface actuator. Since the actuator has a sufficiently-high natural frequency, at low frequencies it can be approximated by a pure time delay of $0.047 \mathrm{~s}$. The equivalent time delay from the actuator plus BWB wheel is just under the allowable $0.20 \mathrm{~s}$, and so Level 1 handling qualities are expected.

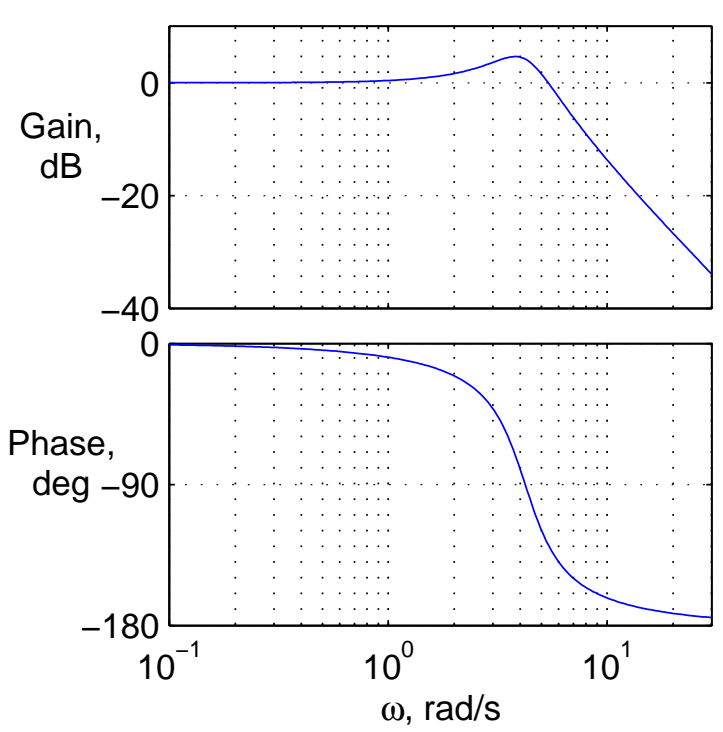

(a) Wheel

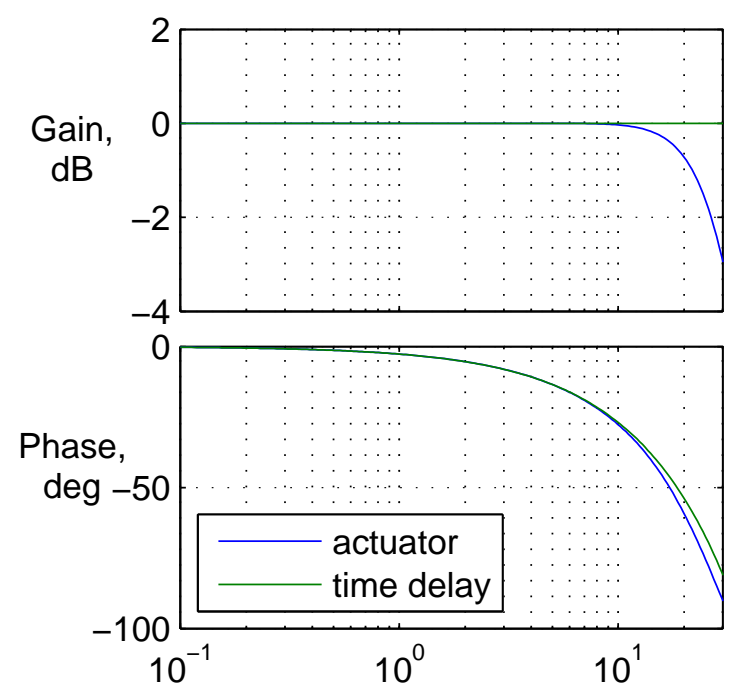

$\omega, \mathrm{rad} / \mathrm{s}$

(b) Actuator

Figure 3.7: Bode plots of the simulated BWB wheel and BWB actuator

Bailey and Knotts 23] found that a lateral control with a natural frequency of $8 \mathrm{rad} / \mathrm{s}$ had an obvious and degrading effect on handling qualities. As discussed at the beginning of this chapter, Bailey and Knotts' experiments were on a fighter aircraft. It is possible that the handling qualities of a heavy-transport aircraft would not be equally affected by a low lateral-control natural frequency. If Bailey and Knotts' findings are applied, then the simulated BWB wheel may degrade the lateral handling qualities.

The remaining criteria that were applied by de Castro pertain to the Dutch roll mode and spiral mode. These criteria are not categorized as small- or large-angle criteria by Mitchell et al. Given that these criteria are applicable to all aircraft, these criteria were also applied in the current study. Table XL of MIL-HDBK-1797 gives the recommended minimum Dutch roll frequency and damping. For Level 1 handling qualities, a heavytransport aircraft performing non-aggressive, precise maneuvers must have a Dutch-roll 
damping ratio of at least 0.08 and a natural frequency of at least $0.4 \mathrm{rad} / \mathrm{s}$. The product of the damping and natural frequency must be at least 0.10 . The damping ratio and natural frequency of the augmented BWB in level flight at $90 \mathrm{~m} / \mathrm{s}$ are 0.14 and 0.44 $\mathrm{rad} / \mathrm{s}$, respectively. The product of the two, $0.06 \mathrm{rad} / \mathrm{s}$, is below the Level 1 limit of 0.10 , but above the Level 2 limit of 0.05 . The criterion of MIL-HDBK-1797 states that the spiral-mode time to double must be greater than $12 \mathrm{~s}$. The spiral mode of the augmented BWB is convergent, which satisfies the Level 1 criterion.

If de Castro's gains were used, the damping ratio and natural frequency would be 0.045 and 0.45 , respectively. The product of the two is 0.020 . Based on this damping ratio, Level 2 handling qualities would be expected. Based on the product, Level 3 handling qualities would be expected. Table 3.8 summarizes the differences in Dutch roll mode characteristics between sets of FCS gains.

Table 3.8: Differences in Dutch roll mode characteristics

\begin{tabular}{rcc}
\hline & $\begin{array}{c}\text { With FCS gains } \\
\text { in current study }\end{array}$ & $\begin{array}{c}\text { With FCS gains } \\
\text { in De Castro } 8\end{array}$ \\
\hline$\zeta_{d}$ & 0.14 & 0.045 \\
$\omega_{d}, \mathrm{rad} / \mathrm{s}$ & 0.44 & 0.45 \\
$\zeta_{d} \omega_{d}, \mathrm{rad} / \mathrm{s}$ & 0.06 & 0.02 \\
\hline
\end{tabular}




\section{Chapter 4}

\section{BWB Real-Time Simulation}

\subsection{Flight Research Simulator}

The UTIAS Flight Research Simulator has a modified DC-8 simulator cockpit with outthe-window displays, speakers and a digital synthesizer to generate sounds, loaded controls, and an EFIS display for flight instruments. The cockpit is mounted on a CAE 300 series hydraulic motion system [29]. The six actuators have a stroke of $91.4 \mathrm{~cm}$. The bandwidth of the motion system is $10 \mathrm{~Hz}$ based on a gain of $-3 \mathrm{~dB}$ or $5 \mathrm{~Hz}$ based on a phase angle of $90^{\circ}$. The motion envelope, for single degree-of-freedom operation, is given in Table 4.1.

Table 4.1: Single degree of freedom motion envelope of the FRS

\begin{tabular}{lccc}
\hline DoF & Displacement & Velocity & Acceleration \\
\hline surge & $+0.70 \mathrm{~m},-0.61 \mathrm{~m}$ & $\pm 0.7 \mathrm{~m} / \mathrm{s}$ & $\pm 1.2 \mathrm{~g}$ \\
sway & $\pm 0.59 \mathrm{~m}$ & $\pm 0.7 \mathrm{~m} / \mathrm{s}$ & $\pm 1.2 \mathrm{~g}$ \\
heave & $+0.56 \mathrm{~m},-0.49 \mathrm{~m}$ & $\pm 0.6 \mathrm{~m} / \mathrm{s}$ & $+2 \mathrm{~g}, 0 \mathrm{~g}$ \\
roll & $\pm 21^{\circ}$ & $\pm 30^{\circ} / \mathrm{s}$ & $\pm 400^{\circ} / \mathrm{s}^{2}$ \\
pitch & $+22^{\circ},-20^{\circ}$ & $\pm 30^{\circ} / \mathrm{s}$ & $\pm 400^{\circ} / \mathrm{s}^{2}$ \\
yaw & $\pm 24^{\circ}$ & $\pm 30^{\circ} / \mathrm{s}$ & $\pm 400^{\circ} / \mathrm{s}^{2}$ \\
\hline
\end{tabular}

The out-the-window visual display is created by three high-end PCs with NVIDIA GTX 285 processors. The scenery and terrain models are created by X-Plane. Figure 4.1 shows the out-the-window scene at the start of the approach tasks. Three 24" Sony Multiscan colour CRT monitors project the images through Vital II infinity-optics display 
boxes with a total display size of $140^{\circ} \mathrm{H} \times 35^{\circ} \mathrm{V}$. The resolution of each monitor is 1280 $\mathrm{H} \times 1024 \mathrm{~V}$ pixels, and the refresh rate is $60 \mathrm{~Hz}$. The total transport delay is $58 \mathrm{~ms}$ (measured from the receipt of data to half the field of view of the visual system) 30].

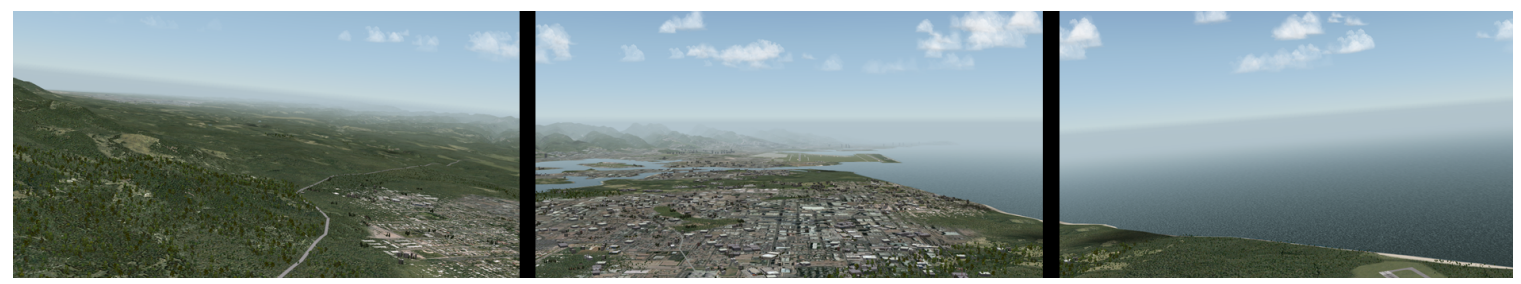

Figure 4.1: Out-the-window scene for approach tasks

Inside the cockpit, two touchscreen LCD displays are used to display Electronic Flight Instrument System information (EFIS). Figures $4.2 \mathrm{a}$ and $4.2 \mathrm{~b}$ show screen shots of the left and right EFIS displays. The only engine information that was used in the piloted handling trials was the engine compressor first stage speed, $\mathrm{N}_{1}$. Sounds in the cockpit are

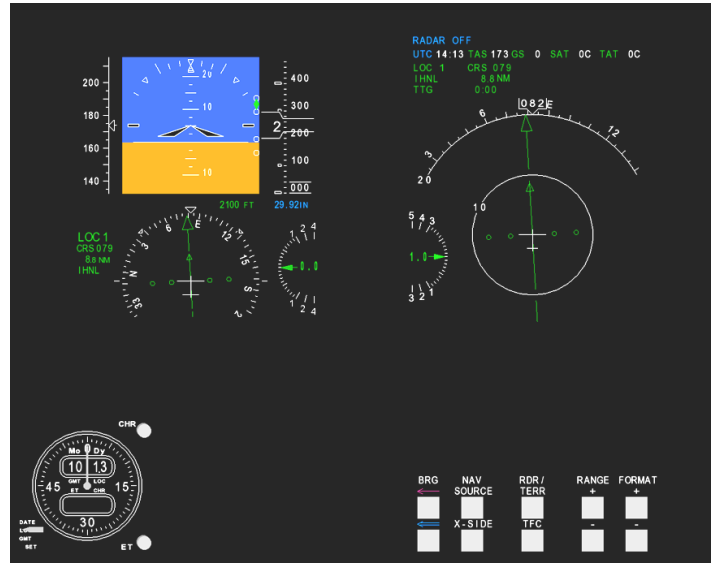

(a) Left

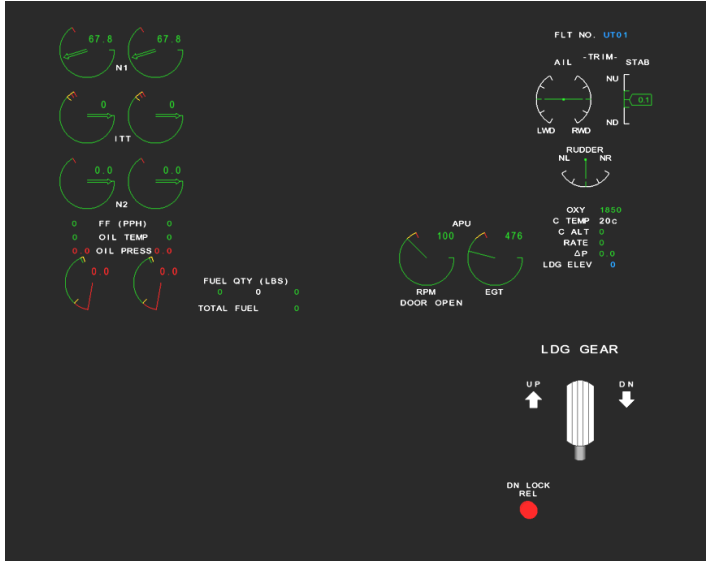

(b) Right

Figure 4.2: Screen shots of EFIS displays

generated by an E-max digital sampling keyboard and a Yamaha TX81Z tone generator. The sounds that are made in the cockpit are engine noise, aerodynamic hiss, left and right fan buzz, and a high-power rumble. The column, wheel, and pedal forces are provided by an Opinicus Corp. REALFeel 4000x force loader unit. The range of motion of the inceptors is given in Table 4.2. Table 4.2 also shows the total gain between the inceptor and the input to the flight control system. Two autothrottle channels (the middle two throttle levers) are provided by REALFeel 2000RC force loader units. A rudder trim 
wheel is available for the pilot to use as needed. The FRS also has an aileron trim wheel, which was used in the current study to displace the BWB's control surfaces allocated to roll control. The aileron trim wheel was not functional during the piloted-handling trials. Subjects were informed of this limitation before the handling trial started. The interior and exterior of the FRS are shown in Figure 4.3 .

Table 4.2: Inceptor range of motion and gain

\begin{tabular}{lcc}
\hline Column & $14 \mathrm{~cm}$ forward, $24 \mathrm{~cm}$ aft & $0.01 \mathrm{rad} / \mathrm{s} / \mathrm{cm}$ \\
Wheel & $\pm 120^{\circ}$ & $0.75 \mathrm{rad} / \mathrm{rad}$ \\
Rudder pedals & $\pm 10.75 \mathrm{~cm}$ & $0.11 \mathrm{rad} / \mathrm{cm}$ \\
\hline
\end{tabular}
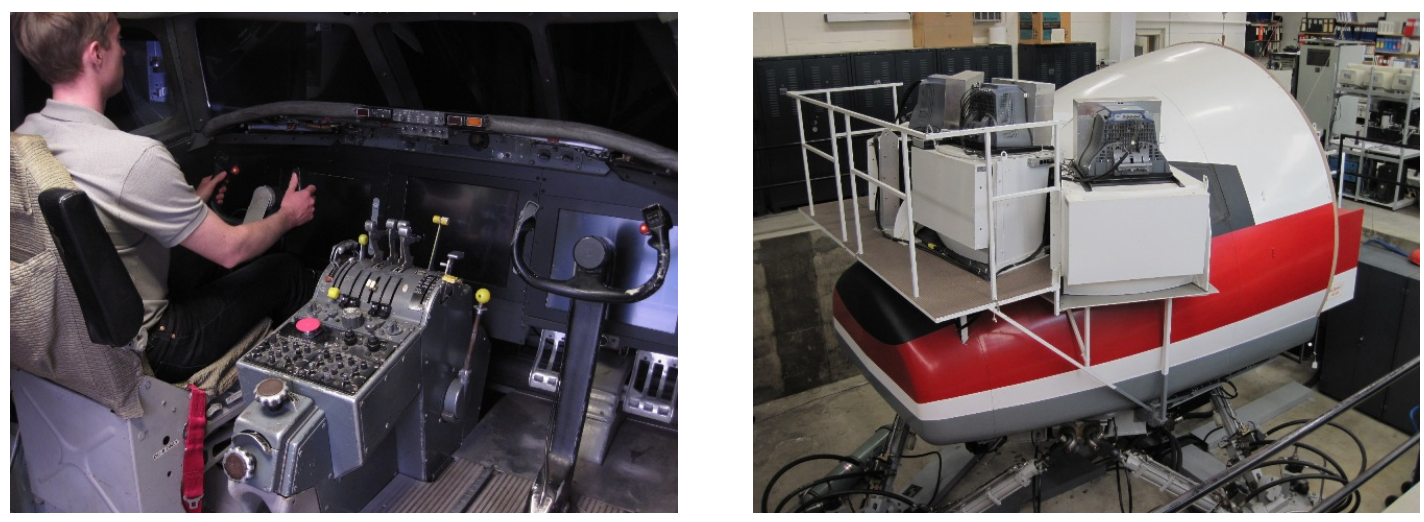

Figure 4.3: UTIAS Flight Research Simulator

\subsection{Motion Drive Algorithm}

\subsubsection{Description}

Reid and Nahon's Classical Linear Washout motion-drive algorithm (MDA) [13] was used in the piloted-handling trials. The MDA filters the aircraft motion so that it can be simulated within the limits of the hexapod motion base. The translational specific forces in the aircraft body frame are one set of inputs to the MDA. The reference point, where the translational specific forces are calculated, was selected to be at the centroid of the simulator motion base. Expressed in the body frame, the position of the pilot's head relative to the centroid is given by the vector $[-0.02-0.47-1.7828]^{T} \mathrm{~m}$. Humans 
sense specific force, which is related to the inertial acceleration by:

$$
\mathbf{f}=\mathbf{a}-\mathbf{g}
$$

The aircraft's angular velocity components in the aircraft body frame are the second set of inputs to the MDA. Although angular accelerations are sensed by humans, the dynamics of the human vestibular system are such that it acts like a velocity sensor in the bandwidth of interest [31. A fixed gain of 0.5 is applied to both the specific force and the aircraft angular velocity. The specific force is transformed from an aircraft-fixed frame to an inertial frame. The specific force is then converted to an acceleration and high-pass filtered, to remove steady-state accelerations that cannot be simulated with the motion base's limited travel. The aircraft angular velocity is converted to Euler rates and then is also high-pass filtered. Sustained specific forces in the $x$ and $y$ body axes are simulated by tilting the simulator cab relative to the gravity vector - this is called tilt-coordination. The amount of tilt required is found by low-pass filtering the $x$ and $y$ components of the specific force and dividing by the gravity vector. In order to prevent false rotational cues, the angular velocity of tilt coordination is limited. The baseline limits applied to tilt coordination are $3 \mathrm{deg} / \mathrm{s}$. It may be acceptable to pilots to use a higher tilt coordination rate limit for pitch, as pilots are more sensitive to roll-tilt rate than pitch-tilt rate [20]. The Classical Washout MDA is shown in Figure 4.4.

As a starting point, Reid and Nahon's [20] Classical Washout Parameters set 2 or "CW2" parameters were used for the high-pass filters. The CW2 translation and rotation high-pass (HP) filters are defined by the following transfer functions:

$$
\begin{aligned}
H P_{x} & =\frac{s^{2}}{(s+2.5)^{2}} \\
H P_{y} & =\frac{s^{2}}{(s+4)^{2}} \\
H P_{z} & =\frac{s^{3}}{\left(s+2 \cdot 4 s+4^{2}\right)(s+0.01)} \\
H P_{p} & =H P_{q}=H P_{r}=\frac{s}{(s+1)}
\end{aligned}
$$

The starting point of the low-pass filters was changed from the CW2 parameters. Reid and Nahon [13] used second-order low-pass filters with a natural frequency of twice the natural frequency of the high-pass filter. Subsequent to the work of Reid and Nahon, Grant [32] developed a method to tune simulator motion. Grant found that experienced 


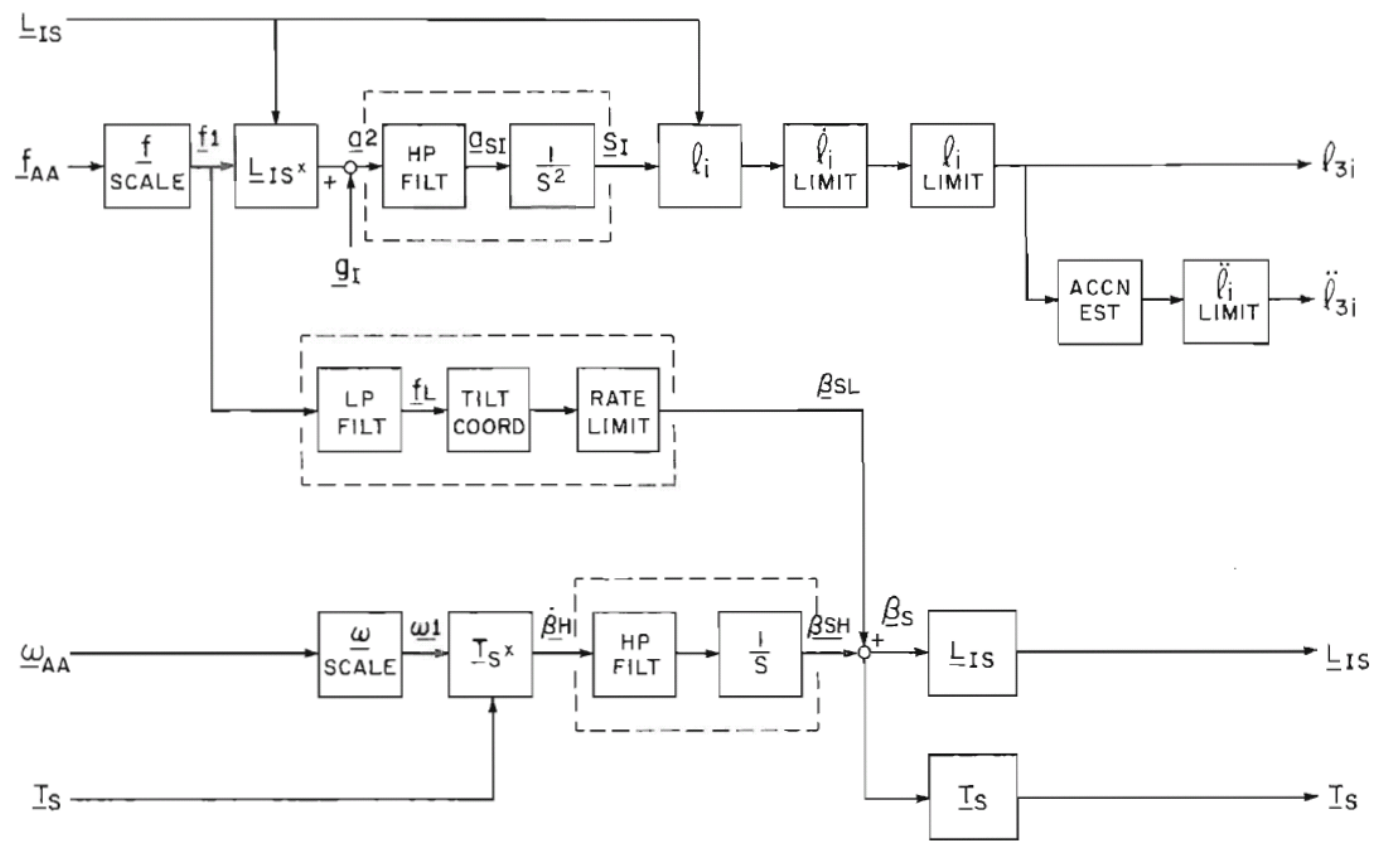

Figure 4.4: Classical-linear-washout motion-drive algorithm 13

airline pilots objected to the jerky surge and sway motion that was generated using the CW2 parameters. Grant found that lowering the low-pass natural frequencies reduced jerkiness. The following low-pass filters, with a lower natural frequency to prevent jerk response, were used as a starting point in the current study:

$$
\begin{aligned}
& L P_{x}=\frac{2.5^{2}}{s^{2}+2 \cdot 1 \cdot 2.5 s+2.5^{2}} \cdot \frac{100}{s+100} \\
& L P_{y}=\frac{3^{2}}{s^{2}+2 \cdot 1 \cdot 3 s+3^{2}} \cdot \frac{100}{s+100}
\end{aligned}
$$

The low-pass filters have the form of a second-order filter in series with a first-order filter. The first-order low-pass filter, with a break frequency of $100 \mathrm{rad} / \mathrm{s}$, is used so that the tilt-coordination angular acceleration can be limited.

\subsubsection{Frequency Response}

The frequency response of the classical-linear-washout MDA depends on the nature of the aircraft motion input. If there is no crossfeed between the translational and rotational motion, such as for a heave maneuver, yaw maneuver, or coordinated roll maneuver, the response depends only on the high-pass filters. If there is crossfeed, so that tilt- 
coordination is used, then the frequency response is a combination of the low-pass and high-pass filters. If there is no tilt-rate limiting, then the transfer function for surge or sway is given by the following equation [33]:

$$
\overline{f_{s s}^{i}} / \overline{f_{a a}^{i}}=k_{i}\left[L P_{i}+\left(1-L P_{i}\right) H P_{i}\right]
$$

The subscripts ss and $a a$ designate the simulator and aircraft-fixed frames, respectively. The superscript $i$ is replaced by $x$ to indicate surge, and $y$ to indicate sway. Similarly, the subscript $i$ on the low-pass (LP) and high-pass (HP) filters designates which component of specific force is being considered. As described in Section 4.2.1, the gain $k_{i}$ is 0.5 for all specific force components (as well as for the angular velocity filters). The fidelity of the simulator motion can be estimated by applying Schroeder's [12] criteria to the frequency response at $1 \mathrm{rad} / \mathrm{s}$. Applying this criteria allows the filter gains and cutoff frequencies to be tailored to each task, to provide the pilot with appropriate motion cues.

\subsubsection{Tuning the Parameters for Each Task}

The motion drive algorithm must be tuned for the particular tasks to be flown in the BWB simulator. Tuning involves choosing the filter gains and break frequencies to minimize the motion "error" perceived by the pilot. Since the Classical Washout Parameter set 2 (CW2) were optimized for the Boeing 747, improvements to the motion fidelity can be made by customizing the filter parameters to the BWB and the specific tasks to be flown. The tasks are given in Table 4.3. Two approaches to tuning are used. Offline tuning uses recorded time histories of the aircraft's motion in response to pilot inputs and atmospheric disturbances as inputs to the MDA. The simulator response, including motion error and actuator displacement, to a set of filter parameters is assessed. Changes are then made to reduce the motion error while keeping the actuator length commands safely within the hardware limitations of the motion base. In realtime tuning, a pilot or other expert performs typical maneuvers in the simulator such as turns, climbs, and descents. The pilot or expert then communicates to the person acting as tuner how well the motion cues complement the visual cues.

Two experts were consulted for their opinions of the suitability of the motion drive algorithm parameters. The first expert, an Associate Professor in the Vehicle Simulation Group at UTIAS, has extensive experience with simulator motion 33. He was unable to 
Table 4.3: Description of the tasks

\begin{tabular}{ll}
\hline & Description \\
\hline Task 1 & Normal takeoff \\
Task 2 & Normal approach and landing \\
Task 3 & Deleted \\
Task 4 & Takeoff with engine failure \\
Task 5 & Approach with engine failure \\
Task 6 & Approach with longitudinal offset \\
Task 7 & Approach with lateral offset \\
\hline
\end{tabular}

feel any heave motion even when applying large column inputs, suggesting that a cutoff frequency $\omega_{H P_{z}}$ of $4 \mathrm{rad} / \mathrm{s}$ was too high. The cutoff frequency was therefore reduced to 2 $\mathrm{rad} / \mathrm{s}$. He was also unable to feel any pitch rate cue, with $\omega_{H P_{q}}$ at $1 \mathrm{rad} / \mathrm{s}$. The high-pass pitch-rate cutoff frequency was lowered to $0.5 \mathrm{rad} / \mathrm{s}$ to make the pitch-rate filter less restrictive. The second expert was a former air-force pilot with experience in turboprop transport aircraft. He commented that, while completing the level-off phase of Task 1, with $\omega_{H P_{z}}=2 \mathrm{rad} / \mathrm{s}$ the motion felt jerky and sensitive. The input from these two experts led to the changes given in Table 4.4. To accommodate the conflicting opinions regarding heave motion, $\omega_{H P_{z}}$ was set to $4 \mathrm{rad} / \mathrm{s}$ for the duration of takeoff tasks ( 1 and 4) and lowered to $2 \mathrm{rad} / \mathrm{s}$ for the approach tasks until $200 \mathrm{ft}$ AGL was reached.

Table 4.4: Initial and modified MDA parameters

\begin{tabular}{rcccc}
\hline & & & $\begin{array}{c}\text { Above } 200 \mathrm{ft}, \\
\text { approaches }\end{array}$ & $\begin{array}{c}\text { Above 200 ft, } \\
\text { takeoffs }\end{array}$ \\
\hline$\omega_{L P_{x}}, \mathrm{rad} / \mathrm{s}$ & 2.5 & 3.5 & 2.5 & 2.5 \\
$\omega_{H P_{y}}, \mathrm{rad} / \mathrm{s}$ & 4 & 2 & 0.5 & 0.5 \\
$\omega_{H P_{z}}, \mathrm{rad} / \mathrm{s}$ & 4 & 4 & 2 & 4 \\
$\omega_{H P_{p}}, \mathrm{rad} / \mathrm{s}$ & 1 & 1 & 2.5 & 2.5 \\
$\omega_{H P_{q}}, \mathrm{rad} / \mathrm{s}$ & 1 & 0.5 & 0.5 & 0.5 \\
$\dot{\theta}_{\text {lim }}, \mathrm{deg} / \mathrm{s}$ & 1 & 1 & 0.7 & 1 \\
\hline
\end{tabular}




\subsubsection{Simulator Motion Fidelity}

As discussed in Section 4.2.2, the fidelity of the simulator motion can be predicted based on the frequency response of the motion-drive algorithm. To assess the fidelity of the MDA parameters described in Section 4.2.3, the amplitude ratio and phase of the translational and rotational channels were found at $1 \mathrm{rad} / \mathrm{s}$. Figure 4.5 shows the amplitude ratio and phase of the 3 specific force channels and the 3 angular rate channels, for each set of filter parameters. Low motion fidelity is expected for all motion except for pitch rate, which is expected to be medium fidelity. While it may seem unnecessary to use motion at all if it is generally expected to be low fidelity, handling-trial experiments have been successfully conducted in simulators with hexapod motion bases [10] [11]. Except for very specific low-motion tasks, Schroeder's criteria will generally predict low motion fidelity for simulators with hexapod motion bases.

\subsubsection{Reduced Motion}

The secondary purpose of the piloted-handling trials is to determine the effect of simulator motion on HQRs. There are six tasks. Each task is flown twice, once with full simulator motion and once with a reduced amount of simulator motion. Reduced simulator motion is used instead of no motion, as some pilots might have a bias for or against motion in simulators. A complete lack of motion would be easily detected by the pilot, even if the pilot was not informed of this condition. Reduced motion is used as part of a ruse, where the pilots are told that several flight control systems are being presented to them. In reality, it is the amount of simulator motion that is being varied within tasks. The reduced motion is an approximation to the aircraft's response to a gust along the aircraft's vertical axis. Etkin [15] describes a method by which the change in normal load factor is found by aerodynamic transfer functions. The aircraft is treated as a point. The aerodynamic transfer functions are given as [15],

$$
\mathbf{A}(s) \overline{\mathbf{y}}(s)=\mathbf{B}(s)\left[\begin{array}{l}
\overline{u_{g}} \\
\overline{w_{g}}
\end{array}\right]
$$

where $\overline{u_{g}}$ and $\overline{w_{g}}$ are the Laplace transforms of the nondimensional turbulence gust components along the aircraft's $x$ and $z$ body axes, and the system matrix of longitudinal 

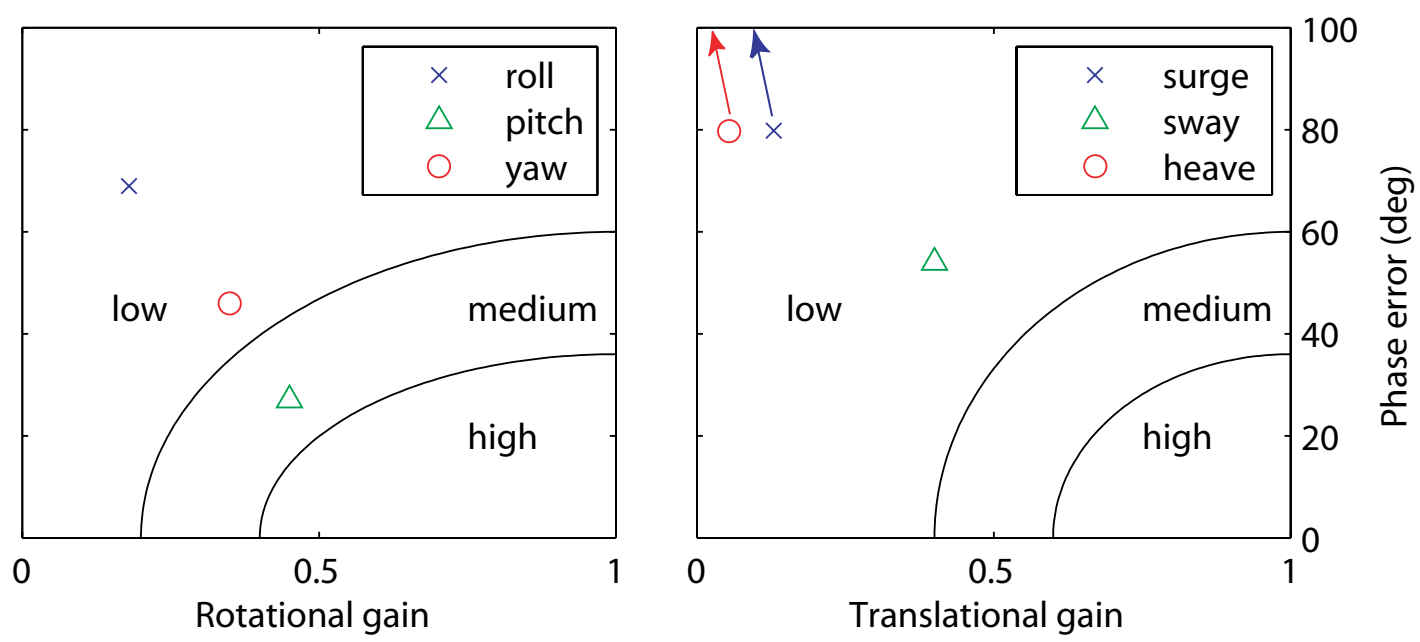

(a) Above $200 \mathrm{ft}$ AGL
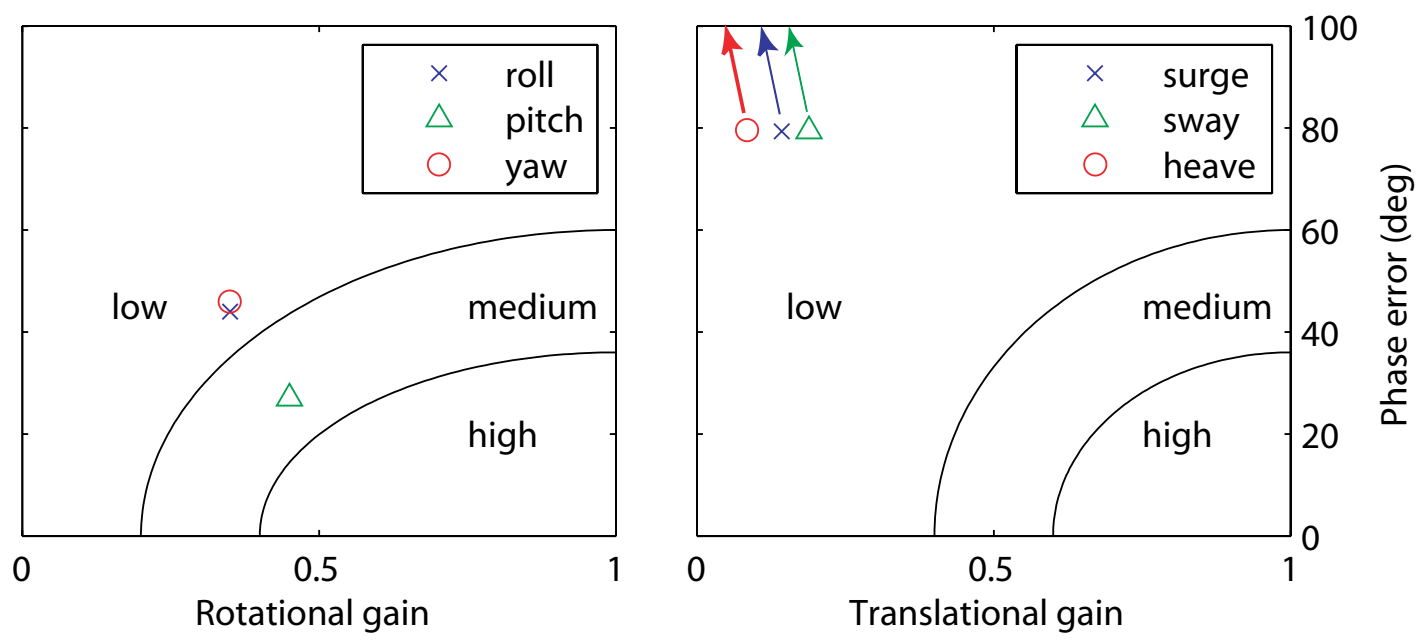

(b) Below $200 \mathrm{ft}$ AGL

Figure 4.5: Expected simulator motion fidelity 
force and moment coefficients is [15],

$$
\begin{aligned}
& \mathbf{A}(s)= \\
& {\left[\begin{array}{ccccc}
C_{T_{V}}-C_{D_{V}}-2 \mu s & C_{L_{e}}-C_{D_{\alpha}} & 0 & -C_{W_{e}} & 0 \\
-\left(C_{L_{V}}+2 C_{W_{e}}\right) & -\left(C_{L_{\alpha}}+C_{D_{e}}+2 \mu s\right) & 2 \mu-C_{L_{q}} & 0 & -C_{L_{\delta}} \\
-C_{m_{V}} & -\left(C_{m_{\alpha}}+s C_{m_{\dot{\alpha}}}\right) & -\left(C_{m_{q}}-\hat{I}_{y} s\right) & 0 & -C_{m_{\delta}} \\
0 & 0 & 1 & -s & 0 \\
0 & K_{\alpha} & K_{p}+\frac{K_{i}}{s} & 0 & 1
\end{array}\right]}
\end{aligned}
$$

where $K_{\alpha}, K_{p}$, and $K_{i}$ are the proportional feedback gain on angle of attack, proportional gain on pitch rate, and integral gain on pitch rate, respectively. Note that actuator dynamics are not included in the equations, as they have a much higher natural frequency than the longitudinal modes of the aircraft (actuator $\omega_{a c}=30 \mathrm{rad} / \mathrm{s}$ ). The state vector is given as 15 ,

$$
\overline{\mathbf{y}}=\left[\begin{array}{lllll}
\overline{\Delta V} & \overline{\Delta \alpha} & \bar{q} & \overline{\Delta \theta} & \overline{\Delta \delta_{e}}
\end{array}\right]^{T}
$$

The system matrix on the right-hand side of Equation 4.9 is [15],

$$
\mathbf{B}(s)=\left[\begin{array}{cc}
C_{T_{V}}-C_{D_{V}} & -C_{D_{\alpha}} \\
-C_{L_{V}} & -C_{L_{\alpha}} \\
-C_{m_{V}} & -C_{m_{\alpha}} \\
0 & 0 \\
0 & 0
\end{array}\right]
$$

The change in normal load factor from equilibrium due to a gust is caused by two longitudinal components, $u_{g}$ and $w_{g}$. Since the response due to $w_{g}$ is much larger, $u_{g}$ is neglected. The transfer function for the change in load factor due to a gust $w_{g}$ along the $\mathrm{z}$ body-axis is given as [15],

$$
\frac{\overline{\Delta n}}{\overline{w_{g}}}=\frac{C_{L_{\alpha}}}{C_{W_{e}}}\left(\frac{\overline{\Delta \alpha}}{\overline{w_{g}}}-1\right)+2 \frac{\overline{\Delta V}}{\overline{w_{g}}}
$$

Equation 4.9 is rearranged to find the required transfer functions in Equation 4.13. The resulting transfer function is of $30^{\text {th }}$ order. It might not be feasible, or necessary, to invert the matrix $\mathbf{A}(s)$ in Equation 4.10 in real time. A reasonable approximation might be good enough for the purpose of creating reduced simulator motion.

The exact transfer function has a frequency response that is similar to a high-pass filter. The simplest approximation is therefore a first-order high-pass filter. The cutoff 
frequency and gain of the high-pass filter are functions of the aircraft's speed, $V$. The equation for the filter is given in as,

$$
L P_{n w}=K_{n w} \frac{s}{s+0.1 \frac{V_{e}}{V}}
$$

where the scaling factor is

$$
K_{n w}=-6.3\left(\frac{V}{V_{e}}\right)^{2}
$$

The reference speed, $V_{e}$, is $90 \mathrm{~m} / \mathrm{s}$. This is chosen somewhat arbitrarily, for the purpose of matching the low-order approximation to the frequency response of the exact transfer function. Bode plots of the exact $\left(30^{t h}\right.$ order) transfer function (which treats the aircraft as a point) and a first-order high-pass filter are shown in Figure 4.6. The response of

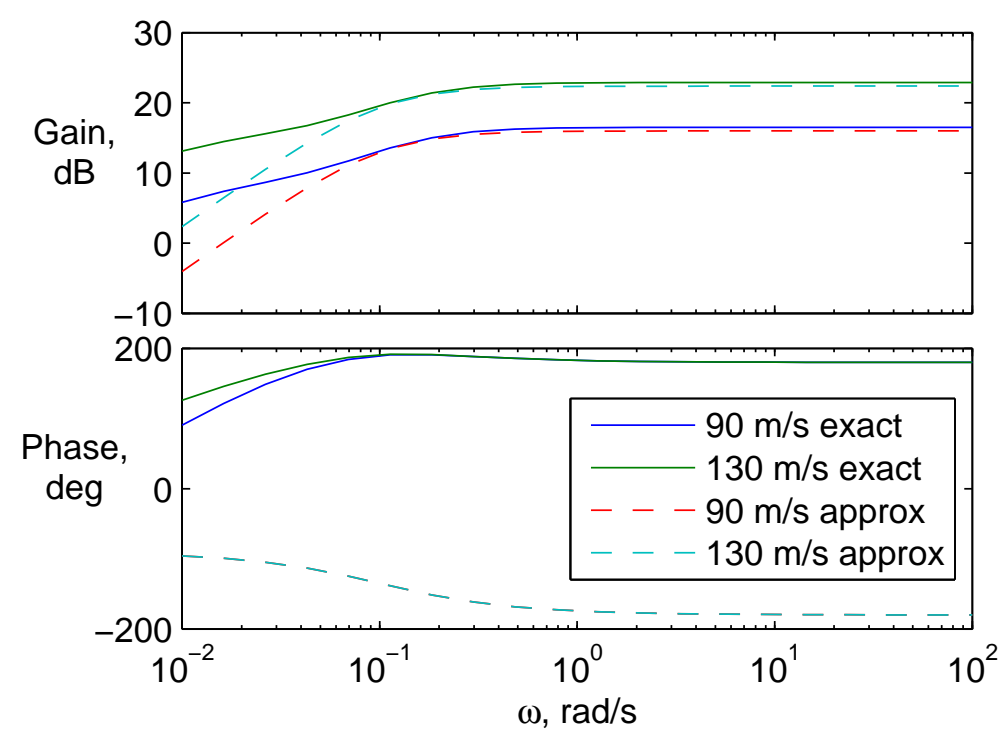

Figure 4.6: Frequency response of the exact gust transfer function and a first-order approximation

the exact transfer function is shown at two speeds, with solid lines. The response of the first-order high-pass filter is shown with dashed lines. There are several differences between the exact transfer function and the high-pass filter. The former has a lower slope at low frequencies, about $-8 \mathrm{~dB} /$ decade. The phase error of the high-pass filter is $360^{\circ}$. The scaling factor shown in Equation 4.15 should not have a negative sign. If the scaling factor were positive instead, the phase error would have been about $180^{\circ}$. 
To further assess the high-pass filter, time histories of the specific force $f_{z}$ are generated and compared to the complete nonlinear model of the augmented BWB (using the same turbulent gust $w_{g}$ ). Two time histories are used. The first, Figure 4.7, is at an altitude of $679 \mathrm{~m}$ and an airspeed of $92.6 \mathrm{~m} / \mathrm{s}$ (the initial conditions for all approach tasks).The second, Figure 4.8, is at an altitude of $1524 \mathrm{~m}$ and airspeed of $129 \mathrm{~m} / \mathrm{s}$ (the

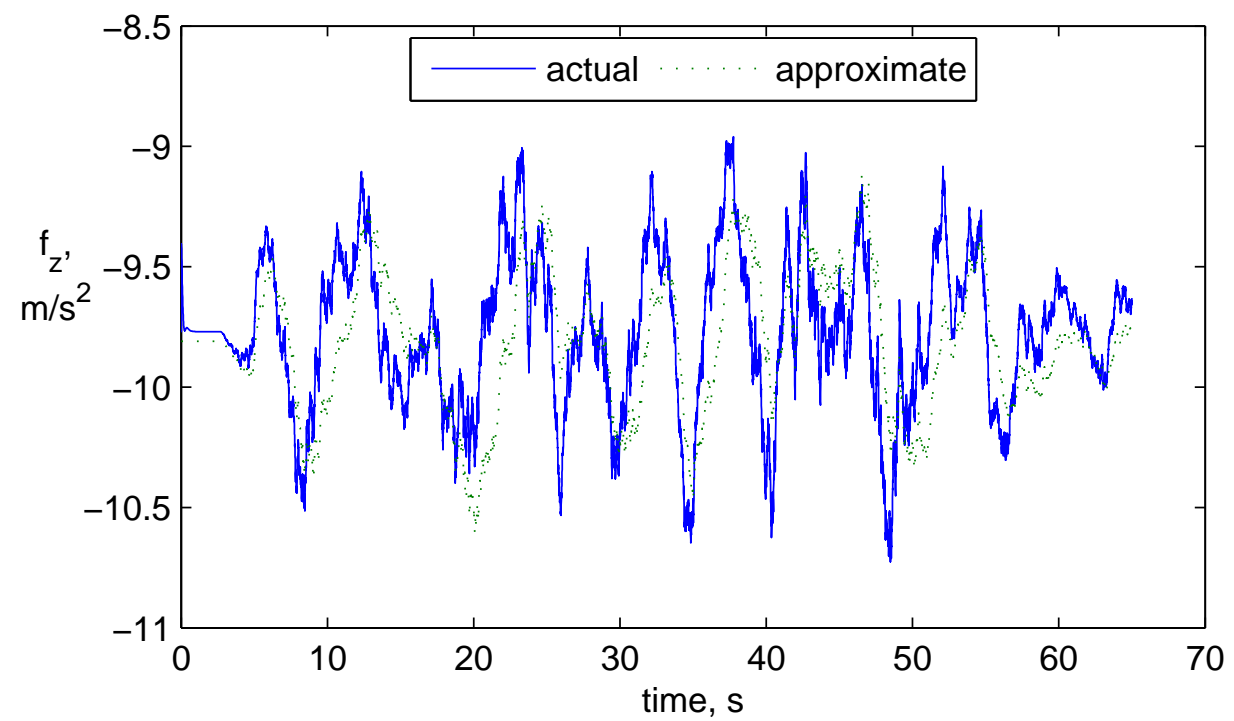

Figure 4.7: Time history of the specific force $f_{z}$, altitude $679 \mathrm{~m}, \mathrm{~V}=92.6 \mathrm{~m} / \mathrm{s}$

final condition of both takeoff tasks). The magnitude of the specific force $f_{z}$ generated by the high-pass filter is comparable to the specific force from the nonlinear BWB model. Clearly there is a significant phase error, although the phase error is not expected to affect the HQRs. The purpose of the reduced simulator motion is simply to generate some reasonable heave motion to mask the fact that the simulator motion is not presenting most of the aircraft-motion cues to the pilot. 


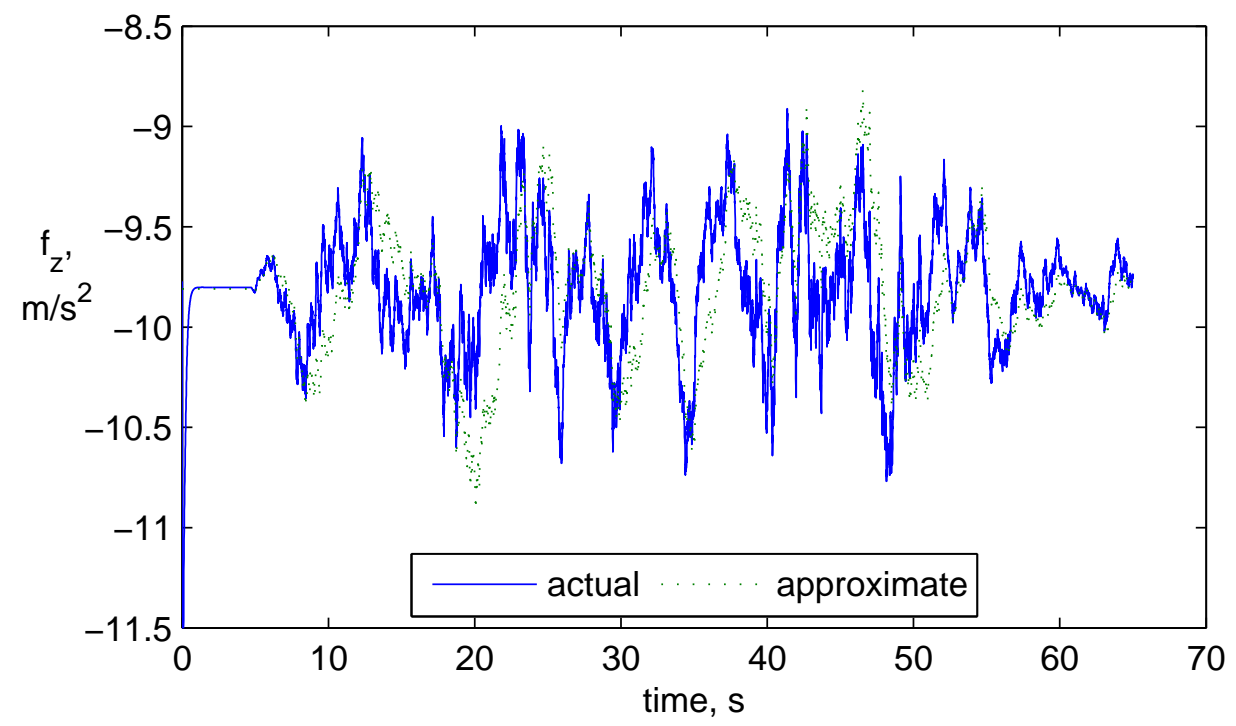

Figure 4.8: Time history of the specific force $f_{z}$, altitude $1524 \mathrm{~m}, \mathrm{~V}=129 \mathrm{~m} / \mathrm{s}$ 


\section{Chapter 5}

\section{Pilot Handling Quality Experiments}

\subsection{Experimental Setup}

Three subjects took part in the handling trials. They were recruited by word-of-mouth and were not paid for participating. Their experience is given in Table 5.1. The subjects were all "high-time" pilots, using Showalter and Parris' [9] definition of "high-time", which is 500 hours of flying time. Only Subject B had flown heavy aircraft. None of the subjects had used the Cooper Harper scale before, although Subjects B and C were familiar with the scale. Each subject was sent an electronic copy of the pilot briefing at least a week before the handling trial. The pilot briefing stated that two flight control systems were being evaluated. Only one flight control system was implemented in the current flight model. The claim that two flight control systems were being evaluated was a ruse; its purpose was to hide the fact that two simulator motion conditions were used. Since some pilots might have a bias for or against simulator motion, the ruse was intended to minimize this potential bias. The pilot briefing is included in the Appendices. Upon arriving at UTIAS, the subject was asked to read a simulator safety briefing and then sign a consent form. Before entering the FRS, the subject was told of any changes (which were minor, if any) to the pilot briefing. The subject was given a hard copy of the pilot briefing upon which to mark HQRs. With the motion turned off, the subject practiced a normal takeoff, a takeoff with an engine failure, and a normal approach before starting the evaluation phase.

Each task was performed twice, once with full motion and once with ruse motion. The run order was randomized and consisted of 12 runs (six tasks, each with two motion conditions). Randomizing the order of tasks was done to minimize any training effect 
Table 5.1: Subjects used in the handling trials

\begin{tabular}{ll}
\hline Flying Experience \\
\hline Subject A & Military/civilian training; 12500 h; flown: T-33, C-47, \\
& Twin Otter, DHC 8, BD700 \\
Subject B & Civilian training; 15000 h; flown: 727, 767 \\
Subject C & Military/civilian training; 9400 h; flown: Twin Otter, \\
& DHC 8 \\
\hline
\end{tabular}

on the results. Subjects could repeat any run before evaluating the task. Desired and adequate levels of performance were specified in the pilot briefing. It was up to the subject to decide whether the task performance was desired, adequate, or inadequate. Self-assessment of performance was used in Schroeder's experiments [12], but in the handling trials of Soparkar and Reid [11], pilots were told of their performance after each run. An audio recording device was used to record any comments made by the experimenter and the subject. The evaluation phase lasted between 1.3 and 2 hours.

The tasks chosen for the current research were taken from the handling trials of de Castro 8]. Runway 08L of Honolulu International Airport (PHNL) and the surrounding area was used for all tasks. The runway is $12300 \mathrm{ft}$ long by $150 \mathrm{ft}$ wide. The first task was a normal takeoff. The aircraft started $700 \mathrm{ft}$ from the end of the runway, aligned with the runway. The wind was from the right, perpendicular to the runway, at a speed of $2 \mathrm{~m} / \mathrm{s}$ (at a height $10 \mathrm{~m}$ above ground). De Castro [8] did not include any wind in any of the tasks that were evaluated for handling qualities. The first task specified a rotation speed, $V_{R}$, of $180 \mathrm{kts}$. Subtask 1a consisted of a climb to $5000 \mathrm{ft}$ with a pitch attitude of $10^{\circ}$ and an indicated airspeed of $200 \mathrm{kts}$. Subtask $1 \mathrm{~b}$ required the aircraft to accelerate to $250 \mathrm{kts}$ while maintaining $5000 \mathrm{ft}$. Subtask 1c called for the aircraft to maintain that airspeed and altitude.

The second task was a normal approach. The aircraft started $8 \mathrm{~nm}$ from the runway, at an airspeed of $180 \mathrm{kts}$ and an altitude of $2230 \mathrm{ft}$. At this altitude the aircraft was below the ILS glideslope. The landing gear was initially retracted. The mean wind was the same as in Task 1. The initial aircraft heading was set so that the aircraft's course over ground was aligned with the runway. Subtask 2 a consisted of capturing the glideslope and then following the approach to $200 \mathrm{ft}$, maintaining $180 \mathrm{kts}$. Subtask 2b was the landing, including the flare and touchdown. The touchdown zone was centered 
at a point in the middle of the runway, $720 \mathrm{ft}$ from the threshold. The same touchdown zone was specified for all landing subtasks.

The third task (called Task 4) was a takeoff with an engine failure. The initial position and heading were the same as in Task 1. To lower the difficulty of this task, the wind was made to be a headwind, aligned with the runway. The left or right outer engine was suddenly failed at an airspeed of $150 \mathrm{kts}(77 \mathrm{~m} / \mathrm{s})$. Which engine failed was determined by a random number generator. Subtask 4 a required the pilot to maintain the runway centreline after engine failure. The aircraft was to be rotated at $180 \mathrm{kts}$. Subtask $4 \mathrm{~b}$ called for a straight, wings level climb. The initial climb attitude was to be $5^{\circ}$, until 1000 $\mathrm{ft}$, at which point the airspeed was to increase to $220 \mathrm{kts}$ and the pitch attitude to $7^{\circ}$. The task ended at an altitude of $5000 \mathrm{ft}$.

The fourth task (called Task 5) was an approach with an engine failure. The initial condition was the same as Task 2, but with the wind direction aligned with the runway, head-on. The left or right outer engine was suddenly failed at an altitude of $1700 \mathrm{ft}$. Subtask 5a required the pilot to maintain the runway heading and wings level until 200 ft. Subtask 5b consisted of the landing, including flare and touchdown.

The fifth task (called Task 6) was an approach with a longitudinal offset. The initial condition, including wind, was the same as for Task 2. The pilot was instructed to deliberately fly one dot above the glideslope, until $600 \mathrm{ft}$ AGL. Subtask 6a consisted of regaining the glideslope while maintaining airspeed. Subtask $6 \mathrm{~b}$ was the landing.

The sixth task (called Task 7) was an approach with a lateral offset. The initial condition was the same as Task 2. The pilot was told to fly one dot to the left of the localizer, until $600 \mathrm{ft}$ AGL. Subtask 7a required the pilot to regain the runway centerline by $200 \mathrm{ft}$ AGL. Subtask 7b was the landing.

\subsection{Experimental Results}

\subsubsection{Handling-Quality Ratings}

The handling-quality ratings the subjects assigned using the Cooper Harper Scale are shown in Figure 5.1. Green markers are used for the full-motion condition, and red markers for the ruse-motion condition. Task 1, normal takeoff, was evaluated on three subtasks. All other tasks were evaluated on two subtasks. The ratings assigned to each subtask are given in Table 5.2. The mean Cooper Harper ratings with full motion and 
ruse motion are given in Table 5.3, as are the ratings from the equivalent task in de Castro's study. The mean ratings are across all subjects and all two (or three) subtasks. The run order of the tasks is given in Table 5.4 .

Table 5.2: Cooper Harper ratings for subtasks

\begin{tabular}{|c|c|c|c|c|c|c|c|}
\hline \multicolumn{2}{|c|}{ Motion condition } & \multicolumn{3}{|c|}{ Full } & \multicolumn{3}{|c|}{ Ruse } \\
\hline & Subject & $\mathrm{A}$ & $\mathrm{B}$ & $\mathrm{C}$ & A & B & $\mathrm{C}$ \\
\hline \multirow{3}{*}{ Task1 } & $1 \mathrm{a}$ & 3 & 2 & 3 & 2 & 3 & 3 \\
\hline & $1 b$ & 3 & 2 & 4 & 3 & 2 & 3 \\
\hline & $1 c$ & 3 & 2 & 4 & 2 & 2 & 4 \\
\hline \multirow{2}{*}{ Task2 } & $2 \mathrm{a}$ & 3 & 5 & 3 & 3 & 5 & 3 \\
\hline & $2 \mathrm{~b}$ & 2 & 5 & 4 & 2 & 4 & 4 \\
\hline \multirow{2}{*}{ Task4 } & $4 \mathrm{a}$ & 3 & 3 & 4 & 3 & 3 & 7 \\
\hline & $4 \mathrm{~b}$ & 3 & 3 & 7 & 3 & 3 & 10 \\
\hline \multirow{2}{*}{ Task5 } & $5 \mathrm{a}$ & 3 & 4 & 4 & 3 & 6 & 4 \\
\hline & $5 b$ & 2 & 4 & 5 & 2 & 5 & 5 \\
\hline \multirow{2}{*}{ Task6 } & $6 a$ & 3 & 3 & 3 & 3 & 3 & 3 \\
\hline & $6 \mathrm{~b}$ & 2 & 3 & 4 & 2 & 3 & 4 \\
\hline \multirow{2}{*}{ Task7 } & $7 \mathrm{a}$ & 3 & 2 & 3 & 3 & 2 & 3 \\
\hline & $7 \mathrm{~b}$ & 3 & 3 & 4 & 2 & 3 & 4 \\
\hline
\end{tabular}

The pilot briefing defined the desired and adequate levels of performance for each subtask. The levels were the same as those used in de Castro's handling trials. The desired and adequate performance levels are taken into consideration by pilots when they assign a Cooper Harper rating to a task. As discussed in Section 5.1, subjects were not informed of the pilot-vehicle performance level following a task. The aircraft states were recorded during each task. The desired and adequate performance criteria were applied to each task, and a numerical rating was assigned to each subtask. Desired performance was rated a 1 , adequate performance a 2 , and inadequate performance a 3. It was found that subjects did not try to touch down in the prescribed zone, which was defined in the pilot briefing. The criterion of longitudinal touchdown position was therefore removed, and only the lateral touchdown position was evaluated. Table 5.5 shows the performance level for each task. A dash is shown for subtasks that were not completed. 


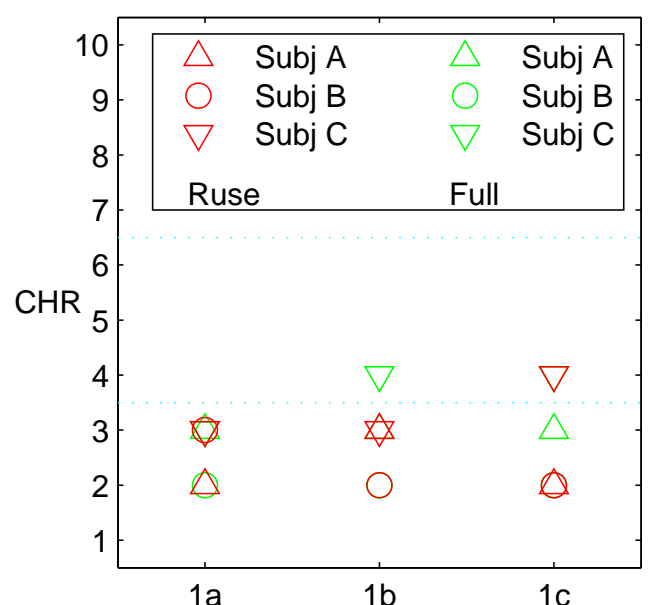

(a) Task 1

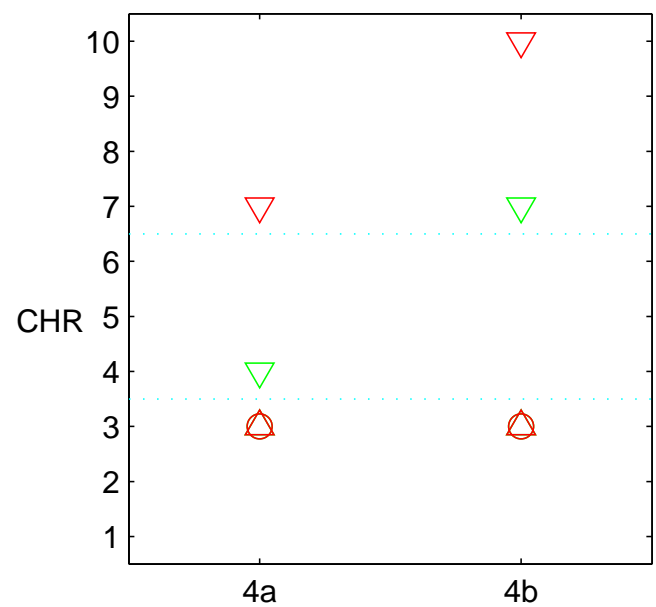

(c) Task 4

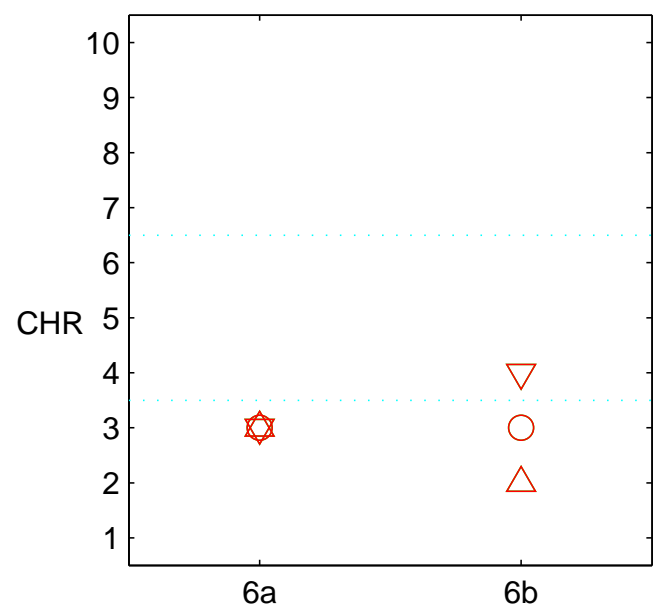

(e) Task 6

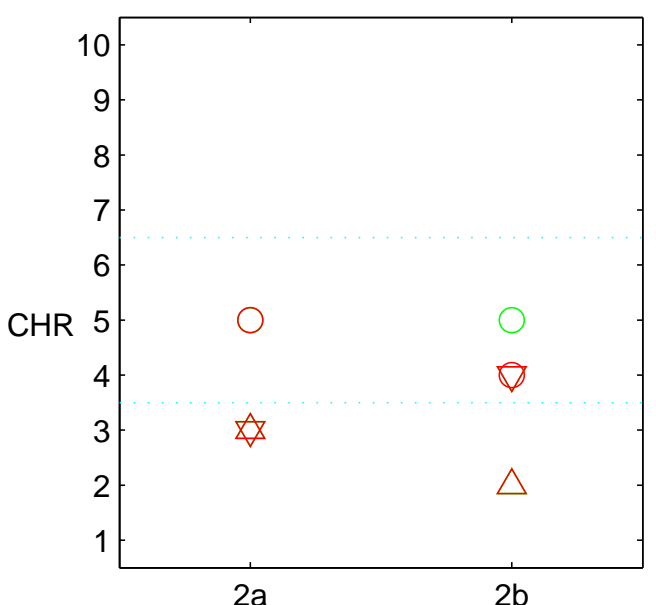

(b) Task 2

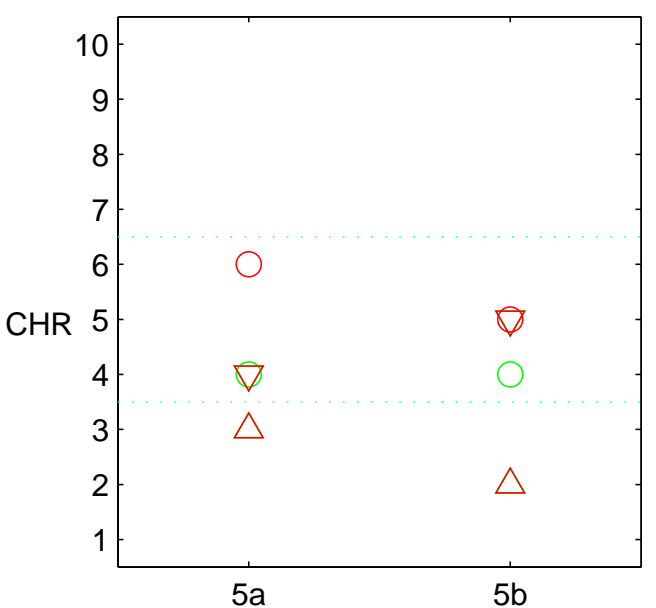

(d) Task 5

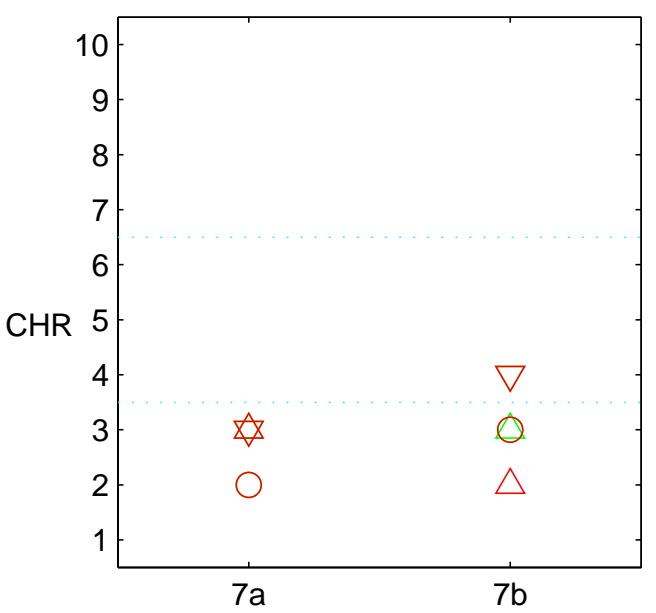

(f) Task 7

Figure 5.1: Cooper Harper ratings of tasks with full motion and ruse motion 
Table 5.3: Mean Cooper Harper ratings

\begin{tabular}{lccc}
\hline & Full motion & Ruse motion & Rating from de Castro $[8]$ \\
\hline Task 1 & 2.89 & 2.67 & 3.17 \\
Task 2 & 3.67 & 3.50 & 4.00 \\
Task 4 & 3.83 & 4.83 & 3.75 \\
Task 5 & 3.67 & 4.17 & 4.00 \\
Task 6 & 3.00 & 3.00 & 4.00 \\
Task 7 & 3.00 & 2.83 & 5.00 \\
\hline
\end{tabular}

Table 5.4: Run order of the tasks and motion condition ( $\mathrm{f}=\mathrm{full}, \mathrm{r}=\mathrm{ruse}$ )

\begin{tabular}{cccc}
\hline Run number & Subject A & Subject B & Subject C \\
\hline 1 & $7 \mathrm{f}$ & $2 \mathrm{r}$ & $7 \mathrm{r}$ \\
2 & $4 \mathrm{f}$ & $2 \mathrm{f}$ & $4 \mathrm{r}$ \\
3 & $2 \mathrm{r}$ & $5 \mathrm{r}$ & $4 \mathrm{f}$ \\
4 & $7 \mathrm{r}$ & $1 \mathrm{r}$ & $5 \mathrm{r}$ \\
5 & $5 \mathrm{r}$ & $5 \mathrm{f}$ & $5 \mathrm{f}$ \\
6 & $2 \mathrm{f}$ & $4 \mathrm{f}$ & $1 \mathrm{r}$ \\
7 & $5 \mathrm{f}$ & $6 \mathrm{r}$ & $2 \mathrm{f}$ \\
8 & $1 \mathrm{r}$ & $7 \mathrm{f}$ & $6 \mathrm{r}$ \\
9 & $6 \mathrm{r}$ & $7 \mathrm{r}$ & $2 \mathrm{r}$ \\
10 & $4 \mathrm{r}$ & $4 \mathrm{r}$ & $7 \mathrm{f}$ \\
11 & $6 \mathrm{f}$ & $6 \mathrm{f}$ & $1 \mathrm{f}$ \\
12 & 1f & $1 \mathrm{f}$ & $6 \mathrm{f}$ \\
\hline
\end{tabular}


Table 5.5: Performance level for subtasks (1=desired, $2=$ adequate, $3=$ inadequate)

\begin{tabular}{|c|c|c|c|c|c|c|c|}
\hline \multicolumn{2}{|c|}{ Motion condition } & \multicolumn{3}{|c|}{ Full } & \multicolumn{3}{|c|}{ Ruse } \\
\hline & Subject & $\mathrm{A}$ & $\mathrm{B}$ & $\mathrm{C}$ & A & B & $\mathrm{C}$ \\
\hline \multirow{3}{*}{ Task1 } & $1 \mathrm{a}$ & 2 & 1 & 3 & 2 & 1 & 2 \\
\hline & $1 b$ & 1 & 1 & 2 & 1 & 1 & 2 \\
\hline & $1 \mathrm{c}$ & 2 & 1 & 3 & 1 & 1 & 3 \\
\hline \multirow{2}{*}{ Task2 } & $2 \mathrm{a}$ & 2 & 2 & 3 & 1 & 2 & 3 \\
\hline & $2 \mathrm{~b}$ & 1 & 1 & 1 & 1 & 1 & 1 \\
\hline \multirow{2}{*}{ Task4 } & $4 \mathrm{a}$ & 2 & 2 & 2 & 1 & 2 & 3 \\
\hline & $4 \mathrm{~b}$ & 1 & 1 & - & 1 & 1 & - \\
\hline \multirow{2}{*}{ Task5 } & $5 \mathrm{a}$ & 1 & 2 & 1 & 1 & 2 & 1 \\
\hline & $5 \mathrm{~b}$ & 1 & 1 & 1 & 1 & 1 & 1 \\
\hline \multirow{2}{*}{ Task6 } & $6 \mathrm{a}$ & 2 & 2 & 2 & 2 & 1 & 3 \\
\hline & $6 \mathrm{~b}$ & 1 & 1 & 1 & 1 & 1 & 1 \\
\hline \multirow{2}{*}{ Task7 } & $7 \mathrm{a}$ & 1 & 2 & 1 & 1 & 1 & 1 \\
\hline & $7 \mathrm{~b}$ & 1 & 1 & 1 & 1 & 1 & 1 \\
\hline
\end{tabular}

In the current research, a pilot estimates the handling qualities of the real aircraft based on a ground-based simulation. This requires some extrapolation on the pilot's part, based on his or her experience flying real aircraft. To determine the degree to which the ratings assigned to each subtask matched the performance levels, the ratings were divided into the following groups: desired, adequate, and inadequate. Each rating level of the Cooper Harper scale includes descriptive phrases that refer to the demands on the pilot. In particular, the level of performance (desired or adequate) is included in the descriptive phrase. Ratings of 1 to 4 specify desired performance, ratings of 5 and 6 specify adequate performance, and ratings of 7 and above specify inadequate performance. Figure 5.2 shows the correspondence between performance level and HQR. The height of each bar shows the number of times the HQR (in terms of desired, adequate, and inadequate) matched each level of performance. By far the greatest number (45) of subtasks were rated at the desired handling quality level when the performance was also at the desired level. The second most frequent pair was a rating of desired performance when the actual performance was adequate. This occurred for 17 subtasks. The third most frequent pair was a rating of desired when the performance was inadequate, which 
occurred 6 times. That desired ratings were assigned when the performance was adequate or inadequate could be due to the fact that a subject felt that he or she could achieve desired performance with a reasonable increase in effort.

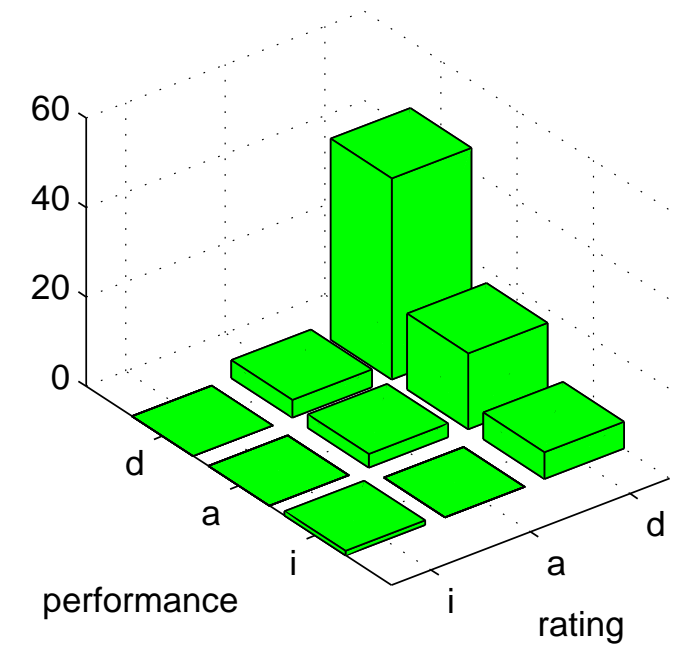

Figure 5.2: Subtask performance and HQ rating

\subsubsection{Analysis of Variance}

There was considerable variability in the ratings assigned to tasks and their subtasks, with ratings between subjects differing by as much as 7 . Table 5.6 shows the mean rating and variance of each subject. The greatest variance occurred for Task 4, the takeoff with engine failure. The first subtask was to maintain the runway centreline after engine failure. The second subtask was to establish a straight, wings level climb after takeoff. With full motion, Subject C rated the second subtask a 7, while the other two subjects rated it a 3 . With ruse motion, Subject $\mathrm{C}$ rated the first subtask a 7 , compared to a 3 for the other two subjects. Subject C rated the second subtask a 10, compared to a 3 for the other subjects, with the ruse motion condition. When Subject C performed Task 4 with ruse motion, the aircraft diverged in roll and the task was stopped before completion. The airspeed was $176 \mathrm{kts}$ when control was lost, which is below the rotation speed of 180 kts.

The piloted-handling trials in the current study are a two-factor within-subjects experimental design. The factors were the task and the motion condition. The task factor 
Table 5.6: Mean ratings and variance of subjects

\begin{tabular}{lcc}
\hline & Mean & Variance \\
\hline Subject A & 2.65 & 0.24 \\
Subject B & 3.27 & 1.32 \\
Subject C & 4.19 & 2.56 \\
\hline
\end{tabular}

had 13 levels (rateable subtasks) while the motion condition had two levels.

The mean ratings and standard deviations are shown in Figure 5.3a for the ruse motion condition and in Figure $5.3 \mathrm{~b}$ for the full motion condition. An ANOVA on the effect of each task (including subtasks) on the HQRs did not find a statistically significant effect $(\mathrm{F}(12,24)=1.010, \mathrm{p}=0.469)$. Similarly, no statistically-significant effect of motion on HQRs was found $(\mathrm{F}(1,2)=0.481, \mathrm{p}=0.56)$. The lack of statistical significance may be due to large variance in the Cooper Harper ratings, which may be a result of using subjects that were inexperienced in rating handling qualities. The null hypotheses must be retained, meaning that any differences in HQRs in these experiments were most likely due to random factors and not the experimental factors. Possible sources of random error include within- and between-subject differences and training effects. Between-subject factors could include inconsistent application of the Cooper Harper scale. The effect of run order or training effects on the results cannot be determined, because each subject was not exposed to all possible combinations. The ratings that Subject B assigned to the landings (subtasks 2b, 5b, 6b, and 7b) were Level 2 for the first 4 landings, and Level 1 for the last 4 landings. This improvement in ratings, and Subject B's comments (Section 5.2.3) suggest that training may have had an effect on Subject B's ratings. 


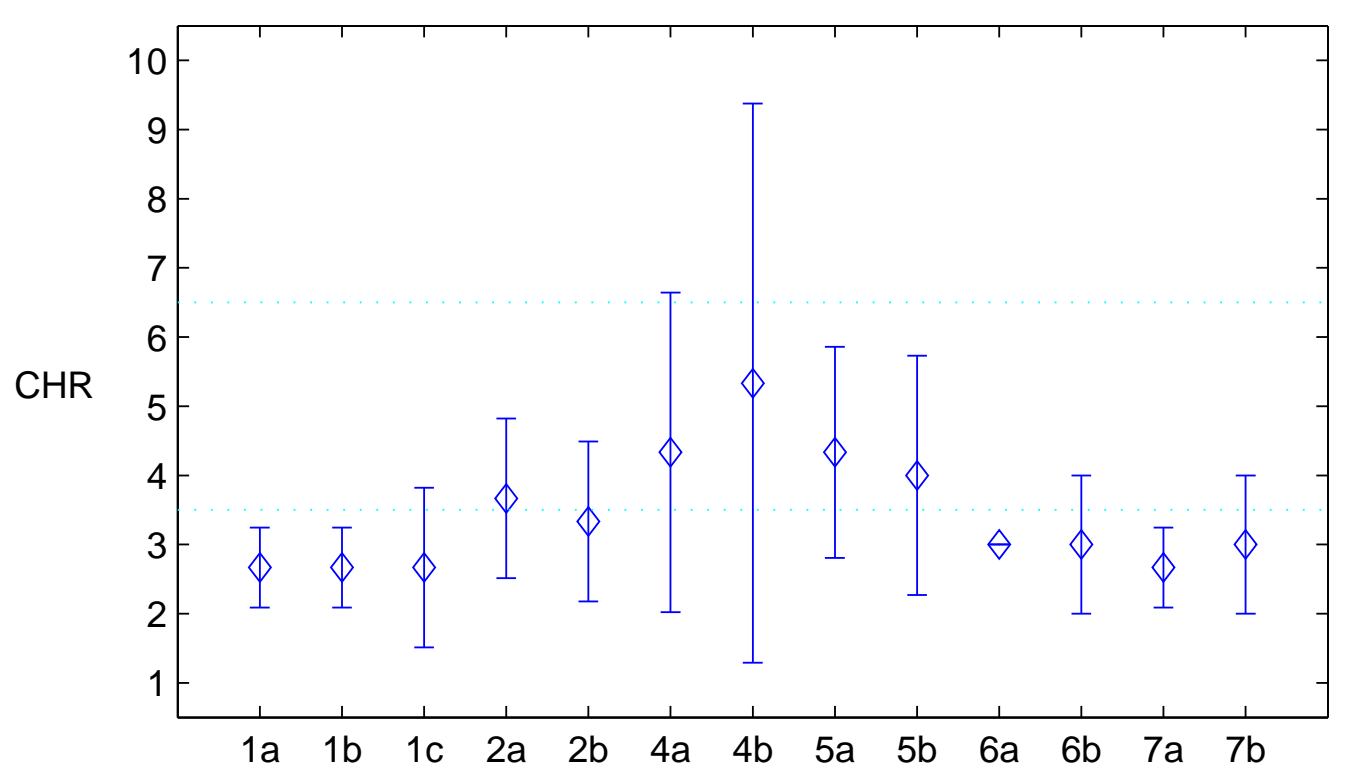

(a) Ruse motion

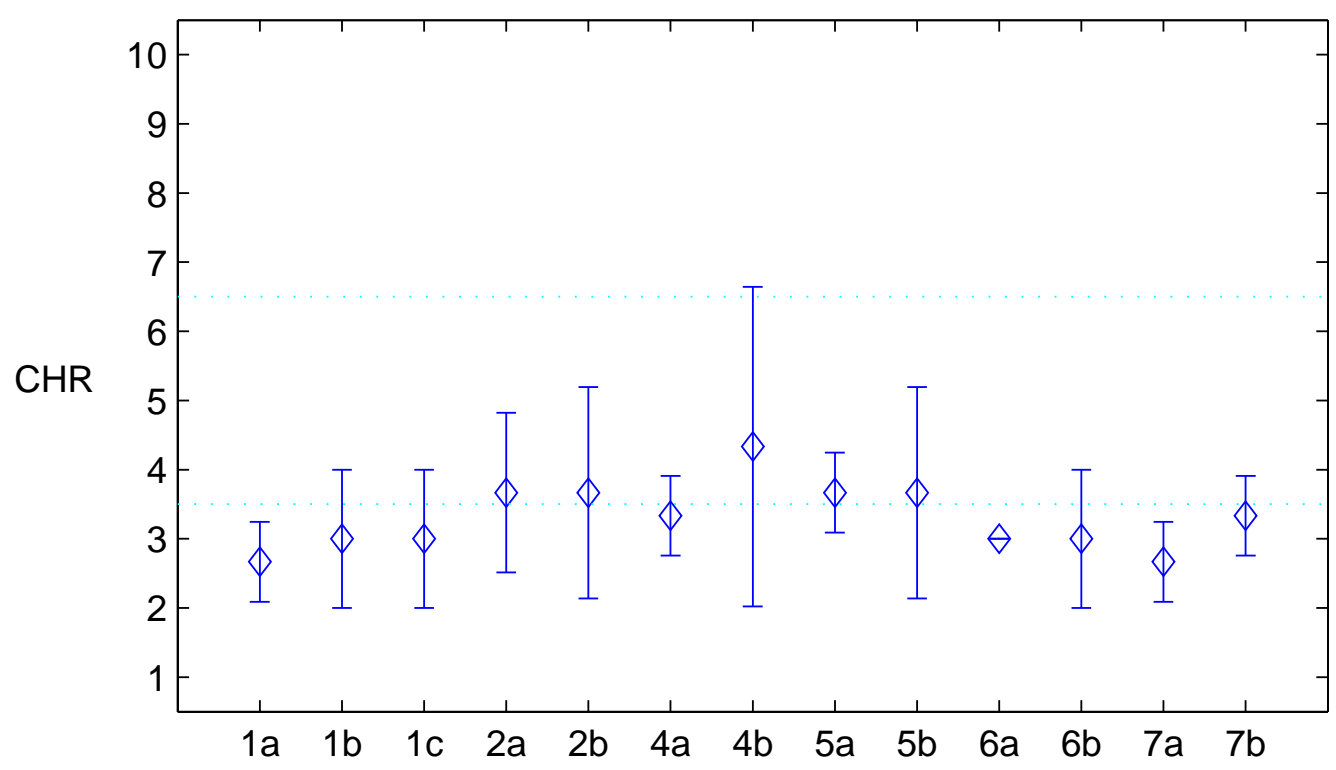

(b) Full motion

Figure 5.3: Mean ratings and standard deviation of subtasks 


\subsubsection{Subjects' Comments}

\section{Subject A}

TASK 1

Full motion, Run 12: "Didn't recall having to reduce power so much at $5000 \mathrm{ft}$. Hunted for the power setting once at $5000 \mathrm{ft}$ and $250 \mathrm{kts.}$

TASK 2

Full motion, Run 6: "Flare and touchdown are a non-event."

TASK 4

Full motion, Run 2: "Used rudder trim." "Overcontrol of ailerons." "More bank and rudder needed than I expected."

Ruse motion, Run 10: "Overcontrol with rudder."

\section{TASK 5}

Ruse motion, Run 5: "Had to point left."

TASK 6

Ruse motion, Run 9: "Skidded on the ground." "Overcompensated at $600 \mathrm{ft}$ - went below the glideslope."

\section{GENERAL COMMENTS}

- Sensitive in roll

- Tends to have a slight sway

- The altitude tape display is unusual

- For engine failure during takeoff, the rudder trim is not too effective

- Pitch is responsive

- Roll tends to wallow

- A larger lateral offset, greater than 1 dot, would be more challenging and a better indicator of lateral handling qualities

\section{Subject B}

TASK 1

Ruse motion, Run 4: "Pilots will typically want to use some aileron into the wind. Hands 
off is unusual." "Much easier task, getting the hang of it."

Full motion, Run 12: "Easy to hold 10. Easy to hold $5000 \mathrm{ft} . "$

\section{TASK 2}

Ruse motion, Run 1: "Crosswind affects the workload." "Unconventional pitch and roll." "Wallowing in yaw."

Full motion, Run 2: "You've introduced turbulence this time?" "Hands off the controls helps." "That time I felt I had less control."

TASK 4

Full motion, Run 6: "7 too small." "Full rudder pedal is not enough to maintain heading. Need some bank." "Not bothering to use rudder trim."

Ruse motion, Run 10: "Lack of rudder trim."

TASK 5

Ruse motion, Run 3: "Lots of sideslip, like $10^{\circ}$, needed to maintain control. This is a lot for a transport airplane."

Full motion, Run 5: "By the end of the day, I'll have the hang of it!"

TASK 6

Ruse motion, Run 7: "Where is the wind?" "Is it on the ground? No motion cue."

Full motion, Run 11: "ILS glideslope is too low compared to the visuals."

\section{TASK 7}

Full motion, Run 8: "Airplane can regain the centreline by $200 \mathrm{ft} . "$

\section{GENERAL COMMENTS}

- The ground/nosewheel steering is ineffective

- Inertia seems wrong - accelerates too quickly

- Pitch rate command controller is ok, no problem

- Wallows laterally, noticeable on a precision approach

- Engine failure requires huge sideslip

- Rudder trim and aileron trim would help

- The ILS glideslope is wrong for this aircraft - it should intersect the runway about $1000 \mathrm{ft}$ past the threshold

- Eye to wheel height feels like a 767, not a 747 


\section{Subject C}

\section{TASK 1}

Ruse motion, Run 6: "Pitching up to $15^{\circ}$ to control the speed."

Full motion, Run 11: "Pitch is $15^{\circ}$." "Not familiar with the airplane, so speed control is difficult."

TASK 2

Full motion, Run 7: "That felt like a landing!" "Don't like the ailerons on the ground." TASK 4

Full motion, Run 3: "Full left rudder." "Held it on the ground until 180 kts." "I took your advice."

\section{TASK 5}

Ruse motion, Run 4: "Braking is out of whack." "Can't use the ailerons."

Full motion, Run 5: "Airspeed was a bit higher (200 kts)." "Released the wheel, just used rudder."

\section{TASK 6}

Ruse motion, Run 8: "Aileron control the reason for the rating of 4."

Full motion, Run 12: "Rating of 4 due to the ailerons."

\section{TASK 7}

Ruse motion, Run 1: "Rating of 4 due to the ailerons on the ground."

\section{GENERAL COMMENTS}

- Simulator controls don't give the expected force feedback. In a real airplane the force-displacement curve is not linear; the spring constant increases with control displacement, so the pilot can feel how much the control surfaces are deflected. This makes it possible to fly the aircraft with some spare capacity to devote to other tasks.

\subsection{Discussion of Results}

\subsubsection{Comparison with Previous Handling Trials}

Because the ANOVA found no significant effect of motion on handling quality ratings, the ratings obtained in the current study with full motion and ruse motion are combined. The mean ratings of each task (across motion conditions) are compared to de Castro's 
results. The effect of differences between the flight models and tasks of the current study and de Castro's study are discussed below.

There was generally good agreement between the current Cooper Harper ratings and de Castro's results [8]. Except for Task 7, the ratings were within \pm 1 of the previous results. The changes to the ground-force model and the inclusion of the engines' pitching moment in the current study did not seem to affect longitudinal handling qualities. In fact, for both motion conditions, Tasks 1, 2, and 6 were all rated lower in the current research than in previous trials. These three tasks require primarily longitudinal control. Since the PRCAH controller holds the pitch attitude constant, so long as the control surfaces aren't saturated, the additional pitching moment from the engines has no effect on longitudinal handling qualities.

The lateral handling qualities were rated considerably different from de Castro's results. In the current study Task 7 was rated 2.00 lower with full motion and 2.17 lower with ruse motion. Two factors may have caused the ratings for Task 7 in the current study to be lower than de Castro's results.

The first factor is that the gains for the lateral controller were different in the current study than in de Castro's study (Table 3.7). The Dutch roll damping ratio of 0.14 (at an airspeed of $90 \mathrm{~m} / \mathrm{s}$ ) in the current study may have led to lower Cooper Harper ratings for Task 7. As shown in Chapter 3, if de Castro's gains were used, Level 2 or 3 lateral handling qualities were predicted based on Dutch roll damping and the product of Dutch roll damping and natural frequency, respectively.

The second factor is the amount of lateral offset that pilots had to establish and then correct for. De Castro's pilot briefing suggests that pilots can line up with a taxiway beside the runway to establish the required lateral offset. De Castro does not specify which airport and runway were used in those handling trials, and so the distance between the runway and the taxiway can only be guessed. The FAA's Airport Design Advisory Circular 34] states that taxiways must be at least $500 \mathrm{ft}$ from a parallel runway, at airports that are designed to handle aircraft as large as the BWB. It is possible that the lateral offset obtained by lining up with the taxiway was considerably greater than the offset specified in the current study. In the FRS, the ILS localizer Course Deviation Indicator deflects by 1 dot for each $1^{\circ}$ off the localizer course. This gives a lateral offset of $200 \mathrm{ft}$ when the aircraft is at a height of $600 \mathrm{ft}$. If the CDI in previous handling trials used a different scale than this $\left(2^{\circ}\right.$ per dot, for example), or if the pilots lined up with a taxiway that was $500 \mathrm{ft}$ to one side of the runway, then the task might be more difficult. 
Mitchell et al. 24] cite several flight-research studies with lateral offset tasks. The lateral offset in those studies ranged from $200 \mathrm{ft}$ to $300 \mathrm{ft}$. The height at which the correction was initiated ranged from $180 \mathrm{ft}$ to $200 \mathrm{ft}$. So while the lateral offset of the current study is reasonable compared to those studies, the correction was initiated at a much greater height in the current study.

Apart from the reasons discussed above, there are three additional reasons why the ratings for some tasks differed from de Castro's results: different inceptor characteristics, subject differences, and random effects. Additional factors that could have led to higher ratings in the current study were the atmospheric turbulence and a constant-direction, variable-velocity wind. However, given that the turbulence intensity and wind speed were fairly low, these factors were not expected to significantly raise the HQRs.

\subsubsection{Comparison with Predicted Handling Qualities}

The longitudinal handling qualities were predicted to be Level 1. Table 5.3 shows that the tasks were rated between Level 1 and 2 for both the full- and ruse-motion conditions. Tasks 1, 2, and 6 require primarily longitudinal control. The mean HQRs of Tasks 1 and 6 are Level 1, and the mean ratings of Task 2 are Level 2. Thus the actual ratings are close to the predicted ratings.

The lateral handling qualities were predicted to be Level 1 or 2 , depending on the predictive method. Based on the roll-mode time constant and roll time delay of the augmented BWB, Level 1 lateral handling qualities were predicted. The Dutch-roll-mode criteria predicted Level 2 handling qualities. Tasks 4, 5, and 7 require both longitudinal and lateral control. For these three tasks, only the subtasks that require significant lateral control are considered. The subtasks are 4b, 5a, and 7a, and their mean ratings are 4.83, 4 , and 2.67, respectively. Subtasks $4 \mathrm{~b}$ and $5 \mathrm{a}$ cannot be compared to the predicted lateral handling qualities, because they require considerable directional control and only lateral control was considered when predicting the handling qualities.

Since subtask 7a required primarily roll control, this is the subtask that is compared to the predicted handling qualities of Chapter 3. Subtask 7a was rated as Level 1. This agrees with the prediction of the roll-mode-time-constant criterion and the roll-time-delay criterion. Subtask 7 a was rated better than the Level 2 handling qualities predicted by the Dutch-roll-mode criteria. 


\subsubsection{Effect of Simulator Motion}

The mean Cooper Harper ratings with full motion differed by 0.5 points or less compared to the ratings with ruse motion, except for Task 4 . This small difference and the ANOVA suggest that motion did not have a significant effect on HQRs. Subjects B and C commented on the simulator motion. Subject B noticed the lack of motion cue after touching down in Task 6 with ruse motion, and asked if turbulence had been introduced in Task 2 with full motion. Subject C commented after touching down in Task 2 with full motion that it "felt like a landing". Among these two subjects, for the tasks that they commented on the motion or lack thereof, there was only one difference in HQ rating. Subject B rated the landing in Task 2 a 5 with full motion, compared to a 4 with ruse motion. No subjects asked about or commented on the fictitious second flight control system. It seems that the ruse of the fictitious second flight control system was effective; for while some subjects commented on the simulator motion, they did not state that the motion affected their HQRs.

With ruse motion, Tasks 4 and 5 were rated worse in the current study than in de Castro's trials [8]. Tasks 4 and 5 might have been more difficult in the current study than in the previous trials because of a greater yawing moment for the engine failure tasks in the current study. Appendix D in de Castro's study shows that, in the simulator, the engine moment was made to be 3.5 times less than what it would be in the aircraft. Three of the four pilots commented in de Castro's trials that the engine failure was not immediately noticeable. In the current study, Task 4 (in particular subtask 4b) gave the greatest amount of spread in ratings. This is understandable given that a slight decrease in airspeed may have caused rudder saturation and loss of control. Subject C's ratings of Task 4 decreased by 3 points with full motion. Subject $\mathrm{C}$ completed Task 4 with ruse motion before full motion. Subject C's comments indicate that outside advice influenced his or her second performance of Task 4 . So while Task 4 with ruse motion was rated worse than in de Castro's trials, it is probably safest to assume that any difference in ratings of Task 4 were due to some combination of training effect and the greater engine yawing moment.

\subsubsection{Limitations}

The current study has several major limitations. First, the handling-trial subjects were not test pilots, and as such they did not have experience using the Cooper Harper scale. 
Second, only Subject B had experience flying heavy aircraft. These first two limitations may have introduced some bias and scatter into the handling-quality ratings. A third limitation is the small number of subjects and the large variance of their ratings, which limits the statistical power of the results. It was not possible to show a significant effect of motion on the handling-quality ratings. Fourth, according to Schroeder's criteria [12], the predicted motion fidelity was low, except for the pitch rate. The pitch rate was predicted to be medium fidelity for all MDA parameters. The fact that no motion-effect on handling-quality ratings was found may have been due to the relatively-low motion fidelity. A fifth limitation is that the flight model of the BWB treated the aircraft as a rigid body; aeroelasticity was not modeled. Carlsson 35 found that the control effectiveness of a BWB decreased with an increase in airspeed due to static structural deformation. 


\section{Chapter 6}

\section{Conclusion and Recommendations}

The handling qualities of a hybrid BWB were found to be Level 1 or 2, depending on the task. The normal takeoff (Task 1) had the lowest mean Cooper Harper ratings, 2.89 and 2.67 with full motion and ruse motion, respectively. The takeoff with engine failure (Task 4) received the highest Cooper Harper ratings, 3.83 and 4.83 with full motion and ruse motion, respectively. The handling-quality ratings obtained in the current research are similar to the results of de Castro's handling trials [8]. The HQRs of the current study were not significantly affected by ground effect. It was shown in Chapter 3 that ground effect had only a small, beneficial effect on longitudinal handling qualities. Ground effect was therefore not expected to be a significant factor in the HQRs. The significant differences in HQRs for the takeoff-with-engine-failure task (Task 4), compared to de Castro's results, were probably due to a much larger (and more realistic) yawing moment in the current study. In addition, the maximum static engine thrust was $10 \%$ greater in the current study. The larger yawing moment in the current study likely made the task more challenging, leading to higher $\mathrm{HQ}$ ratings. The lower HQ ratings in the current study for the approach with a lateral offset (Task 7) might have been due to higher Dutch roll damping in the current study.

As discussed in the Introduction, Grantham found that handling-quality ratings in a ground-based simulator were conservative. The handling-quality ratings that were obtained in the current study are therefore predictive of the handling qualities of an actual blended wing body. The handling-quality ratings of the current study apply only to the six low-speed tasks that were evaluated, and only to a BWB with the flight control system as described by de Castro and adjusted in the current study.

Simulator motion did not have a large effect on HQRs. The largest difference in 
mean HQ ratings with full motion compared to ruse motion was 1, and this may have been due to effects other than the motion condition. The reason for the small effect of motion on $\mathrm{HQ}$ ratings may be that the simulator motion was predicted to be low fidelity, except for the pitch-rate motion, which was predicted to be medium fidelity. The main benefit of motion in the piloted-handling trials seemed to be as a means for the pilot to know when the aircraft touched down during landing. Schroeder [12] suggests that if the simulator-motion fidelity is not adequate, then the task should be re-designed.

The small effect of motion on $\mathrm{HQ}$ ratings may also have been because the tasks were such that the pilot generally created his or her own motion. Schroeder reviewed two studies that found that simulator motion does not seem to be "beneficial for tasks in which the pilot creates his own motion." Except for the engine-failure-during takeoff task, the tasks in the current trials required tracking in fairly calm air. Showalter and Parris [9] found that motion cueing had a statistically-significant effect on pilot performance of a landing-with-wind-shear task. In their study the wind shear was strong enough that severe Dutch roll of the aircraft was induced. Simulator motion would be more important to evaluating handling qualities for tasks with more turbulence or wind shear.

Based on the results of the piloted-handling trials, there are four suggestions for future trials. First, different tasks could be evaluated. Tasks at high airspeeds such as cruise and initial descent could be performed in future trials. If a hexapod motion system is to be used, flight tasks should be designed such that the simulator motion can be tuned to achieve high (or at least medium) fidelity on the Schroeder criteria. Second, static aeroelasticity should be modeled if high-speed tasks are to be used. Third, incorporating drag rudders, as used on NASA and Boeing's X-48B, in the aerodynamic model might help with low-speed control. Data exists on the yawing moment of a flying wing with drag rudders, which might be applicable to a BWB [36]. Fourth, a different flight control system could be used. Goldthorpe et al. [37] describe the "de-augmentation/reaugmentation" controller used on the X-48B. The controller uses dynamic inversion to de-couple the forces and moments of the elevons, allowing the pilot to execute pure roll or yaw maneuvers. Using a different FCS than that used in the current study would obviously affect the handling-quality ratings. 


\section{References}

[1] Liebeck, R. H., Page, M. A., and Rawdon, B. K., "Blended-Wing-Body Subsonic Commercial Transport," AIAA, Aerospace Sciences Meeting \& Exhibit, 36th, AIAA, Reston, VA, Jan. 1998, pp. 1-11.

[2] Stettner, M. and Voss, R., "Aeroelastics, Flight Mechanics and Handling Qualities of the MOB BWB Configuration," 9th AIAA/ISSMO Symposium and Exhibit on Multidisciplinary Analysis and Optimization, AIAA, Reston, VA, Sep. 2002, pp. $1-10$.

[3] Vicroy, D. D., "Blended-Wing-Body Low-Speed Flight Dynamics: Summary of Ground Tests and Sample Results (Invited)," 47th AIAA Aerospace Sciences Meeting Including The New Horizons Forum and Aerospace Exposition, AIAA, Reston, VA, Jan. 2009, pp. 1-10.

[4] Risch, T., Cosentino, G., Regan, C. D., Kisska, M., and Princen, N., "X-48B FlightTest Progress Overview," 47th AIAA Aerospace Sciences Meeting Including the New Horizons Forum and Aerospace Exposition. 2009.

[5] Cooper, G. E. and Harper, Jr., R. P., "The Use of Pilot Rating in the Evaluation of Aircraft Handling Qualities," TN D-5153, NASA, Washington, DC, Apr. 1969.

[6] US Department of Defense, "Flying Qualities of Piloted Aircraft," MIL-HDBK1797, Dec. 1997.

[7] Cameron, D. and Princen, N., "Control Allocation Challenges and Requirements for the Blended Wing Body," AIAA Guidance, Navigation, and Control Conference and Exhibit, AIAA, Reston, VA, Aug. 2000, pp. 1-5.

[8] de Castro, H., Flying and Handling Qualities of a Fly-by-Wire Blended-Wing-Body Civil Transport Aircraft, PhD thesis, Cranfield University, 2003. 
[9] Showalter, T. W. and Parris, B. L., "The Effects of Motion and g-Seat Cues on Pilot Simulator Performance of Three Piloting Tasks," TP 1601, NASA, 1980.

[10] Grantham, W. D., Comparison of Flying Qualities Derived from In-Flight and Ground-Based Simulators for a Jet-Transport Airplane for the Approach and Landing Pilot Tasks, Langley Research Center, Hampton, VA, 1989.

[11] Soparkar, S. and Reid, L. D., "The Influence of Simulator Motion on Handling Qualities," Canadian Aeronautics and Space Journal, Vol. 52, No. 2, 2006, pp. 21.

[12] Schroeder, J. A., "Helicopter Flight Simulation Motion Platform Requirements," TP-1999-208766, NASA, Ames Research Center, Jul. 1999.

[13] Reid, L. D. and Nahon, M. A., Flight Simulation Motion-Base Drive Algorithms: Part 2 - Selecting the System Parameters, Institute for Aerospace Studies, University of Toronto, 1986, UTIAS Report No. 307.

[14] Etkin, B. and Reid, L. D., Dynamics of Flight: Stability and Control, John Wiley \& Sons, Inc., New York, 3rd ed., 1996.

[15] Etkin, B., Dynamics of Atmospheric Flight, Dover Publications, Mineola, NY, 2005.

[16] Staelens, Y., Study of Belly-Flaps to Enhance Lift and Pitching Moment Coeffcient of a Blended-Wing-Body Airplane in Landing and Takeoff Configuration, PhD dissertation, University of Southern California, Dec. 2007.

[17] Cheung, G., Implementation of Aircraft Landing Gear Model for Real-Time Simulation of Ground Manoeuvres, BASc dissertation, University of Toronto, Apr. 2009.

[18] Chester, D. H., "Aircraft Landing Impact Parametric Study with Emphasis on Nose Gear Landing Conditions," Journal of Aircraft, Vol. 39, No. 3, 2002, pp. 394-403.

[19] Clover, C. L. and Bernard, J. E., "Longitudinal Tire Dynamics," Vehicle System Dynamics, Vol. 29, No. 4, 1998, pp. 231-259.

[20] Reid, L. D. and Nahon, M. A., Flight Simulation Motion-Base Drive Algorithms: Part 3 - Pilot Evaluations, Institute for Aerospace Studies, Downsview, Ont., 1986. 
[21] Robinson, P. A., "The Modelling of Turbulence and Downbursts for Flight Simulators," UTIAS Report No. 339, University of Toronto Institute for Aerospace Studies, Jan. 1991.

[22] Gerlach, O. H. and Baarspul, M., "Calculation of the Response of an Aircraft to Random Atmospheric Turbulence. Part II: Asymmetric Motions," Report VTH-139, Technological University of Delft, Apr. 1968.

[23] Bailey, R. and Knotts, L., "Interaction of Feel System and Flight Control System Dynamics on Lateral Flying Qualities," CR-179445, NASA, Edwards, CA, 1990.

[24] Mitchell, D. G., Hoh, R. H., Aponso, B. L., and Klyde, D. H., "Proposed Incorporation of Mission-Oriented Flying Qualities into MIL-STD-1797A," TR No. 1291-1, Systems Technology, Inc., and HOH Aeronautics, Inc., Oct. 1994.

[25] ur Rahman, N., Propulsion and Flight Controls Integration for the Blended Wing Body Aircraft, PhD thesis, Cranfield University, Department of Aerospace Sciences, School of Engineering, May 2009.

[26] Gautrey, J. and Cook, M., "A Generic Control Anticipation Parameter for Aircraft Handling Qualities Evaluation," Aeronautical Journal, Vol. 102, No. 1013, Mar. 1998, pp. 151-9.

[27] Gibson, J. C., "Piloted handling qualities design criteria for high order flight control systems," Criteria for Handling Qualities of Military Aircraft, AGARD, 1982, AGARD-CP-333.

[28] "Military Specification, Flying Qualities of Piloted Airplanes," MIL-F-8785C, Nov. 1980.

[29] Grant, P. R., "Vehicle Simulation Group," http://arrow.utias.utoronto.ca/ prgrant/index.html, Oct. 2009.

[30] Grant, P. R., Yam, B., Hosman, R., and Schroeder, J. A., "Effect of Simulator Motion on Pilot Behavior and Perception," Journal of Aircraft, Vol. 43, No. 6, 2006, pp. 1914-1924.

[31] Goldberg, J. M. and Fernández, C., "Vestibular Mechanisms," Annual Review of Physiology, Vol. 37, 1975, pp. 129-162. 
[32] Grant, P. R., The Development of a Tuning Paradigm for Flight Simulator Motion Drive Algorithms, Ph.D. thesis, University of Toronto Institute for Aerospace Studies, 1996.

[33] Grant, P. R. and Reid, L. D., "Motion Washout Filter Tuning: Rules and Requirements," Journal of Aircraft, Vol. 34, No. 2, 1997, pp. 145-151.

[34] Office of Airport Safety and Standards - Airport Engineering Division, Airport Design, Federal Aviation Administration, Sep. 1989.

[35] Carlsson, M., "Control Surface Response of a Blended Wing Body Aeroelastic WindTunnel Model," Journal of Aircraft, Vol. 42, No. 3, 2005, pp. 738.

[36] Stenfelt, G. and Ringertz, U., "Lateral Stability and Control of a Tailless Aircraft Configuration," Journal of Aircraft, Vol. 46, No. 6, 2009, pp. 2161.

[37] Goldthorpe, S. H., Rossitto, K. F., Hyde, D. C., and Krothapalli, K. R., "X-48B Blended Wing Body Flight Test Performance of Maximum Sideslip and High to Post Stall Angle-of-Attack Command Tracking," AIAA Guidance, Navigation, and Control Conference, Aug. 2010, pp. 1-17. 


\section{Appendix A}

\section{Stability Derivatives and Data}

Table A.1: Longitudinal nondimensional derivatives 8

\begin{tabular}{cccc}
\hline & $C_{x}$ & $C_{z}$ & $C_{m}$ \\
\hline$\hat{u}$ & 0 & 0 & 0 \\
$\alpha$ & 0 & -5.8347 & 0.7412 \\
$\hat{q}$ & 0 & -1.0787 & -0.8799 \\
$\hat{\dot{\alpha}}$ & 0 & 0 & 0 \\
\hline
\end{tabular}

Table A.2: Lift, and pitching moment coefficients with $\alpha=0[8$

\begin{tabular}{cc}
\hline$C_{L_{0}}$ & $C_{m_{0}}$ \\
\hline 0.3204 & -0.040 \\
\hline
\end{tabular}

Table A.3: Lateral nondimensional derivatives [8]

\begin{tabular}{cccc}
\hline & $C_{y}$ & $C_{l}$ & $C_{n}$ \\
\hline$\beta$ & -0.1398 & $-0.0104-1.1233 \alpha$ & $0.0213-0.2584 \alpha$ \\
$\hat{p}$ & $-0.372+2.5356 \alpha$ & $-0.4641+0.1255 \alpha$ & $0.0631-0.8337 \alpha$ \\
$\hat{r}$ & $-0.2888+0.485 \alpha$ & $-0.0787+0.7612 \alpha$ & $-0.0349+0.0037 \alpha$ \\
$\hat{\dot{\beta}}$ & 0 & 0 & 0 \\
\hline
\end{tabular}


Table A.4: Longitudinal nondimensional control derivatives $|8|$

\begin{tabular}{ccccl}
\hline & & & & \multicolumn{1}{c}{ Control surfaces } \\
& $C_{x}$ & $C_{z}$ & $C_{m}$ & used (Figure 2.1 \\
\hline$\delta_{e}$ & 0 & -2.2575 & -0.7162 & $\{2,3, \ldots, 14\}$ \\
\hline
\end{tabular}

Table A.5: Lateral nondimensional control derivatives 8

\begin{tabular}{ccccl}
\hline & & & & \multicolumn{1}{c}{ Control surfaces } \\
& $C_{y}$ & $C_{l}$ & $C_{n}$ & used (Figure 2.1 \\
\hline$\delta_{a}$ & $-0.041+0.0819 \alpha$ & -0.15 & $0.0041-0.0504 \alpha$ & $\{3,13\}$ \\
$\delta_{r}$ & $0.097-0.0656 \alpha$ & $0.0253+0.0178 \alpha$ & $-0.0158+0.0352 \alpha$ & $\{1,15\}$ \\
\hline
\end{tabular}

Table A.6: Drag parameters 8

\begin{tabular}{cccc}
\hline$C_{D_{0}}$ & $k_{1}$ & $k_{2}$ & $C_{D_{L G}}$ \\
0.0117 & -0.02 & 0.12 & 0.049525 \\
\hline
\end{tabular}

Table A.7: Mass and other data 8

\begin{tabular}{cc}
\hline $\mathrm{m}, \mathrm{kg}$ & 371280 \\
$I_{x}, \mathrm{~kg} \cdot \mathrm{m}^{2}$ & $47.032 \mathrm{e} 6$ \\
$I_{y}, \mathrm{~kg} \cdot \mathrm{m}^{2}$ & $25.1 \mathrm{e} 6$ \\
$I_{z}, \mathrm{~kg} \cdot \mathrm{m}^{2}$ & $99.734 \mathrm{e} 6$ \\
$S_{\text {trapezoidal }}, \mathrm{m}^{2}$ & 841.7 \\
$\mathrm{~b}, \mathrm{~m}$ & 80 \\
$\bar{c}, \mathrm{~m}$ & 12.31 \\
$k_{n}$ & -0.13 \\
\hline
\end{tabular}

Table A.8: Pilot's eye position relative to CG

$\frac{\overline{[x} y z]_{\text {body axis }}, \mathrm{m}}{[27.43-0.465-2.22]}$




\section{UNIVERSITY OF TORONTO

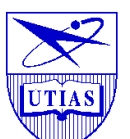 \\ INSTITUTE FOR AEROSPACE STUDIES \\ BRIEFING FOR PILOTED HANDLING TRIALS}

\section{Objective}

The objective of the handling trials is to obtain pilot evaluations of the handling qualities of a blended wing body aircraft. Two flight control systems will be assessed by the subjects. Subjects will be asked to perform six low speed flight tasks, and rate the handling qualities using the Cooper Harper Scale after each task. The results will be compared to similar trials conducted at Cranfield University in 2003 in a fixed-base simulator.

\section{Experimental Procedure}

The subject will first read this briefing describing the objective and procedures of the experiment. The subject will then read the UTIAS simulator safety instructions. Next, the subject will read an informed consent form that they must sign in order to participate. The subject will then be led into the UTIAS Flight Research Simulator, seated and belted in. The motion base will then be energized. The subject will be given about 15 minutes to familiarize themselves with the aircraft and tasks before the evaluation phase begins.

The entire session will take approximately two and a half hours. The subject can take breaks as needed. During the experiment, the subject will be wearing a headset through which they can communicate with the experimenter. A cockpit voice recorder will be used and subjects are encouraged to make brief comments about the handling qualities during and after a task.

Upon completion of the session the subject will remain seated until the motion system is fully de-energized and the experimenter informs the subject it is safe to undo the seatbelts. The subject will then be led out of the simulator. 


\section{TASK DESCRIPTION AND EVALUATION}

The flying instructions for each task are given on the following pages. Desired and adequate performance is specified for each task. 
TASK 1 - Normal takeoff, including climb and acceleration segments

Initial condition: Aircraft at the runway threshold ready for takeoff

Advance the throttle to full. Hold $10^{\circ}$ pitch attitude. Climb to $5000 \mathrm{ft}$ at $200 \mathrm{KIAS}$. Level off and accelerate to $250 \mathrm{KIAS}$ (use $2^{\circ}$ pitch and N1 of 65 ). Maintain this speed and altitude.

Landing Gear

DOWN INITIAL

UP FINAL

Altitude (ft) 10 INITIAL 5000 FINAL

$\mathrm{V}_{1}(\mathrm{KIAS})$ 135

$\mathrm{V}_{\mathrm{R}}(\mathrm{KIAS})$ 180

$\mathrm{V}_{2}+10$ (KIAS) CLIMB 200

Airspeed (KIAS) 0 INITIAL 250 FINAL

Heading 080 INITIAL 080 FINAL

Surface Wind 180 TRUE @ 4 KNOTS

\section{Evaluation}

Hold $10^{\circ}$ pitch attitude (desired $\pm 2^{\circ}$; adequate $\pm 5^{\circ}$ )

Cooper-Harper Rating:

\begin{tabular}{|l|l|l|l|l|l|l|l|l|l|l|}
\hline Run 1 & 1 & 2 & 3 & 4 & 5 & 6 & 7 & 8 & 9 & 10 \\
\hline Run 2 & 1 & 2 & 3 & 4 & 5 & 6 & 7 & 8 & 9 & 10 \\
\hline
\end{tabular}

Maintain $5000 \mathrm{ft}$ while accelerating to $250 \mathrm{KIAS}$ (desired $\pm 100 \mathrm{ft}$; adequate $\pm 200 \mathrm{ft}$ )

Cooper-Harper Rating:

\begin{tabular}{|l|l|l|l|l|l|l|l|l|l|l|}
\hline Run 1 & 1 & 2 & 3 & 4 & 5 & 6 & 7 & 8 & 9 & 10 \\
\hline Run 2 & 1 & 2 & 3 & 4 & 5 & 6 & 7 & 8 & 9 & 10 \\
\hline
\end{tabular}

Maintain $250 \mathrm{KIAS}$ at $5000 \mathrm{ft}$ (desired $\pm 5 \mathrm{kts}$; adequate $\pm 10 \mathrm{kts}$ )

Cooper-Harper Rating:

\begin{tabular}{|l|l|l|l|l|l|l|l|l|l|l|}
\hline Run 1 & 1 & 2 & 3 & 4 & 5 & 6 & 7 & 8 & 9 & 10 \\
\hline Run 2 & 1 & 2 & 3 & 4 & 5 & 6 & 7 & 8 & 9 & 10 \\
\hline
\end{tabular}

Pilot Comments: 
TASK 2 - Normal approach and landing

Initial condition: Aircraft trimmed for level flight

Fly an ILS approach using the glideslope pointer. A pitch angle of $2^{\circ}$ and $\mathrm{N} 1$ of 69 will give the correct speed and rate of descent when the landing gear is down.

Landing Gear

UP INITIAL

DOWN FINAL

Altitude (ft) 2230 INITIAL

10 FINAL

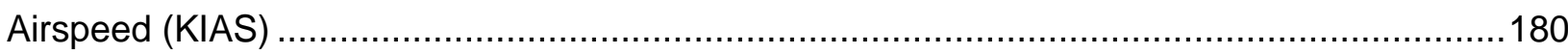

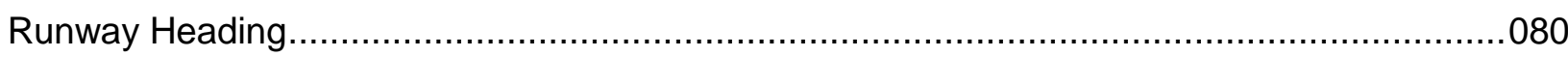

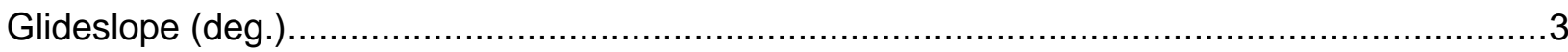

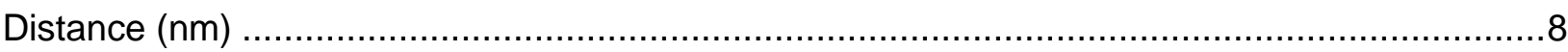

Surface Wind ……………………..........................................180 TRUE @ 4 KNOTS

\section{Evaluation}

Rate the approach until 200ft AGL (desired speed $\pm 5 \mathrm{kts}$; adequate speed $\pm 10 \mathrm{kts}$; desired glideslope $\pm 1 / 2$ dot, adequate glideslope \pm 1 dot)

Cooper-Harper Rating:

\begin{tabular}{|l|l|l|l|l|l|l|l|l|l|l|}
\hline Run 1 & 1 & 2 & 3 & 4 & 5 & 6 & 7 & 8 & 9 & 10 \\
\hline Run 2 & 1 & 2 & 3 & 4 & 5 & 6 & 7 & 8 & 9 & 10 \\
\hline
\end{tabular}

Rate the landing, including the flare and touchdown. See Figure 1 for desired and adequate touchdown zone.

Cooper-Harper Rating:

\begin{tabular}{|l|l|l|l|l|l|l|l|l|l|l|}
\hline Run 1 & 1 & 2 & 3 & 4 & 5 & 6 & 7 & 8 & 9 & 10 \\
\hline Run 2 & 1 & 2 & 3 & 4 & 5 & 6 & 7 & 8 & 9 & 10 \\
\hline
\end{tabular}

Pilot Comments: 
TASK 3 - Deleted

TASK 4 - One engine inoperative takeoff

Initial condition: Aircraft at the runway threshold ready for takeoff

Advance the throttle to full. Climb at about $5^{\circ}$ pitch attitude, or whatever attitude gives a positive rate of climb and a slight increase in airspeed. At 1000ft, increase airspeed to $220 \mathrm{KIAS}$ and climb with a pitch attitude of $7^{\circ}$ until $5000 \mathrm{ft}$ is reached. Level off and accelerate to $250 \mathrm{KIAS}$.

Landing Gear

DOWN INITIAL

UP FINAL

Altitude (ft) 10 INITIAL 5000 FINAL

$\mathrm{V}_{1}(\mathrm{KIAS})$ 135

$\mathrm{V}_{\mathrm{R}}$ (KIAS) 180

$\mathrm{V}_{2}+10$ (KIAS) CLIMB 200

Airspeed (KIAS) 0 INITIAL 250 FINAL

Heading 080 INITIAL 080 FINAL Surface Wind .090 TRUE @ 4 KNOTS

\section{Evaluation}

Maintain runway centreline after the engine failure. (desired: $\pm 25 \%$ of runway width; adequate: $\pm 50 \%$ of runway width)

Cooper-Harper Rating:

\begin{tabular}{|l|l|l|l|l|l|l|l|l|l|l|}
\hline Run 1 & 1 & 2 & 3 & 4 & 5 & 6 & 7 & 8 & 9 & 10 \\
\hline Run 2 & 1 & 2 & 3 & 4 & 5 & 6 & 7 & 8 & 9 & 10 \\
\hline
\end{tabular}

After takeoff, establish a straight, wings level, climb. (desired: $\pm 5^{\circ}$ runway heading and $\pm 5^{\circ}$ bank; adequate: $\pm 10^{\circ}$ runway heading and $\pm 10^{\circ}$ bank)

Cooper-Harper Rating:

\begin{tabular}{|l|l|l|l|l|l|l|l|l|l|l|}
\hline Run 1 & 1 & 2 & 3 & 4 & 5 & 6 & 7 & 8 & 9 & 10 \\
\hline Run 2 & 1 & 2 & 3 & 4 & 5 & 6 & 7 & 8 & 9 & 10 \\
\hline
\end{tabular}

Pilot Comments: 
TASK 5-Approach and landing with one engine inoperative

Initial condition: Aircraft trimmed for level flight

Fly an ILS approach using the glideslope pointer.

Landing Gear

UP INITIAL

DOWN FINAL

Altitude (ft) 2230 INITIAL

10 FINAL

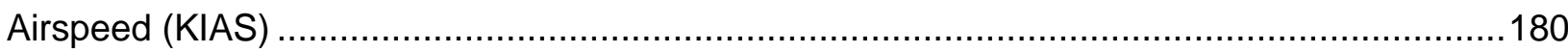

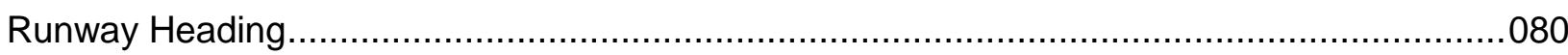

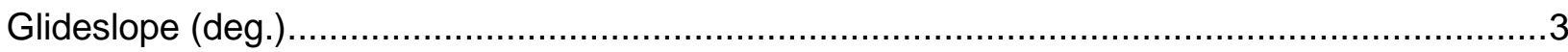

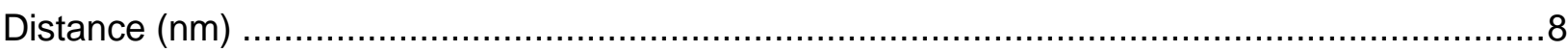

Surface Wind ...........................................................................090 TRUE @ 4 KNOTS

\section{Evaluation}

Maintain heading and wings level (desired: $\pm 5^{\circ}$ heading and $\pm 5^{\circ}$ bank; adequate: $\pm 10^{\circ}$ heading and $\pm 10^{\circ}$ bank) until $200 \mathrm{ft} A G L$.

Cooper-Harper Rating:

\begin{tabular}{|l|l|l|l|l|l|l|l|l|l|l|}
\hline Run 1 & 1 & 2 & 3 & 4 & 5 & 6 & 7 & 8 & 9 & 10 \\
\hline Run 2 & 1 & 2 & 3 & 4 & 5 & 6 & 7 & 8 & 9 & 10 \\
\hline
\end{tabular}

Rate the landing, including the flare and touchdown. See Figure 1 for desired and adequate touchdown zone.

Cooper-Harper Rating:

\begin{tabular}{|l|l|l|l|l|l|l|l|l|l|l|}
\hline Run 1 & 1 & 2 & 3 & 4 & 5 & 6 & 7 & 8 & 9 & 10 \\
\hline Run 2 & 1 & 2 & 3 & 4 & 5 & 6 & 7 & 8 & 9 & 10 \\
\hline
\end{tabular}

Pilot Comments: 
TASK 6-Approach with longitudinal offset and landing

Initial condition: Aircraft trimmed for level flight

Fly an approach above the glideslope, one dot low on the Primary Flight Display. At 600ft AGL, regain the glideslope.

Landing Gear UP INITIAL DOWN FINAL

Altitude (ft) 2230 INITIAL 10 FINAL

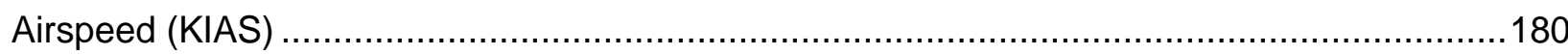

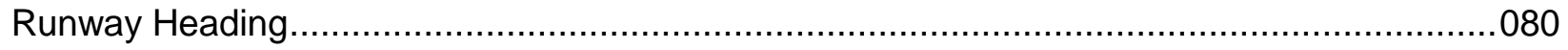

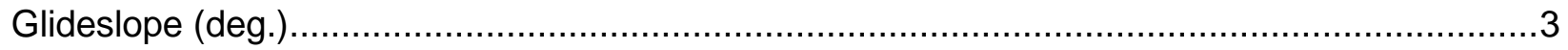

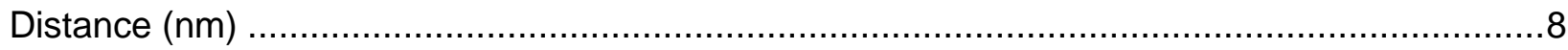

Surface Wind ...............................................................................180 TRUE @ 4 KNOTS

\section{Evaluation}

Regain the glideslope, maintaining airspeed (desired: $\pm 5 \mathrm{kts}$ airspeed; adequate: $\pm 10 \mathrm{kts}$ airspeed).

Cooper-Harper Rating:

\begin{tabular}{|l|l|l|l|l|l|l|l|l|l|l|}
\hline Run 1 & 1 & 2 & 3 & 4 & 5 & 6 & 7 & 8 & 9 & 10 \\
\hline Run 2 & 1 & 2 & 3 & 4 & 5 & 6 & 7 & 8 & 9 & 10 \\
\hline
\end{tabular}

Rate the landing, including the flare and touchdown. See Figure 1 for desired and adequate touchdown zone.

Cooper-Harper Rating:

\begin{tabular}{|l|l|l|l|l|l|l|l|l|l|l|}
\hline Run 1 & 1 & 2 & 3 & 4 & 5 & 6 & 7 & 8 & 9 & 10 \\
\hline Run 2 & 1 & 2 & 3 & 4 & 5 & 6 & 7 & 8 & 9 & 10 \\
\hline
\end{tabular}

\section{Pilot Comments:}


TASK 7-Approach with lateral offset and landing

Initial condition: Aircraft trimmed for level flight

Fly an approach, offset to the left of the runway. Keep the localizer one dot to the right on the Primary Flight Display. At 600ft AGL, switch to a visual approach and correct for the lateral offset.

Landing Gear UP INITIAL

DOWN FINAL

Altitude (ft) 2230 INITIAL

10 FINAL

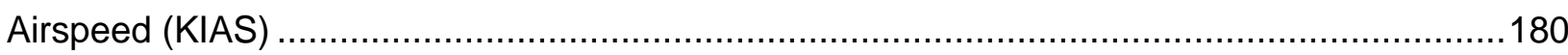

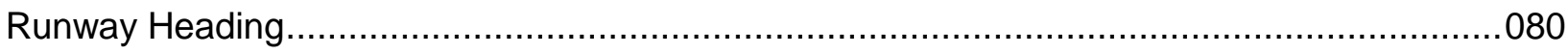

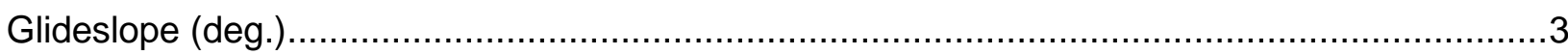

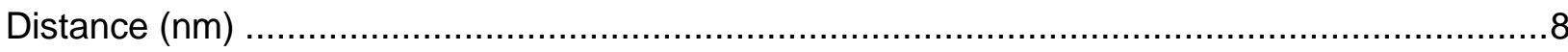

Surface Wind ......................................................................180 TRUE @ 4 KNOTS

\section{Evaluation}

Regain centreline by $200 \mathrm{ft}$ AGL (desired: $\pm 1 / 2$ runway width; adequate: \pm 1 runway width).

Cooper-Harper Rating:

\begin{tabular}{|l|l|l|l|l|l|l|l|l|l|l|}
\hline Run 1 & 1 & 2 & 3 & 4 & 5 & 6 & 7 & 8 & 9 & 10 \\
\hline Run 2 & 1 & 2 & 3 & 4 & 5 & 6 & 7 & 8 & 9 & 10 \\
\hline
\end{tabular}

Rate the landing, including the flare and touchdown. See Figure 1 for desired and adequate touchdown zone.

Cooper-Harper Rating:

\begin{tabular}{|l|l|l|l|l|l|l|l|l|l|l|}
\hline Run 1 & 1 & 2 & 3 & 4 & 5 & 6 & 7 & 8 & 9 & 10 \\
\hline Run 2 & 1 & 2 & 3 & 4 & 5 & 6 & 7 & 8 & 9 & 10 \\
\hline
\end{tabular}

Pilot Comments: 


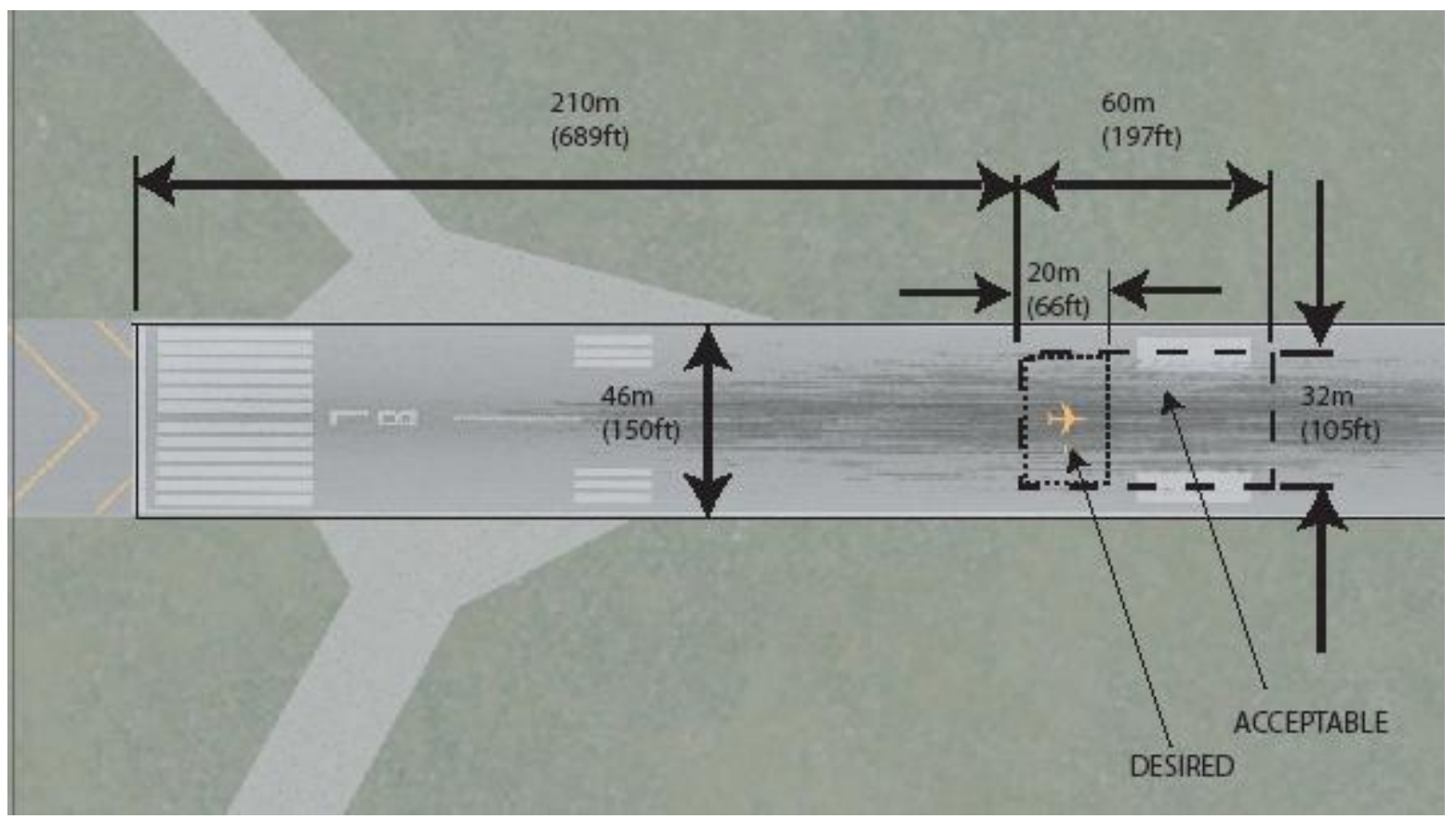

Figure 1. Desired and adequate landing touchdown area.

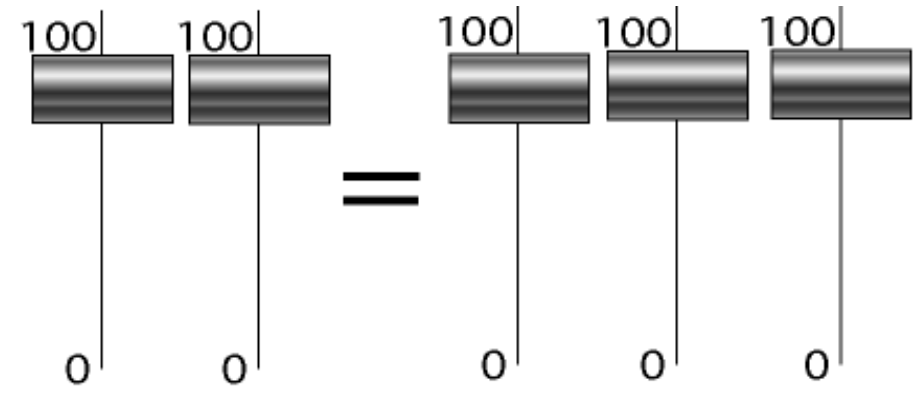

ENGINE 1 ENGINE 3 ENGINE 1 ENGINE 2 ENGINE 3

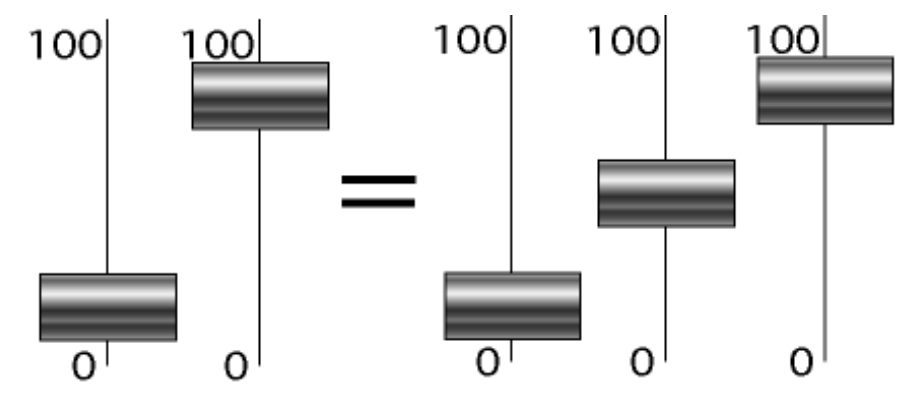

ENGINE 1 ENGINE 3 ENGINE 1 ENGINE 2 ENGINE 3

Figure 2. Throttle Controls. 


\section{FLIGHT MANUAL}

\section{General}

- negative static margin, $-13 \%$ MAC

- 3 engines on the rear upper surface, with dynamics similar to those of the P\&W JT9D engine

- weight $819,000 \mathrm{lbs}(371,280 \mathrm{~kg})$

Instruments and Display List

- $\quad$ outside scene display (3 windows)

- airspeed indicator (IAS)

- pressure altimeter

- radar altimeter

- rate of climb

- horizontal situation indicator

- engines:

$\circ \quad \mathrm{N}_{1}$ (left and right outer engines)

- landing gear position

Controls

- primary - trailing edge flaps acting as an "elevator" and "ailerons", and winglet rudders

- trim -"ailerons" and rudder

- landing gear

- throttles (inner two levers)

- toe brakes, no anti-lock braking

- nose wheel steering:

- fine - rudder pedals

- coarse - wheel

- no flaps

Flight Control Systems

- Longitudinal

- Pitch Rate Command Attitude Hold ("follow up trim")

- Lateral

○ Directional stability augmentation plus yaw damper

Note:

The inner two power levers directly control the outer engines, 1 and 3 . The centre engine power setting is the average of the two inner levers (see Figure 2).

If the EFIS touchscreen landing gear control is difficult to use, an alternate switch is available. The thumb switch on the control wheel can be used instead of the touchscreen to raise or lower the landing gear. If the thumb switch is used, the landing gear lever diagram on the touchscreen will not agree with the actual gear state (up or down). 
COOPER HARPER SCALE

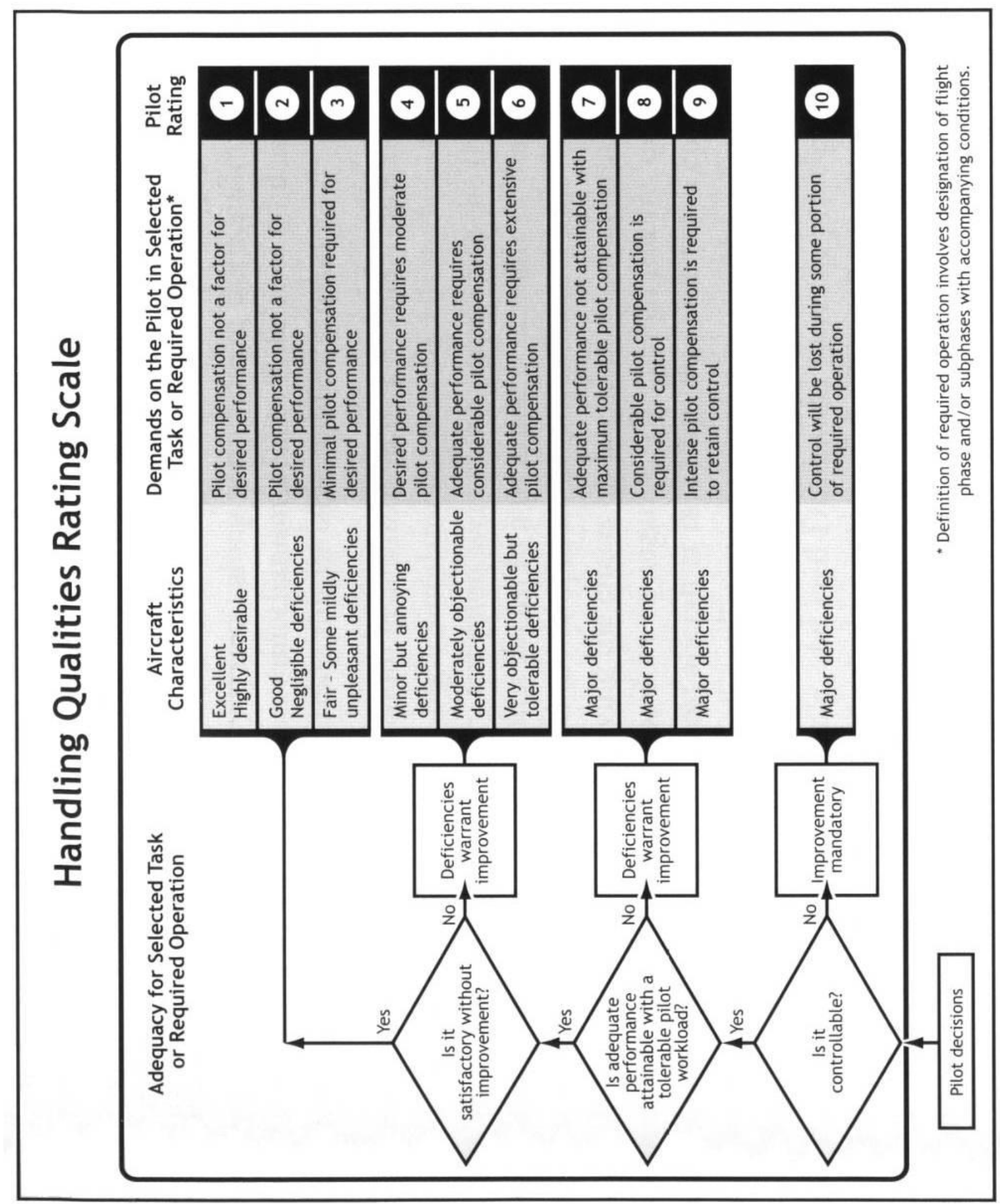

